"YOU GOTTA CARE": HEARING THE STORIES OF PREVIOUSLY INCARCERATED YOUTH IN COMMUNITY COLLEGE

\author{
A dissertation submitted to the faculty of \\ AS \\ 35 \\ 2019 \\ EDD \\ .066 \\ San Francisco State University \\ In partial fulfillment of \\ The Requirements for \\ The Degree \\ Doctor of Education \\ In \\ Educational Leadership
}

by

Tabitha Paige Conaway

San Francisco, California

May 2019 


\section{CERTIFICATION OF APPROVAL}

I certify that I have read "You Gotta Care": Hearing the Stories of Previously Incarcerated Youth in Community College by Tabitha Conaway, and that in my opinion this work meets the criteria for approving a thesis submitted in partial fulfillment of the requirement for the degree Doctorate in Education in Educational Leadership at San Francisco State University.

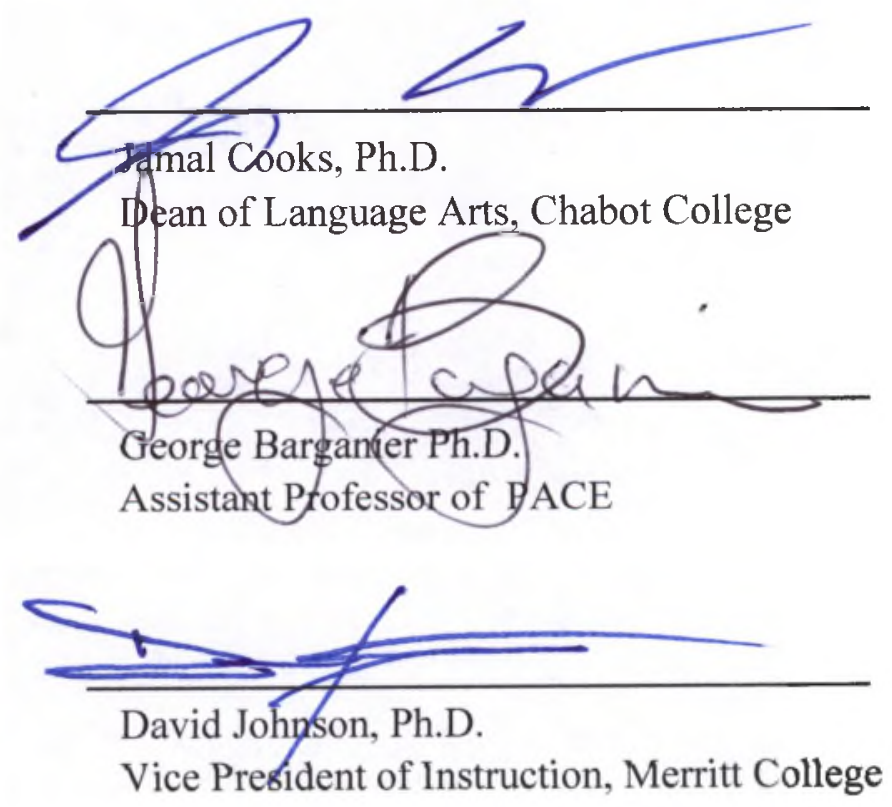


Copyright by

Tabitha Paige Conaway

2019 


\title{
"YOU GOTTA CARE": HEARING THE STORIES OF PREVIOUSLY INCARCERATED YOUTH IN COMMUNITY COLLEGE
}

\author{
Tabitha Conaway \\ San Francisco State University \\ 2019
}

Previously incarcerated youth (PIY) are hyper-marginalized by intersectional patterns of marginalization processes enacted within public institutions, often beginning within schools, yet little is known about their experiences within higher education. The purpose of this study was to explore the academic, social, and emotional experiences of PIY within a community college setting with the intentional purpose of improving practice within community college systems. This study utilized a case-study design and a phenomenological approach to explore the experiences of five students at CBA who identified as PIY. Data for this study was drawn from interviews, observations, field notes, and student classwork. The key findings were categorized into three major themes: School-Prison Nexus, Residue of the School-Prison Nexus to Higher Education, and Academic Reengagement. Findings suggest that understanding how these students perceive their schooling is imperative for creating community colleges better suited to meet the needs of this growing population. Recommendations emphasize authentic care, providing intentional professional development for staff, faculty, and administration, wrap-around services, and the abolishment of the carceral state.

I certify that the Abstract is a correct representation of the content of this dissertation.
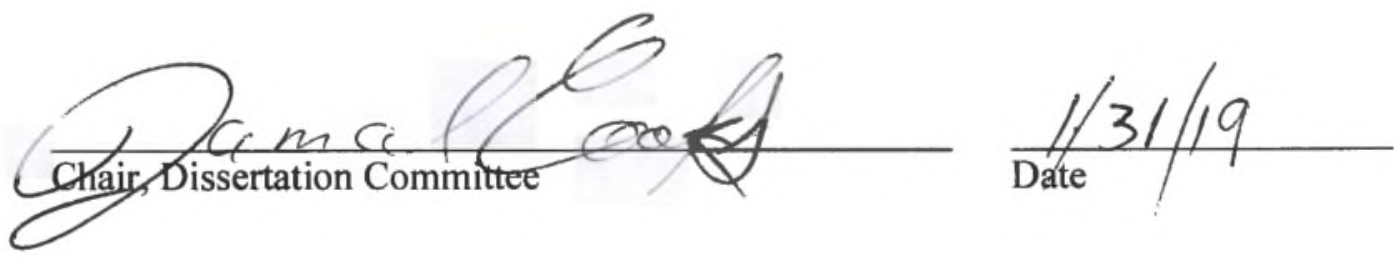


\section{ACKNOWLEDGEMENTS}

Normally the preface and/or acknowledgment section gives the student the opportunity to thank those to whom they are indebted for assistance in the project. This should be done briefly and in good taste. Some students also wish to use this opportunity to state why and under what circumstances the work was written. This section is in justified text that is double spaced with no indentation for the first line. 


\section{TABLE OF CONTENTS}

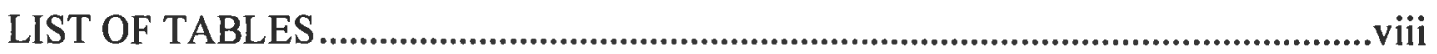

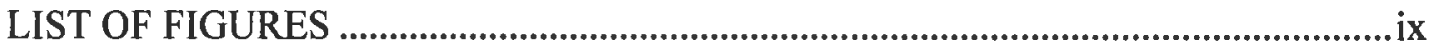

Chapter One: Purpose of Study.....................................................................................

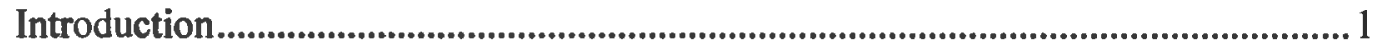

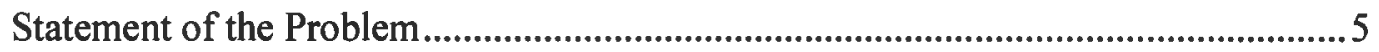

What's Working In Higher Education ...............................................................

Purpose of the Study and Research Questions................................................................. 8

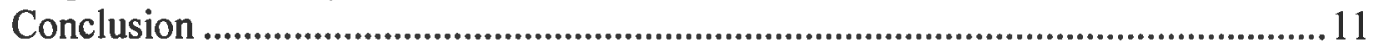

Chapter Two: The Race Problem..................................................................................... 12

Tenet 1: Race matters and so does contextualization ................................................. 16

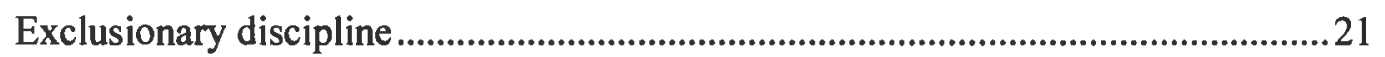

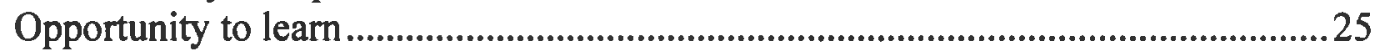

Educational Experiences of Hyper-Marginalized Youth in Higher Ed ......................31

The role of faculty with students of color.............................................................35

Previously Incarcerated Adults in Community College ............................................37

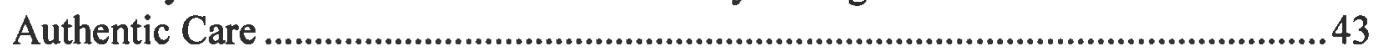

Chapter Three: Methodology .............................................................................................4

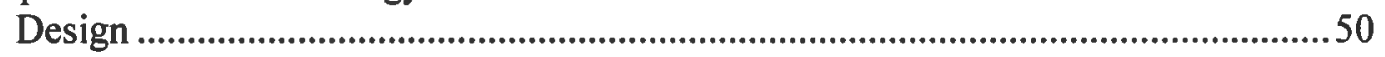

Role of Researcher................................................................................................5

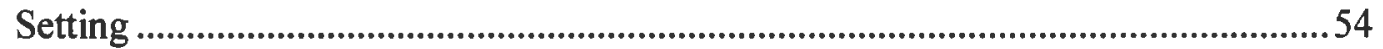

Participant Selection ...................................................................................................5

Participants.................................................................................................................... 58

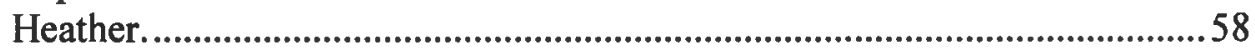

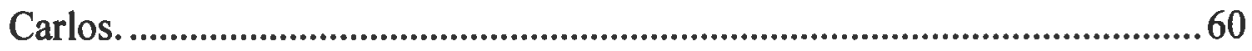

Sonya.......................................................................................................................6 61

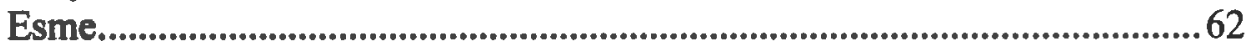

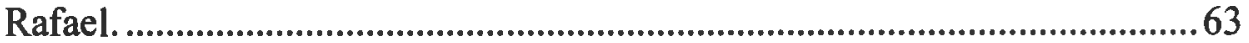

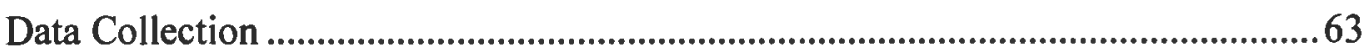

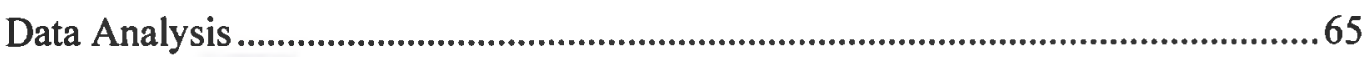

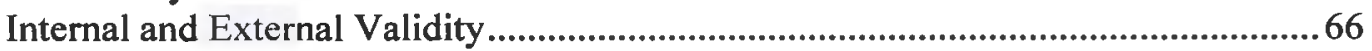

Chapter Four: Results .......................................................................................................67

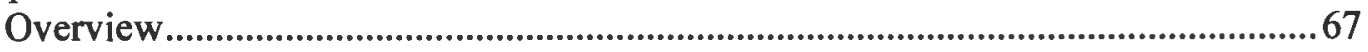

School-Prison Nexus..............................................................................................................69

Segregation: "Why put us in solitary confinement?" ..........................................70

Abandonment: They gave up on me.....................................................................76

Recycled education. .......................................................................................................8 


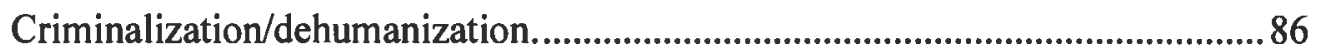

Residue of the School-Prison Nexus to Higher Education ............................................93

Feelings of judgement.........................................................................................94

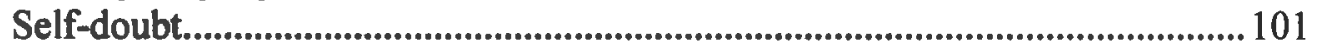

Consequences of a disjointed educational experience....................................... 106

Academic Re-engagement ........................................................................................ 109

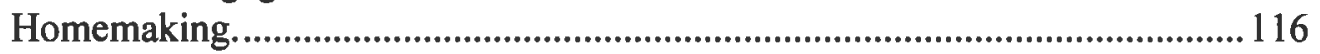

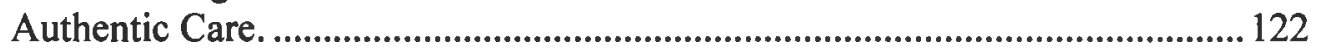

Healing Through Sharing....................................................................................... 126

Chapter Five: Discussion and Implications ...................................................................... 130

Interpretations of Findings (Discussion and Summary) ................................................. 131

School-Prison Nexus................................................................................................ 132

Segregation: Why put us in solitary? .................................................................. 133

Abandonment: They gave up on me. .................................................................. 134

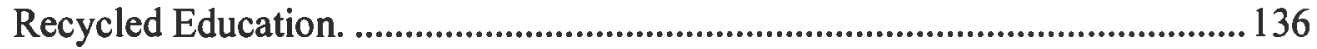

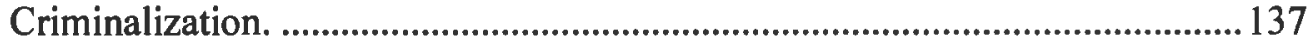

Residue of the School-Prison Nexus to Higher Education ........................................ 138

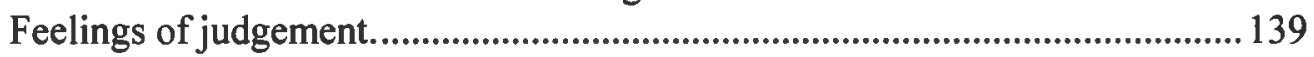

Self-doubt...................................................................................................................... 140

Consequences of a disjointed educational experience.......................................... 141

Academic Reengagement............................................................................................. 142

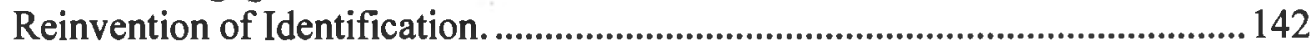

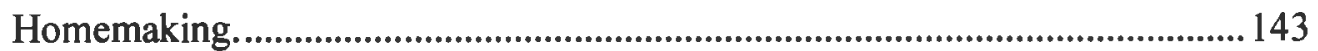

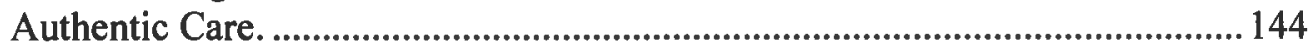

Healing Through Sharing............................................................................................. 145

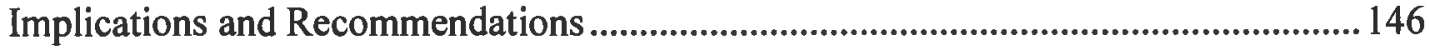

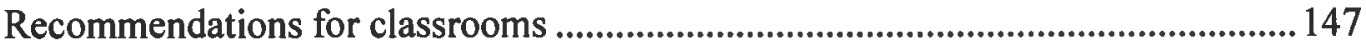

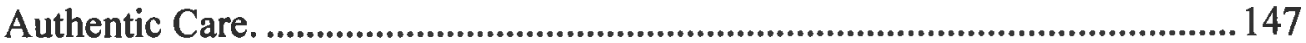

Professional Development. .................................................................................. 148

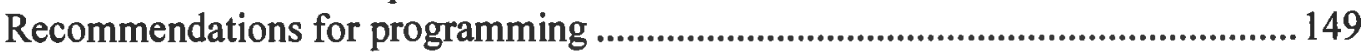

Recommendation for Policy and Initiatives............................................................... 151

Abolishment of the Carceral State ..................................................................... 153

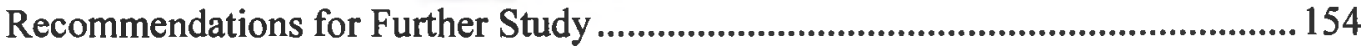

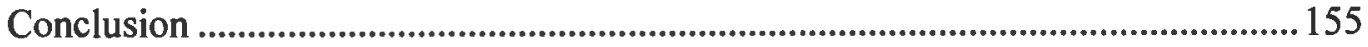




\section{LIST OF TABLES}

Table

1. Summary of Findings
Page

. .69 


\section{LIST OF FIGURES}

$\begin{array}{ll}\text { Figure } & \text { Page }\end{array}$

1. Terrell's Storyboard from LCTR 105 (Spring 2017) ...............................................93 


\section{Chapter One: Purpose of Study}

My first semester in college I maybe slept maybe three or four hours a night because I didn't know anything. I didn't know how to do MLA. I didn't know to write essays, I didn't know how to structure them, I didn't know how to manage my time to do reading. I didn't know how to manage my time to do homework. Because I've never done any of it. Throughout my 12 years in my previous education, I never did my homework, never wrote the essays, barely showed up to class and would just take the test and try and hope, hope that I passed. Because I didn't care, I didn't care at all. And in a lot of it has to do with as soon as I came in to the classroom I was into the office cuz I was late or because someone say something to me and I would say something back. And then now I have behavioral problem and now every time I do something, I do something small, I'm criminalized for it and I'm sent out of the classroom. A lot of it has to do with the fact that my teachers knew I had a probation officer so they're going to say something. So why even, why even come, you know. So, I guess the transition for me as a student was to be just a student you know and my first semester in college I think I had to learn how to be like independent. And I think it's kind of good that it happened to me, cuz like I didn't have crutches to fall back on. I didn't have any way of doing school, so I decided to just dive right in just devote all my time to school and work and like other things. Like one of my professors, like my closest professor, I was talking to him one day and he was like, he just like couldn't believe that I was a first-year college student. He was like, "I thought you're getting ready to transfer, I thought you were getting ready to get out of here, "But it was just because I really cared about the subject material, I really care about people and the way people work. So, I guess caring has been the biggest shift for me. Everything was hard tho' but caring made it easier.

(Carlos, conversation, September 13, 2017)

\section{Introduction}

I was in the second grade when I realized I was a brown girl. Attending elementary school in LAUSD, the majority of my schoolmates were Latino or Chinese. I knew that all of my friends that lived on my street were on a different track. Attending a year-round school, I quickly noticed that all of my neighbors had different vacations than me. Within my G.A.T.E (Gifted and Talented Education) class, I was the only brown girl. I was sent to speech class once a week with English-language learners 
despite the fact that I was a native-English speaker, but this realization came later in the school year. Kimberly, a second-grade girl with blonde braids, poured paint on the teacher's desk while Ms. Hayes was speaking to another student in the hallway. Without hesitation, as soon as Ms. Hayes saw the paint on her desk she walked over to my desk screaming. She grabbed me by the ear, yelling "You little brat, you will be suspended for this." Ignoring my pleas of innocence, she pulled me to the front of the class and proceeded to parade me around as an example of how not to act. Standing in front of the class, Ms.Hayes' fingernails digging into my ears, crying, my classmate Brenda interceded on my behalf. "Ms. Hayes', Tabitha did not spill the paint. Kimberly did, " as she said this, the rest of the class nodded. Ms. Hayes let go of my ear and yelled at me to sit down.

She then moved on with whatever lesson she planned for that day. Kimberly never got into trouble, Ms. Hayes never spoke of this event again, and I never told anyone. What would it have mattered? Of those neighborhood children I grew up with, by the time high school ended, most of the brown boys were locked up, and a good percentage of the brown girls had either spent time in juvenile hall and/or had dropped out of high-school. This story, while very personal, is reflective of the experiences of many youth of color throughout their P-12 educational experiences.

I began my teaching career working primarily with students of color involved with the justice system in juvenile hall and high schools in the urban centers of 
Inglewood and Sacramento, CA. As a high school teacher I desperately wanted to help students, who like me, were poor ${ }^{1}$ students of color. My decision to transition to community college was a direct result of what I considered failure to support Black and Brown students on an academic, social, and emotional level. I witnessed students of color subjected to lower-quality education, I cringed as these students were criminalized for minor social infractions and subjected to exclusionary disciplinary practices, and I cried as many of these brilliant students I had come to care for were thrown into juvenile detention centers for behaviors that are not criminalized in White students. These students, previously incarcerated youth (PIY) ${ }^{2}$, overwhelmingly do not complete high-school, (Balfanz, Spiridakis, Neild, \& Legters, 2003; Foley, 2001; Hirschfeld, 2009; Kirk \& Sampson 2011), and rarely attempt higher education (Balfanz et al., 2003).

The experiences of PIY within academically deficient schools that choose to exclude students of color from education push PIY further behind academically. The

1 For the purposes of this dissertation I am using the word "poor" to refer to low-socioeconomic status. Although all students of color are subjected to majoritarian stories, students who are hyper marginalized by race and lower socioeconomic status have their voices further silenced by inadequate schooling, exclusion, and incarceration at disproportionate rates than their White peers or even students of color from higher socioeconomic statuses.

${ }^{2}$ For this paper the term "previously incarcerated youth" will refer to individuals who spent time in the juvenile justice system and are currently ages 18-24. 
result is a history of negative experiences with education that causes PIY to disengage from the educational system. The collective experiences of substandard education, criminalization and incarceration work together to racialize students, causing PIY to view themselves as being at odds with the educational system. Within teachers' lounges and private conversations these students are often defined as hopeless or not teachable. Once they have been released from juvenile hall, these students often find themselves on a trajectory of self-doubt and failure (Nurse, 2013). While sharing many commonalities with poor students of color without incarceration histories, the struggles and experiences of PIY, because of their incarceration and the detrimental effects of labeling, are more closely aligned with incarcerated adults. Yet, PIY and their experiences are not totally congruent with incarcerated adults, as the racialization process, identity formation and stigma of being an offender are not as amplified. Racialization is the process of assigning specific characteristics to a group and then making racial these assigned characteristics for the purpose of othering a group and positioning them as subaltern within a western hegemonic hierarchy. I will return to this discussion of the creation and purpose of race in more detail in Chapter 2. Nasir (2011), for example, chose to discuss basketball as a racialized practice within the United States. Although she is clear in her assertion that not all basketball players are Black, or that all Black Americans play basketball, the sport has become a racialized practice, meaning that society associates basketball with the Black experience. For the purposes 
of this study, criminalization is discussed in terms of racialization. Criminal activity in the United States has been constructed as a practice limited to those uncivilized, those of color, for the specific reason on maintaining people of color in a subordinate position. It is for this reason that criminal activity has become fused with racial identity. While it is not accurate to define all people of color as criminals, or to conclude that crimes are only committed by people of color, the mainstream narrative posits that crimes, especially violent crime, is a problem limited to only communities of color. So engrained is this concept that crime is an ailment of Black and Brown communities, that in order to rectify criminal activity of European-Americans, the United States has created the concept of White-Collar Crime, a crime that is non-violent and financially motivated.

\section{Statement of the Problem}

As open-access institutions, California community colleges are expanding their mission to provide educational equity for all students: yet, they are falling short of their mission. At the core of this mission is to remove barriers that may obstruct success. But, PIY are often let out of this discussion. Many community college access programs targeting low-income students and those from historically marginalized communities focus on high school students, and for many PIY, their high school years were spent in and out of juvenile hall and continuation school. 
Community colleges faces a problem of lacking the proper infrastructure to service and educate all students, particularly with PIY. Although most colleges do not track previously incarcerated students, the few studies that exist reveal dismal rates of completion, ranging from $13 \%$ to $2 \%$ (Abrams and Franke, 2013; Culhane, Metraux, and Moreno, 2011). A study by Osgood, Foster, and Courtney (2010) found that less than $20 \%$ of previously incarcerated youth (PIY) in the United States earn a high school diploma or an equivalent certification, such as the GED or HiSET. These abysmal completion rates are indicative of the lasting consequences of the school-prison nexus ${ }^{3}$, and are often used as fodder for the lack of support for PIY. The common narrative of PIY categorizes these students as criminals, deviant, and deficient. This research seeks to actively work against this narrative by centering their narratives and developing an understanding of students' experiences within education.

PIY are invisible within community college, as they are not tracked within a community college as a population of students. Within California, the California Community Colleges Chancellor's Office ( $\mathrm{CCCCO}$ ) and accrediting bodies require all community colleges to record their colleges' data and disaggregate it. Similar to P-12, community colleges track course completion rates, transfer rates, persistence rates,

${ }^{3}$ The term school-prison nexus is being used in this dissertation instead of the more commonly known term, school-to-prison pipeline. Annamma (2018) defines the school-prison nexus as how students on color suffer through multiple marginalizing processes as they are bounced from one institution to another (e.g., public schools, foster care, court schools, police custody, social services). These processes will be discussed further in Chapter 2 . 
among a plethora of other data points. The $\mathrm{CCCCO}$ requires all the data collected be disaggregated into sub-populations. Commonly tracked demographic groups include the following: gender, ethnicity, sexuality, EOPS, foster-youth, veterans, age-group, and basic-skills. PIY are not commonly tracked within community college, or any higher educational system. Since PIY are not tracked with community colleges, the population of students, their barriers to success and their needs, are also ignored. Community colleges cannot begin to adequately service PIY until we understand the affective experiences of these students in community college.

It is my premise that the invisible nature of PIY harms their ability to be succeed in community college, as their specific needs are not being addressed within the community college sphere. PIY enter community college with a gap in their educational experiences. Due to their experiences within the school-prison nexus, PIY have often transitioned betwixt and between school to juvenile hall, to group homes, and to fostercare. Their disjointed educational experiences have left many of them un-exposed to academic and socio-emotional skill-sets and practices that their non-incarcerated peers have been able to develop within traditional school setting.

\section{What's Working In Higher Education}

While there is limited data on the completion rates for PIY at community colleges, and even less information on what factors inhibit or contribute to their academic success, we do know that students who feel valued and institutions/programs 
that focus on relationship building and intrusivity lead students to be more academically engaged, and are more likely to persist and complete their education ( Harper, 2009; Kuh et al, 2008). Developing strategies to intentionally increase engagement amongst PIY is one way community college leaders can increase rates of persistence and academic achievement for this group of students.

While PIY are largely invisible in the literature, there are multiple effective practices that are promising such as the importance of establishing deep, trusting, and caring relationships (Duncan-Andrade, 2007; Valenzuela, 1999), and the significance of critical hope (Duncan-Andrade, 2009; Freire, 1997), that we can draw from when trying to serve this population. Furthermore, changes in instruction, like the adoption of culturally relevant pedagogy, has shown to yield positive outcomes for traditionally marginalized students of color and may begin to address the systemic inequities that PIY face (Gay, 2010; Ladson-Billings, 1995; Paris \& Alim, 2014). Despite the parallels between PIY and other at-risk students in college, they do have different needs. Yet, within the literature, the voices of PIY have largely been ignored.

\section{Purpose of the Study and Research Questions}

The purpose of this study was to explore the academic, social, and emotional experiences of PIY within a community college setting with the intentional purpose to improve practice within community college systems. PIY are hyper-marginalized by intersectional patterns of marginalization processes enacted within public institutions, 
often beginning within schools. The disjointed educational histories of PIY, coupled with the "targeted racial criminalization" process of incarceration (Annamma, 2018; Rabaka, 2010), has created a sub-population of students that is made to feel invisible and unworthy of an education. PIY are consistently marginalized by institutions that practice a pedagogy of otherization and this othering serves as justification to exclude, racialize and criminalize. Through these processes, their collective voice is silenced. The conversation around incarcerated youth has been framed simply as a way to reduce recidivism, as a way to acculturate PIY into more acceptable normative practices (e.g., white-middle class values). Instead, we as educators need to focus on the liberatory ability of education. This research is particularly important for community colleges, which are the main access points for PIY striving to gain either a degree or work training. Community colleges, if aware, can successfully shift their educational climate and practices to meet the needs of these students. By being intentional in curriculum, instruction, and relationship building, community colleges can be responsive to the needs of PIY and begin to correct years of harm caused by the school-prison nexus.

In order to better the normative practices that continue to pose barriers for PIY, and put into place the practices and supports needed for PIY to succeed within community college, the educational experiences of these students need to be explored. Empirical studies overwhelmingly ignore PIY within higher education and instead focus on this population only while they are in the P-12 system or if they reoffend as adults. 
The qualitative case study is designed as an opportunity to privilege student voice, as often the literature on incarcerated students further marginalizes their voice. This study provides suggestions on how practices studied can be applied to other community colleges seeking to support this marginalized population with the ultimate goal that the themes identified will be an asset to all students. To this end, the following research questions are guiding this paper:

1. What are the educational experiences of five previously incarcerated youth attending the College of the Bay Area?

2. What are the main barriers to and facilitators for program completion within community college?

The stories and experiences of PIY are valuable and I captured this data through the use of phenomenological interviews with PIY which followed a standardized, open-ended protocol. The question protocol was developed based on a review of the literature and themes discovered during the pilot study described later in Chapter 3.

All students interviewed are students within Project Change at the College of the Bay Area. Project Change is a comprehensive program designed to provide wraparound services and resources to incarcerated and previously incarcerated youth. The College of the Bay Area ${ }^{4}$ is one of the only programs in California with a full program dedicated to PIY. The comprehensive program offers dual-credit courses within juvenile hall, supports students in their transition to community college, and financial,

\footnotetext{
${ }^{4}$ More information about the College of the Bay Area is included in a description of the study
} setting within Chapter 3: Methodology. 
academic, and social support once on campus. Since PIY are an under-researched group within community colleges, this case study is exploratory in nature, and seeks to provide a platform for these students to share their success narratives with the ultimate goal that their stories will inspire change.

\section{Conclusion}

It is imperative that we truly listen to the stories of PIY and understand their educational experiences if we as community college educators are going to support this growing population. Designing services and programs to help students succeed must be based on the students' stated needs and desires. This qualitative exploratory case study utilizes phenomenological interviews viewed through the lens of Critical Race Theory.

This dissertation is organized into five chapters. Chapter Two presents a discussion on the formation of race in the United States and the role of incarceration within that process. Literature relating to the school-prison nexus is examined, as well as discussions of student experiences within the community college realm. Chapter Three discusses in detail the methods that were used to answer the aforementioned research questions. Chapter Four presents the findings from student interviews which seek to reframe how PIY are perceived in higher education and Chapter Five concludes with implications for practice and policy changes to improve the community college experience for PIY. 


\section{Chapter Two: The Race Problem}

It is my premise that the current pattern of incarceration in the United States is not neutral but a result of racist policies and practices. In the United States, more than one million youth are court involved each year (Leone \& Weinberg, 2010). Despite these growing numbers, this population is often overlooked in discussions of education. As the proportion of incarcerated students of color continues to increase, the opposite is true for white youth. These previously incarcerated students are disproportionately marginalized youth, as $82 \%$ of incarcerated youth attending a school in juvenile hall are either Black or Latino (Youth Law Center, 2016). Although the exact demographics of juvenile halls vary by county and state, the national trend shows that incarceration practices disproportionately impact students of color and negatively affect their educational achievement (Leiber, 2002; Nurse, 2013; Youth Law Center, 2016). Educational and criminal policies may not specifically target students of color, but this population is disproportionately impacted, which is emblematic of institutionalized racism.

As higher education has become increasingly a requirement for upward mobility, previously incarcerated youth (PIY) are often let out of this process. Many access programs for higher education targeting low-income students and those from historically marginalized communities have traditionally focused on high school 
students, and for many PIY, their high school years were spent in and out of juvenile hall and continuation school (Kirk \& Sampson, 2013)

As the large number of incarcerated youth are released and transition back into their communities, community colleges will play a significant role in their ability to succeed. Not only do community colleges provide valuable education and training that can increase earning potential (Jacobson \& Mohker, 2009), but also these institutions can buffer the likelihood of recidivism (Stanford Justice Center, 2016). Most empirical research focuses on high school re-entry and completion, and so there is gap in the literature in regards to PIY experiences in higher education. As open-access institutions, community colleges will be the main vehicle for previously incarcerated youth to continue their education or receive technical or career training. The problem community colleges face is that currently, they are not prepared to adequately service this growing population.

\section{Methodology of Review}

This review seeks to identify the barriers to community college for PIY and discuss possible facilitators for success. Success is defined as academic persistence, academic achievement (e.g., passing classes), and social adjustment. Although PIY is being used as an acronym for previously incarcerated youth, it should be noted that due to the disproportionately of students incarcerated, PIY inherently means previously incarcerated youth of color. For this review, students of color is synonymous with 
hyper-marginalized students; low-income, first-generation, underrepresented students who identify as Black, Latinx, Native-American, Pacific Islander, Filipino, including multiracial and multiethnic students.

This review includes peer-reviewed research from databases, such as ERIC online journal, ProQuest Education Journals and JSTOR along with policy reports from sources such as the Youth Law Center. With the exception of seminal pieces, the literature reviewed was limited reports, reviews, books, and articles published since 2000. Keywords and Boolean terms used include: exclusionary discipline, juvenile hall, incarcerated students, suspensions, expulsions, critical race theory, recidivism, schoolto-prison-pipeline, school-prison nexus, re-entry students. In addition to databases searches, I practiced branching as way to find peer-reviewed articles.

This review of the literature is divided into three parts, each of which contributes to a rationale for my study of PIY within community college by illustrating the importance of focusing on PIY and verifying the lack of empirical studies focusing on the educational experiences of PIY within higher education. The first part of the review of literature takes an interdisciplinary approach and intentionally forefronts a discussion on how race impacts incarceration through a discussion of CRT. The second part begins with a discussion of the school-prison nexus, focusing explicitly on high-poverty, highminority schools, exclusionary discipline, opportunity to learn, and juvenile hall education. This section seeks to synthesize the process by which PIY were labeled as 
criminals, denied resources, and had "criminal identities reinforced in juvenile incarceration education" (Annamma, 2018, p. 16). The third part examines the marginality of students of color within higher education specifically focusing on: (a) the experiences of hyper-marginalized students within higher education with particular emphasis on the community college experience and (b) the educational experiences of formerly incarcerated adults who have spent time within prisons and their journey in higher education.

The Creation of the Race Myth, Criminalization, and Critical Race Theory

Critical Race Theory (CRT) is a valuable theoretical lens, methodology, and framework used to identify, analyze, challenge, and transform facets of our educational system that continue to subordinate students of color. Although CRT began within the field of legal studies as an extension of critical theory (Solórzano \& Yosso, 2010), it has extended to the field of education (Ladson-Billings \& Tate, 1995; Solórzano, 1997,1998). The five basic tenets of CRT, identified by Daniel Solórzano $(1997,1998)$ challenge the dominant discourse regarding race and education, and they are as follows: the centrality of race and racism; the challenge to dominant ideology; centrality of experiential knowledge: a commitment to social justice and praxis; and the interdisciplinary perspective.

To understand how race subordination affects students, it is necessary for CRT to draw from a variety of disciplines, such as history, ethnic studies, law, and film. For 
this study, this interdisciplinary approach is especially important, as the racialization of students of color through criminalization can only be discussed through a long view of power and subordination in the United States. As practitioners of CRT challenge dominant ideology, it is firmly committed to social justice and seeks to eliminate all forms of racial, gender, and class oppression (Solórzano, et al., 2005). The centrality of race and racism are discussed in more detail below, please note that $\mathrm{I}$ have reworded the tenet listed below intentionally to make them resonate more with how I incorporate CRT into my praxis.

CRT challenges dominant views on colorblindness, deficit theory, and meritocracy by examining how policy and practice are used to exclude certain racial groups from educational opportunities (Solórzano, 1998). The centrality of race and racism in CRT is an acknowledgment that race continues to play a significant role in inequity and oppression in the United States (Ladson-Billings \& Tate, 1995). CRT posits that the discussion of race and racism is necessary when discussing inequity; as such, CRT challenges the dominant ideology that ignores institutional and systemic racism through the ideologies such as color-blindness and deficit frameworks.

Tenet 1: Race matters and so does contextualization

Racism. Although the purpose of my dissertation is ultimately to help PIY succeed within community college, this cannot be done without the explicit understanding of the role that race and racism play not only in the school-prison nexus, 
but as a systemic force within the educational system as a way to maintain oppressive social structures (Jain, 2009; Delgado \& Stefancic, 2017). To that end, this section of the literature review will explore Critical Race Theory and the presupposition that racism has led directly to educational disparities (Howard, 2010) as well as racial disparities within incarceration practices.

The discussion of race and racialization is imperative to this discourse, as it is this entanglement of physical characteristics and criminality that have influenced the lived experiences of PIY, and it is these experiences that differentiate them from other PIY without incarceration experiences. This history of racialization and domination in America is important to understand, especially using a CRT lens as it places the experiences of PIY of color historically and actively seeks to challenge acontextualization and ahistoricism.

Despite the fact that race is not biological structure, it does have very real social consequences. Race, as we understand it, began with the colonization of the Americas (Quijano, 2000) as a way to dominate labor and knowledge. Rabaka (2010) argues that European colonialism actively employed the use of race and racism as modernity's greatest weapon. A binary was created predicated on a false dichotomy, placing the colonizer in stark opposition to the colonized. Phenotypic differences, the most significant which was skin color (Quijano, 1999), became codified into a hierarchy placing power into the hands of the colonizer and placing the colonized as an antithesis 
to the colonizer, thus justifying domination (Quijano, 2000). Maldonado-Torres (2007) posits that the binary structure of colonizer vs colonized was strengthened by linking the colonizer with humanity and the colonized with "degrees of humanity." This process of naturalizing the colonized as savage, or lacking full-humanity, came to validate racism, dehumanization, and their subjugation as unpaid laborers. Within the United States this process justified enslaving Africans and the genocide of Native Americans (Quijano, 2000).

European colonial domination and the creation of race worked together to secure Western hegemony over the world, thus "concentrating all forms of the control of subjectivity, culture, and especially knowledge and the productions of knowledge under its hegemony" (Quijano, 2000, pg. 540). While the colonized were plagued by this concept of race that associated them with barbarity, the colonizer, in contrast, purposefully classified themselves as white to highlight their association with the light of God; humanity. This process associated valuable knowledge only with colonizer, thus stripping the colonized of anything but animal like strength within the colonial lens. Different ethnic groups within the Americas and Africa were reimagined as a single group: Indian and African. Quijano (2000) describes this new identity simply as "racial, colonial, and negative" (pg. 551). Agricultural knowledge possessed by various native groups within the Americas was erased in the colonial narrative; replaced by the lone image of savage Indians riding horseback with the desire to quell civilization from 
spreading westward. The cultivation knowledge of those enslaved along the rice coast of Africa that made the rice colonies of South Carolina profitable has also been erased in colonial narrative and replaced by a tale of savage Africans coming as empty of vessels. It is this function of hegemony that controls authority, assuring the reproduction of this hierarchy. Thus, the ending of slavery did not end the narrative of Black Americans and other people of color as colonial subjects; dominated. The processes of Jim Crow, the carceral state, and sharecropping ensured that colonial relations between those in possession of whiteness and those without remained in place. The end of slavery did not end the relationship between labor domination and racism; instead, it transitioned into the current carceral practices that continue to subjugate people of color.

CRT as a conceptual, methodological, and theoretical framework challenges educators and researchers to reexamine the role that race and racism play in legitimizing, enforcing, and concealing oppressive social structures (Delgado \& Stefancic, 2012; Ladson-Billings, 1998; Solórzano, 1998). My purpose of discussing the creation and function of race is simple, Quijano (2000) discusses how Eurocentrism permeates every level of society, this ensures that Americans as a whole are educated under this hegemony, meaning, individuals can be subjugated to this invisible power without actively seeking to maintain a racial hierarchy. American structures that are 
advertised as color-blind, like our justice system and educational system, are in fact a part of this machine designed to maintain racial hierarchy.

For PIY of color, the history and continuing use of systemic racism and domination is important to understand as inequities and bias in the justice system and educational system have a direct negative impact on this population prior to them stepping foot on a community college campus.

\section{Systems and Structures}

Low-income Black and Latinx youth are disproportionately underserved in their $\mathrm{K}-12$ educational experiences. While there is ample literature on educational inequity and the opportunity gap with respect to students of color and lower socioeconomic students (Darling-Hammond, 2010; Blumenstyk, 2015), the impact of incarceration on juvenile educational experiences and the social justice implications is less documented. The reality is that almost two-thirds of all Black and Latino students attend schools where the majority of students are eligible for free or reduced lunch (DarlingHammond, 2010). These high-poverty, high-minority schools (HPHMS) are inequitably funded and have fewer resources than other schools. In California, HPHMS employ the largest number of unqualified teachers, and specifically, are five times more likely to have unqualified teachers than predominantly White schools (Darling-Hammond, 2010). In addition to unqualified teachers, HPHMS have less access to funding and high-quality curriculum (Nieto, 2005). The stark contrast in resources for HPHMS can 
account for much of the poor academic achievement by lower-socioeconomic and Black and Latino youth. Prior to incarceration, many of these at-risk youth have already fallen behind their peers academically (Leone and Weinburg, 2010).

\section{Exclusionary discipline}

Research on disciplinary practices in P-12 consistently highlight a disproportionate impact on Black and Latinx students, pushing them out of the P-12 system and into the juvenile justice system and court schools. The process of severely punishing students of color and those of lower socioeconomic status is commonly referred to as the school-to-prison pipeline (Krezmien, Leone, \& Wilson, 2014). Examining school disciplinary practices through a CRT lens exposes the reality that students of color are disproportionately likely to experience disciplinary practices which unfairly racialize and criminalize Black and Latinx students, especially males (Aud et al., 2011; Cammarota, 2004; Fabelo et al., 2011; Irwin, Davidson, \& Hall-Sanchez, 2013; Welch \& Payne, 2010). Rocque and Paternoster (2011) found that Black students were 2 times more likely to be disciplined compared to their white counterparts. The relationship between being a Black student and being victim of exclusionary discipline increased significantly as the percent of Black students within a school increased. This statement is strengthened by studies, such as Perry and Morris' (2016) examination of school disciplinary practices in a large urban school district in Kentucky. Using data from the Kentucky School Discipline Study, the study included 16,248 students and 
25,221 observations in a three-year period. Results indicated that Black students were over seven times more likely to be suspended as their White peers. Latino students were over twice as likely to be suspended as White students, with the likelihood of a nonWhite student being suspended 2.61 times more likely than that of their White peers (Morris \& Perry 2016). The effect is only partially accounted for by socioeconomic status, family status, and special educational status. Holding variables constant, students of color were disproportionately subjected to suspension. This increase in exclusionary disciplinary practices is also associated with classrooms where teachers feel there are higher levels of overall "bad behavior." The authors speculate that the association of increased exclusionary disciplinary practices with a higher proportion of Black students is evidence of racial threat. Meaning, that teachers feel, many times subconsciously, that Black students are deficient and in direct opposition to the teachers' cultural norms, and are thus labeled as troublemakers.

Hyper-criminalization of these youth has led and still leads to harmful exclusionary practices negatively affecting their education and freedom. Common adolescent behaviors such as arguing, loitering, hanging out in large groups, or simply standing in-front of stores, are vilified when enacted by students of color (Ferguson, 2000; Rios, 2017; Rios and Galicia, 2013). A report by the Advancement Project (2013) examining the discipline crisis within Mississippi public schools provides numerous examples of criminalization of students of color. In 2010, the report cites, 
that Black male students were reportedly cuffed to the railings within a school gym as punishment for not wearing a belt. Winn (2010a) asserts that Black girls are incarcerated for acts as simple as running away from abusive situations. In a study by Rios and Galicia (2013), not only were Latino males subject to hyper-surveillance, inside and outside school, but the school played a significant role in collaborating with law enforcement to create a system where school punishment and the juvenile justice system became one and the same. Further, in some urban schools, police officers are located on site, so consequences of misbehavior can quickly escalate to arrest (Kupchik, 2010). Behaviors that may have once been dealt with on campus are now reported to the campus school-resource officers (SROs). These students of color have their actions scrutinized more closely (Rios, 2017; Gilliam, Maupin, Reyes, Accavitti \& Shic, 2016), and are penalized more harshly for their actions that do not confirm to middle-class values (Ferguson, 2000; Rios, 2017; Rios and Galicia, 2013).

Despite the intuitive appeal, SROs have in terms of campus safety, research suggests that their presence on campus increase the rate of exclusionary disciplinary practices. Fisher and Hennessy (2015) conducted a quasi-experimental synthesis of the empirical literature examining out-of-school discipline. Their finding demonstrates an alarming trend, that the presence of an SROs on campus increases the number of exclusionary discipline incidents by one per week in school population of 1500 . While an additional exclusionary discipline incident might not seem drastic, the long-term 
consequences of exclusionary discipline are. Roberts et al. (2012) found that over $80 \%$ of public high schools in the U.S. have either suspended or expelled a student for a minimum of five days. Over the 2009-2010 school year, these extended expulsions or suspensions totaled 400,000 punishments (Roberts et al., 2013). This type of punishment is not affecting all students at equal rates, students of color are specifically being sent to the SRO without school officials attempting to resolve the conflict internally.

In an attempt to curb negative behavior, schools have increasingly added zero tolerance policies. Zero tolerance policies have contributed to increased delinquency and arrest (Fabelo et al., 2011). Monahan et al. (2014) examine the likelihood of arrest during months when a student is either suspended, expelled, or truant. Collecting data from 1,354 adolescents in a large urban area, their study found that students were over two times more likely to be arrested the month they were suspended or expelled from school compared to peers who were not subjected to exclusionary disciplinary practices. While their findings acknowledge that zero tolerance policies contribute to increased delinquency and arrest, the authors fail to address how racism influences patterns of school discipline, school culture, and the criminal justice system. The sample consists primarily of Black and Brown male students, yet the researchers fail to name racism as a reason for this disproportionately in arrests. 


\section{Opportunity to learn}

Teachers expect students of color to misbehave, punish students of color more severely than their White peers, and deny them time in class to learn. It is not surprising that the practice of excluding students from class diminishes their academic performance. Studies examining the relationship between exclusionary disciplinary practices and academic achievement report a negative relationship (Raffaele Mendez, 2003; Skiba et al., 2003), partially explained by the extent that exclusionary practices limit students' opportunities to learn. Punishments like suspension and expulsion are predicated on the belief that disruptive students need to be removed from the learning environment, thus these students lose out on valuable learning time. In a study of an urban elementary school, Scott and Barrett (2004) estimated almost 500 hours of lost instructional time for suspended students within one school year. When including lost instructional time due to office referrals, students missed out on an additional 12,160 minutes. Although their study focused on a school implementing positive behavior interventions, the researchers and the school worked together to identify lost instructional time. This problem is further compounded by the fact it is common practice to further punish students who are removed from class for disciplinary reasons by providing no alternative assignments (Rossow \& Parkinson, 1999). Out of class time coupled with reduced grades due to missing assignment is meant as a deterrent to future disruptions. Brown (2007) conducted a study that focused on the experiences of 37 
students who were attending an urban public alternative school as a result of suspensions or expulsions. She found that students were missing significant amounts of school time. Within the district of Brown's study, policy states that students, once expelled, should re-enroll in a school within a one-month period. Her study exposes that there is often a drastic difference between official policy and reality, as over half of the students reported not being enrolled in school for over a month, and 5 students reported being out of school for between 6-months to a year. It is important to note that the alternative school comprised a student body of $98 \%$ Black and Latino students. The school district composition is composed of $45.5 \%$ Black, $31.2 \%$ Latino, $14 \%$ White, and $8.9 \%$ Asian, yet Black and Latino students made up nearly $90 \%$ of those subjected to exclusionary discipline. Nationwide, students of color are disproportionately losing valuable instructional time due to exclusionary discipline. This lost learning time is culminated over the years into what many call the racial achievement gap.

Yet, while many within the educational system speak about the achievement gap like it is the problem, they ignore the root cause of this gap. Morris and Perry (2016) argue that instead of focusing on the gap in academic achievement between students of color and their White counterparts, that as educators we need to focus on how exclusionary punishment hinders academic growth and contributes to the punishment gap. Their research reveals that over a three-year period, students who have been suspended each year are predicted to score 16.21 points lower on a 
standardized test score than those who have never been suspended or expelled. As students of color are more susceptible to exclusionary disciplinary punishment, the gap in academic achievement is partially explained by punishment practices.

Twenty percent of the Black-White differences on standardized reading exams can be accounted for through racially biased disciplinary practices (Morris \& Perry, 2016). In fact, a previous article by Yang (2009) goes further than Morris and Perry and concludes that the achievement gap is directly reflective of the punishment gap. The experience of being denied the opportunity to learn within the P-12 system can have long-term effects for PIY. As PIY enter community college classrooms they often enter without the specific content knowledge that faculty assume they gathered in high school. Majoritarian stories frame this disjointed educational experience as a gap in achievement, unpreparedness, and as a deficiency on the part of the student.

\section{Incarceration and lowered academic achievement}

Once incarcerated, the punishment gap is amplified as youth navigate a disjointed P-12 experience, bouncing between court schools and public schools, often missing school, and receiving a subpar education while incarcerated (Youth Law Center, 2016). In addition to the evidence that incarcerated youth are consistently performing below non-incarcerated students on standardized exam (Foley, 2001; Leone \& Weinberg, 2012) over a quarter of incarcerated students exhibited diminished ability math and reading (Youth Law Center, 2016; Krezmien, et al., 2014). Overall, this 
impoverished and disjointed educational history characterized by exclusionary disciplinary practices, poor academic performance, even grade retention (Suitts, Dunn, \& Sabree, 2014) results in students who, once released, often do not re-enroll in their local public school (Youth Law Center, 2016), and are less likely to graduate high school (Hjalmarsson, 2007; Balfanz et al., 2003; Bernburg \& Krohn, 2003). Kirk and Sampson (2013) examine the link between juvenile arrest and educational attainment within Chicago public schools and found that students who had been arrested as adolescents were 22 percent more likely to drop-out of high school compared to their peers who had not experienced arrest. These students, alienated by policies and inequitable conditions, disengage from a system that has not served them well.

While a disjointed educational history does create students who may not envision themselves as college students, educational achievement may be what is necessary for PIY to turn their lives around. To add, although academic achievement during incarceration is a key to academic success post-release, the lack of literacy skills among many PIY is a significant deterrent to re-engagement with school post-release. Incarcerated youth are often denied meaningful educational opportunities, creating a population that suffers from marginal literacy and illiteracy (Leone, et al., 2005). PIY without essential literacy skills are at a disadvantage when attempting to further their education, as a plan for schooling post-release is essential to success (Abrams, 2012). 
Yet, although literacy is critical for incarcerated students, many educators refuse to see incarcerated students as able to learn critical literacy skills, and replace inquiry learning (Castro et al., 2015) with drill-packets. The lowered expectations of the instructors help to create students who are unable to critique the racist institutions that have funneled them into juvenile hall. Winn (2010b) argues that because many PIY have never been exposed to critical literacies they are unable to participate in a discussion of, or critique, the school-to-prison pipeline. Without the critical literacy skills necessary to place their experiences within the larger context of systematic institutional oppression, incarcerated students instead focus of their own personal failures, or as Winn (2010b) calls it, incarceration discourse. Winn (2010a) defines incarceration discourse as reifying stereotypes without considering the historical, educational, and economic disparities that can lead to criminal behavior. After conducting a study of Girl Time, a playwriting and performance program for incarcerated and previously incarcerated girls, Winn (2010b) argues that using critical literacy skill to critique the school-to-prison pipeline imperative to its dismantlement. Skills garnered from literacy instruction encourage students to question, criticize, and ultimately create a change in the school-to-prison pipeline (Winn et al., 2011). Not only does the ability to engage in the writing process allow PIY to critique a system that has failed them, but it allows them to redefine themselves through their writing (Winn, 2010a). 
While programs, like Girl Time, can provide adjudicated students with the critical literacy skills they need, there are populations of PIY without these skills entering community colleges every year. Crenshaw et al. (2015) state, schools can "funnel Black girls and other girls of color onto pathways to nowhere and render their academic and professional vulnerabilities invisible" (p.14). In the same vein, without community colleges being prepared to provide PIY with the critical literacy skills necessary to succeed, they can set these students onto a path to nowhere. Without community colleges being prepared to provide PIY with the critical literacy skills necessary to succeed, they can set these students onto a path to nowhere.

\section{On the Periphery and Community College}

I have researched the experiences of both hyper-marginalized students and previously incarcerated adults within higher education attempting to give more precedence to community college. On most community college campuses, PIY are usually grouped with other hyper-marginalized students. Racially, these students are similar, often times growing up in the same neighborhoods, attending the same schools until PIY are forced into court and community schools. Similar to incarcerated adults, PIY have been institutionalized because of their incarceration experiences, but typically for less time, and with less stigma attached to their criminal experiences, as PIY do not typically need to disclose their incarceration histories in employment or educational applications. Yet, stigma still remains, as does their trauma associated with 
incarceration and their disjointed educational experiences. These factors separate PIY from other hyper-marginalized students of color on college campuses and place them in betwixt both groups. While any discussion of a single group of students can easily essentialize a group, my purpose is not to argue that all PIY are the same, but that there are shared experiences that we can draw from in order to better serve this population. It is necessary to examine and build upon the literature in regard to students of color and previously incarcerated adults within higher education, particularly due to the possible facilitators and barriers for success PIY so well deserve.

\section{Educational Experiences of Hyper-Marginalized Youth in Higher Ed}

The purpose of this section is to highlight the experiences of hyper-marginalized youth within higher education with the specific goal of understanding their experiences so that this body of research can be used to help us better understand the experiences of PIY within higher education.

The majoritarian story of students of color as deficient follows students into higher education. Close to $70 \%$ of students who place into remedial courses are historically marginalized students, with over $40 \%$ of all students enrolled in remedial courses identified as Latino/a (Illowsky et al., 2013). Out of the students who enroll in remedial courses, the annual completion rate in California for $2010-2011$ was only $62 \%$ overall, and even lower, $53.3 \%$, when you only examine remedial math course completion alone (Illowsky et al., 2010). These completion rates for remedial courses 
are a snapshot into the experiences of students of color in higher education. It is my premise that failure of remedial coursework is just but a symptom in a larger, institutional illness; racism. Despite having graduated high-school, remedial courses suppose that students are not as prepared as their peers, and therefore must catch-up, or re-learn items they should have learned in high school. The premise of these courses themselves can be off-putting for students of color, as many students who place into remedial classes may never actually enroll in these courses and either try to avoid math and English or drop out of college (Blumenstyk, 2015).

Despite the mission of community colleges, research has demonstrated that the community college system has not been a welcoming place for all students, in fact, studies show that students of color can feel isolated and marginalized within higher education (Solórzano, Ceja, \& Yosso, 2000; Solórzano, Villalpando, \& Oseguera, 2005). From a CRT lens, marginality refers to the process by which people of color are pushed to the periphery because of their race, gender, class, sexuality, and class (Solórzano \& Villalpando, 1998). Marginalized groups are limited in their access to resources and viewed as marginal by the college.

Sense of belonging is one way to explore the experiences of students of color within higher education. Studies have demonstrated a link between intentions to persist, academic achievement, retention and a sense of belonging (Hausmann, Schofield, \& Woods, 2007; Hurtado \& Carter, 1997). A sense of belonging may be essential for 
understanding the experiences of students who feel excluded from campus activities and pushed to the periphery, such as hyper-marginalized students of color and PIY youth (Hurtado \& Carter, 1997; Strayhorn, 2008). Using CRT to examine the experiences of students of color on college campuses highlights a dissonance between students of color and the college environment. College campuses must be willing to validate students (Terenzini et al., 1994; Locks et al., 2008) and make them feel like their culture and their personhood is valued and welcomed, if the marginality of students of color is going to be reduced in any manner.

Perceptions of campus climate influence a sense of belonging, as students subjected to consistent microaggressions contribute to a lower sense of belonging among students of color. In a qualitative study by Solórzano, Ceja, and Yosso (2000) employing a CRT framework, 34 African-American students attending predominantlywhite institutions (PWIs) were interviewed in focus groups about their educational and social experiences within higher education. This study found that African-American students experienced isolation, invisibility, and feelings of inadequacy, discouragement and frustration due to being microaggressed by faculty and peers. Expanding on previous work by CRT scholars in the field of microaggressions, Yosso, Smith, Ceja, and Solórzano (2009) conducted focus groups with 37 Latinx students attending one of three PWIs classified as Carnegie Doctoral/Research Universities-Extensive. During their data-analysis microaggressions became a consistent theme amongst participants. 
The researchers concluded that regularly occurring confrontations with microaggressions have the ability to instill feelings of alienation and discouragement amongst students. These verbal assaults by faculty, students, and peers create an atmosphere in which students of color feel unwanted. It is no wonder why a study by Vasquez- Urias (2012) found that by their second-year at community college, 35.2 percent of Latinx students fail to continue. Together these studies highlight the fact that microaggressions, interpersonal, racial jokes, and institutional, have the ability to negatively affect retention of students of color.

The cumulative impact of students of color feeling unwelcomed within college, rather through overt or covert forms of racism, can contribute to lower-levels of well-being, leaving students emotionally drained, and with a decreased sense of belonging. Solórzano et al. (2000) found that students negotiating a denigrating college environment struggled academically and were plagued with self-doubt. Johnson et al. (2007) posited that a decreased sense of belonging among students of color can be accounted for by campus racism, noting that African American students were the least likely to report positively on the campus racial climate. Feeling unwanted at an institution negatively affects retention of students of color, as a sense of belonging is considered a basic human need, affecting motivation and behavior (Maslow, 1954; Strayhorn, 2012). Paraphrasing Hurtado and Carter (1997), a students' sense of belonging reflects how included they feel within the college community. The premise 
behind sense of belonging emphasizes that the institution has a role in making the student feel welcome at the college. Students' perceptions of campus racial climate directly affected their sense of belonging (Hurtado \& Carter, 2007; Locks, Hurtado, Bowman, \& Oseguera, 2008). Building upon the study conducted by Hurtado and Carter (1997), Johnson et al. (2007) researched sense of belonging amongst a racially diverse participant group. Results from Johnson et al. (2007) suggest that campus climates consisting of racial hostilities have a direct and negative effect on students' sense of belonging.

Researchers have recognized that there are several dimensions of campus climate that affect a student's sense of belonging, including, but not limited to facultystudent interactions (Velasquez, 1999; Wood \& Turner, 2010), campus racial climates (Hurtado \& Carter, 1997; Johnson et al., 2007; Locks et al., 2008) This is especially true, according to Anderson and Freeman (2004), in contexts in which individuals may feel unsupported, unwelcomed, or demeaned. In this context, acquiring a sense of belonging is in direct opposition to the experiences of many students of color.

The role of faculty with students of color.

Quality faculty-student interactions have the power to improve a student's sense of belonging and contribute to students' motivation, achievement, and success (Komarraju, Musulkin, \& Bhattacharya, 2010; Kuh et al., 2010). Using data derived from the Community College Survey of Men (CCSM), Newman, Wood, and Harris 
(2015) examined elements that contribute to students' perceptions of belonging with faculty. The CCSM is a needs assessment tool used by over 37 community colleges to examine factors inhibiting or increasing the academic success rate of historically marginalized male students. For the purposes of this study the participants were limited to the 364 Black male respondents from the 17 community colleges. Results highlight Black male students who perceived that their instructor held racial-gender based stereotypes had a lowered sense of belonging. In contrast, students who felt validated by their instructor, or heard validating messages, were more likely to perceive a sense of belonging with the instructor.

Validated Black male students are more likely to have a higher sense of belonging and this higher sense of belonging positively influences faculty-student engagement. Bauer (2014) used a delimited sub-sample from CCSM which consisted of 289 Black men currently attending community college. The study sought to investigate the link between faculty validation and levels of student-faculty engagement for parttime and full-time students. As many community college students attend school parttime, this study hypothesized that there would be a marked difference in student-faculty engagement dependent on time-status, thus possibly explaining the low completion rates for Black male students. Yet, Bauer (2014) found that Black male part-time and full-time students were essentially matched in their responses and that Black male parttime students reported student-faculty engagement levels that matched full-time 
students. This study suggests that regardless of the time a student is on campus, faculty are the gatekeepers for student success. For students who are marginalized, like Black men, faculty's belief in student ability and caring, greatly influence how engaged students are. For PIY to be successful at community colleges, faculty need to create inclusive environments in which all students feel respected and validated.

Despite the literature highlighting the need for faculty-student engagement, marginalized students in community college continue to have dismal rates for persistence, course completion and graduation, which seems to suggest a disconnect between marginalized students and faculty expectations. In contrast to the quantitative survey studies, Wood and Turner (2010) conducted a qualitative study comprising 28 semi-structured interviews at a community college in the southwestern United States classified as a Minority Serving Institute (MSI). Participants in the study noted 4 elements central to student-faculty engagement; specifically, friendly demeanor from faculty, checking in on student progress, listening to students' concerns, and encouraging student success. To strategically target ways to nurture student-faculty relationships many institutions have created learning communities that allow for more time for student and faculty to interact inside and outside of the classroom.

\section{Previously Incarcerated Adults in Community College}

It is odd to realize that although the mainstream narrative outwardly focuses on rehabilitation and reentry into society, that the actions and beliefs by this country's 
institutions seem to focus on the perpetual repayment for crimes individuals have committed/ been accused of and the continuous association with criminality that is magnified by historical ties of criminality to skin color. Despite the fact that higher education for previously incarcerated adults is linked to decreased rates of recidivism, increased economic standing, and increased parenting skills, this area continues to be understudied, with a large number of studies focusing on the participation in prison education programs (Anders and Noblit 2011; Fine et al. 2001; Fine and Ruglis 2009). With the increase in efforts to promote diversity and equity within higher education, individuals that have been system involved seem to be ignored or actively excluded from these efforts. In fact, the Center of Community Alternatives (CCA) National Survey revealed that overwhelmingly colleges and universities are using the college application process as a way to exclude those with incarceration histories (Weissman et al. 2010). Based on the responses of 273 colleges and universities, the survey indicated that $90 \%$ of applicants who indicated that they were convicted of crimes were then asked to provide a letter with an explanation of their crime and $63 \%$ were asked to submit a letter from corrections discussing their conviction/s (Weissman et al. 2010). This process, although framed as a way to limit crime on college campuses, serves as a method for excluding those with conviction histories. Forcing those with convictions to check a box results in what Rosenthal et al. (2015) refers to as "felony application attrition" with many students withdrawing their application for admission after being 
asked for more information regarding their conviction history. In fact, two-thirds of SUNY applicants who had conviction histories and were asked to provide letters and/or documentation of their conviction subsequently withdrew their applications, a higher percentage dropped out of the process than were actually rejected (Rosenthal et al. 2015). While excluding those with conviction histories from attending institutions of higher education may seem like it would increase safety on colleges campuses, crime on most campuses is committed by first time offenders, thus excluding students with conviction histories for no reason (Drysdale et al., 2010; Runyan et al., 2013).

For those students who avoid the felony application attrition, they face the further challenge of successfully completing their education within institutions not designed to support their journey. Colleges/Universities with programs designed to support previously incarcerated adults, typically referred to as re-entry programs, often focus on correcting "imagined deficits" of the students, as opposed to providing ways to navigate institutional barriers (Miller, Mondear, Starter \& Schwartz (2014). Examining the experiences of men of color who enter higher education post incarceration, Miller et al. (2014) explain the barriers that surround institutions of higher education. Focusing on the imagined deficits, such as intellectual inferiority and criminality ignore the real areas in which support is needed. Despite being in a program designed to help previously incarcerated adults transition into community college, participants in the study conducted by Miller et al. (2014) discussed how the discourse within the program 
linked a lack of education to crimes, thus creating a color-blind narrative of the justice system, ignoring systemic and institutional barriers that can make it much more likely that people of color are pushed into the justice system. Van Thompson and Schwartz (2017) suggest that programs which focus on the perceived criminality of the students do so at a detriment to the real concern, which is that many of the previously incarcerated adults have suffered educational trauma in P-12. These students often suffered the psychological effects of the school-prison nexus, being subjected to degrading language, verbal abuse, excessive monitoring, criminalization, and low expectations. When college programs focus on perceived deficits they can mirror some of the same P-12 schooling experiences that contribute to ideas of hopelessness and inferiority being internalized (Van Thompson \& Schwartz, 2017). Thus, many college programs designed to help the previously incarcerated population actually are causing harm to the educational and psychological journey of this population.

Another barrier that previously incarcerated adults face when attempting to pursue higher education is the fear of being outed, the stigma that comes with having been incarcerated can feel overwhelming. Strayhorn, Johnson and Barrett (2015) examined the adjustment of formerly incarcerated Black males within colleges and universities. The researchers found that many participants in their study viewed the exoffender label as an impediment to their future goals and Maruna (2011) highlighted how individuals with criminal records struggle psychologically with the decision to 
reveal their stigmatized identity of incarceration or to conceal this part of themselves. Copenhaver, Edwards-Willey, and Byers (2007) studied the role of stigma for previously incarcerated individuals in higher education and noted that many participants feared people on the college campus finding out about their conviction history because of all the judgements and stereotypes that surround ideas of criminality in American culture. Strayhorn, Johnson, and Barrett (2015) supported these findings in their study in which participants discussed the negative association of the ex-offender label. Participants discussed how the label negatively affected some peer relationships and made it easier for faculty to have negatively shape their view on the participants as students in the classroom. They felt that the ex-offender label carried stereotypes of hardened criminals, murderers, thugs, regardless of the actual offense of the students (Giraldo, Huerta, and Solórzano, 2017; Strayhorn at al., 2015). These negative associations coupled with being students of color encouraged low expectations and microaggressions.

It's not only the acts of aggressions or doubts that can push adult reentry students out of college, it's also beliefs of inadequacy developed over a lifetime of being subjected to substandard institutions and living within a colonial model that devalues people of color and their academic ability. This belief that education is not for people of color, and definitely not for those who have been incarcerated, can cause students to leave or not enroll in higher education post incarceration. In a study by Giraldo, Huerta, 
and Solórzano (2017) examining the experiences of previously incarcerated, ganginvolved students as they transition into community college, the authors highlighted how these students had connected educational spaces with ideas of violence and exclusion. In the same vein, Miller, Mondear, State, and Schwartz (2014) identified the belief that education was not attainable for previously incarcerated adults as a barrier for academic achievement in this population.

Yet, despite educational spaces being places of violence, fear, and failure, they can also become places of growth and possibility. More recently, studies of the experiences of formerly incarcerated adults in higher education have highlighted the strengths that students bring with them in higher educational spaces and how these strengths enable them to persist and view their educational journeys as part of their giving back to their communities (Batson \& Miller, 2018; Giraldo, Huerta, \& Solórzano, 2017; Halkovic, 2014; Pats \& Palmer, 2014; Rose, 2015). When the higher educational experiences of formerly incarcerated students are positive, students are able to view higher education as a place of possibility, a place where they can begin to service their community.

For many justice-impacted adults, higher education allows them to positively influence the life-trajectories of others. Students, who are able to push past institutional barriers and normative practices of institutions, have found benefit in education, feeling that education and higher-ed specifically has transformed them (Baston and Miller 
2017), and allowed them to take on the role of positive role-models for other criminal justice involved adults. Halkovic (2015) conducted participatory action research with college students with documented criminal justice histories which sought to identify the gifts that students with criminal justice experiences bring with them into institutions of higher education. The students interviewed overwhelmingly dedicated themselves to being role-models.

\section{Authentic Care}

One way to intentionally engage PIY in the college environment is the intentional practice of authentic care. In the literature, authentic care has demonstrated particular success in benefiting traditionally marginalized students (Noddings, 2005; Walker, 1993; Valenzuela, 1999; Beauboeuf-Lafontant, 2002; Rolan-Dow, 2005; Duncan-Andrade, 2009; Hidalgo and Duncan-Andrade, 2009). The impetus behind authentic care is the belief that students need genuine care to flourish. Caring only topically, or aesthetically (Valenzuela, 1999), places the broad concept of learning over creating truly nutritive relationships with students. Authentic care, although part of the discourse of care, offers a more precise definition than simply caring for students. Valenzuela (1999) envisions authentic care as educators striving to understand and value the realities that students brings with them. Care, as defined by Valenzuela (1999), intentionally includes valuing the cultures, experiences, and languages that students bring with them. Her study examines how Mexican students and their families 
describe the role of care in the educational process and offers a critique of institutions that devalue students' cultures, languages, and ways of knowing. Within institutions that that do not authentically care about students, students are quickly labeled as deviant and kicked out of class. Authentic caring fights against the binary that aesthetic care creates and accentuates a reciprocal relationship based on respect coupled with additive schooling. For PIY, authentic care would explicitly include the valuing their incarceration histories and the racialization process that accompanies incarceration. It is through this process of authentic care that PIY are able to change the way they see themselves and become college students.

Authentic care as a pedagogy is designed to center students' experiences and empower students to build on the wealth they bring with them to school. This wealth that students bring with them to school is an amalgamation of culture, language, incarceration status, racialization, and it is this wealth that educators must recognize and value. Building off this idea, Watson, Sealey-Ruiz, and Jackson (2016) use Roberts' (2010) theoretical framework of culturally relevant critical care (CRC) to study schoolbased mentoring program targeting Black and Latino males. Roberts (2010) framework for CRC is an integration of caring theory, African American caring pedagogy, and critical race theory. Using a phenomenological qualitative study, 14 participants in a mentoring program shared their experiences as mentor and participants in a mentoring program. Watson, Sealey-Ruiz, and Jackson's (2016) study specifically targets a 
mentoring program designed to service male students who had been pushed out of traditional high school because of violating academic probation, subjected to exclusionary disciplinary practices, or school closure. Many of their participant had experiences within the juvenile justice system and foster care. Due to their experiences with institutions not designed to serve them, these young men brought with them issue of trust, justifiably. Mentors employing a caring theory, as embedded within the framework of CRC, valued students' experiences and created relationships based off of openness and providing open space for students' voices to be valued and heard. These practices allow students to comfortably bring their whole self, including their incarceration experiences, into conversation and feel safe. Watson, Sealey-Ruiz, and Jackson (2016) recognize that it was due to this foundation of mutual trust and created a space for students to share their voices. The combination of space to share and caring relationships centered in mutual-trust reinforces Valenzuela's (1999) discussion on authentic care.

High expectations for academic success are an integral component of authentic care. Complicating Valenzuela's (1999) discussion on authentic care, RiveraMcCutchen (2012) discusses how a culture of low expectations can be equally as harmful as a culture of aesthetic caring. With a case study at an urban high school, Rivera-McCutchen examines the experiences of marginalized students in an environment that disconnects authentic care from high expectations. Educators in the 
study did not truly believe students could achieve academic success, and the faculty often "expressed skepticism about students' abilities to reach grade-level standards (Rivera-McCutchen, 2012, pg. 674). As a result of this skepticism resulted in lowered expectation from faculty and students underprepared for college.

\section{Conclusion}

As demonstrated by this review of the literature, despite understanding that the incarceration of students is wrong, there has been no mass movement within higher education specifically focusing on youth impacted by the juvenile justice system. Community colleges have a unique opportunity to help PIY change the way they view institutions and themselves. Yet, offering access to an education through an open-door policy is not enough to reverse this the trend of criminalization that can follow PIY. For PIY to successfully persist and matriculate, they need be authentically cared about and supported. As I have tried to show above, the need to understand the experience of PIY within community college is imperative, especially now as CA community colleges are moving towards guided pathways. In a time of such radical change, we need to build space for PIY. 


\section{Chapter Three: Methodology}

The purpose of this study was twofold, (1) to understand the academic, social, and emotional experiences of PIY at the College of the Bay Area, and (2) to inform practice for instructors, program directors, institutions, and policy makers within the community college system. My research questions that this study sought to address were the following: How do PIY at the College of the Bay Area describe their academic experiences? What are the implications of this research for instructors, program directors, institutions, and policy makers within the community college system? Since my goal was to understand the experiences of students, qualitative methods were the most appropriate. In this chapter I will provide an overview of my methodology and the reasoning behind my decisions. As CRT informed my phenomenological approach, I discuss the role of experiential knowledge and my CRT lens used for qualitative analysis. I conclude this chapter by outlining my steps for data collection and analysis.

Critical Race Theory (CRT) is at the center of my conceptual framework and thus frames my research design. The intent behind employing CRT is to intentionally seek to challenge other research practices that have added to deficit-based views on communities of color. As other researchers attempt to understand the experiences of students of color and previously incarcerated students (as PIY in higher ed is not in the literature), many find themselves in direct opposition to the mainstream narrative that emphasizes achievement gaps, deficiencies within students and students' cultures, and 
innate criminality within students of color. Touting quantitative data as omnipotent and colorblind, researchers and educators reproduce data that is designed to highlight the achievement gap between white students and their peers of color. Yet, while there are persistent achievement discrepancies between White students and their peers of color (Aud et al., 2010; Darling Hammond, 2010), this fact is often used to explain the normalized views of students of color as deficient or not as academically skilled as their White peers. The view of this failure places the blame squarely on the shoulders of students. Faculty often discuss how students of color are not prepared for college work, how their cultures are at odds with the system of education, and how students are not as prepared as other groups of students. A reframing of these achievement discrepancies highlights an opportunity gap instead of an achievement gap, thus focusing on the disease of institutional racism and not merely the symptoms of disproportionate underachievement.

In CRT scholarship, similarly in standpoint analysis, the privileging of experiential knowledge is a primary tenet, with an explicit focus on the subaltern voice (Delgado Bernal, 2002; Bell, 1992). The role of experiential knowledge, especially in relation to understanding the continued inequities students' experience, is imperative in higher education (Solórzano, 1998; Yosso, 2006). Solórzano and Yosso (2002) advocate for scholars to employ critical race methodologies (CRM) which expands upon the work of CRT scholars. Paraphrasing Solórzano and Yosso (2002), CRM 
forefronts race and racism within the research process particularly working against the essentialization of students. CRM seeks to actively challenge other research methodologies that continue to view students of color as deficient and views the "racialized, gendered, and classed experiences of students of color...as sources of strength" (Solórzano \& Yosso, 2002, p. 24). Influenced by a worldview which centers the pervasive role of race in the United States, CRM empowers me as the researcher to include the importance of race and incarceration status throughout my study by intentionally drawing upon the lived experiences of my participants. In education, majoritarian stories (stories reifying the racial power structure) have become told and retold in so many settings that for many educators these stories can become more powerful and important than the stories of students of color. These stories manifest in policies and teaching practices towards students of color. Majoritarian stories vilify students of color for their differences, exclude students of color from the classroom, and classify these students as deficient and criminal. Delgado (1989) emphasizes that these poor students of color are largely disallowed from educational discourse, thus making storytelling a powerful mechanism in challenging majoritarian stories. Counterstories within education allow the subaltern to demonstrate agency and raise awareness about racial injustices (Yosso, 2006).

Focusing on student voice is my attempt at humanizing previously incarcerated youth. As a construct, PIY are often thought of as nothing more than numbers that 
indicate criminality, failure, and a downward spiraling path to prison. The voices of PIY are often drowned out by the empirical work that positions PIY as the other, and incapable of overpowering their struggles, failing their journeys, and having their insights ignored on how institutions can best support their affective success. The voices of PIY are often silenced throughout society, even within educational contexts. Focusing on student voice, prioritizing their experiences, and positioning their knowledge to develop practical solutions for their situations humanizes these students (Romero-Little, Sims, \& Romero, 2013). By focusing on their journeys through education, their hardships, their joys, their solutions, my hope is you begin to see these wonderful human beings as I do and work to create institutions that better service them. Design

This study embraced a phenomenological strategy within an exploratory case study to better understand the lived experiences of PIY participating in Project Change at the College of the Bay Area. Paraphrasing Saldana (2011), a case study as a research method focuses on a single unit of analysis and serves to explore a phenomenon within an authentic context. For the purposes of this study, the college and the Project Change program serve as the case for the unit of analysis. Because Project Change serves PIY within a community college structure it allows for a wide-range of experiences to be shared. This case study is exploratory in nature, as the experiences of PIY within higher 
education have not been thoroughly examined in the literature and are often misunderstood (Butin, 2010).

Bogdan and Biklin (2007) inform my decision to use qualitative methods, as they believe that qualitative research can focus on the interactions of humans in their natural environments. Yet, for my study, my goal goes beyond the desire to study PIY within their natural environments, and utilize an inquiry-based approach to help understand how the participants interpret their experiences within educational institutions. While I am specifically interested in how PIY define their experiences within community college, I am keenly aware this experience is not in a vacuum. I acknowledge that the educational experiences of PIY within their P-12 education, especially during incarceration, greatly affect how they interpret and experience events within the community college setting. It is my belief that the ability to properly understand how PIY experience community college is directly related to the experiences, baggage, and trauma they bring with them from their P-12 experiences. Pieterson (2002) highlights that the meaning making process is imperative to phenomenological research. Pieterson describes meaning making as the act of participants determining what events, experiences, interactions, mean to them. This qualitative study was designed as an opportunity to privilege student voice, because as previously mentioned, the existing literature on incarcerated students marginalizes their voice. Lawrence-Lightfoot (1986), encourages the use of interviews, and suggests that it 
is one way to give voice to groups "who rarely get the chance to enter into public conversation about school" (p. 26). With this in mind, I collected data through phenomenologically based interviews and employed Seidman's (2006) three-interview protocol with five students to understand the experiences of PIY. The open-ended questions provided space for the students to reconstruct their experiences and to assign importance to events without my influence. Participants' narratives served as counterstories to existing majoritarian stories, which frames failure as student deficit and hides the role race and racism play in community college.

\section{Role of Researcher}

I currently work at the College of the Bay Area in multiple roles. At the time of the study I was the only instructor for Project Change teaching the college course within juvenile hall. As the primary instructor, I created all curriculum and curriculum guides for the course and participated in planning meetings between the college, the local County office of Education, and the Probation department. Additionally, since at the time I was the only faculty employed with experience teaching in a juvenile hall (I had taught in another juvenile hall before being employed by CBA) I was highly active in assisting the program's coordinator with planning events for students, attending student meetings, and attending conferences and field trips with Project Change students. In addition to my role with Project Change, I am also an instructional aide in within the Learning Center at CBA. My role in the Learning Center privileges me with the ability 
to interact with students on a constant daily basis that is devoid of the fear sometimes associated with teachers who are assigning grades. It is important to note, that even outside the paradigms of this study, I have established relationships with all participants. Within my role as faculty, and especially in my role as staff within the Learning Center, I am a constant presence in the lives of these students and have been for at least three years. As I know this is the case with many community college staff, the students come to me with things well outside my scope as an employee and confide in me. While none of the students are currently in classes that I teach, they still reach out to me for support various fields ranging from transfer application support to life events.

Taking the constructivist approach, I consider myself as the main instrument of this research study (Charmaz, 2014). As the main instrument used to collect and interpret data, it is important that I am cognitive of my own history and purpose as I conduct this particular research. My experiences teaching in both juvenile hall and at community colleges have shown me that PIY are underserviced in their educational experiences. I have witnessed how the trauma of their P-12 experiences and incarceration can have severe effects on their overall experiences within the community college system. As a way of ensuring that my own assumptions did not overtake the data, I enlisted the support of my critical colleagues within my qualitative research course. 
In the process of looking at this data I noticed that there were black males enrolling within my classes in juvenile hall, but these students were not transitioning to CBA once released. They are missing- many of the Black males that were in my college course in juvenile hall went on to be charged as an adult and transitioned to prison upon their 19th birthday or were only in juvenile hall until the courts decided to charge them as adults. The few others that did transition to CBA (Black women- not Black males) did not complete their first semester successfully. The Black women (only two transitioned to CBA from the juvenile hall program) were housing insecure and felt that they were unsupported by the coordinator. In private conversations while at CBA the women told me that they did not feel welcomed and believed that the coordinator and other students thought they were ghetto. Shortly after our conversation, the young ladies were busted for probation violation and sent to an adult facility. My hope in mentioning this is that the lack of Black student transitioning to college from juvenile hall can be a future research focus.

\section{Setting}

Research for this study was conducted at two locations. The first location is the College of the Bay Area (CBA), where I currently work as faculty and staff in the Learning Center. College of the Bay Area is a community college situated in the San Francisco bay area between San Francisco and the Silicon Valley, nestled in the San Mateo hills. The current college enrollment is approximately 13,000 students, of which 
$28 \%$ identify as White, $29 \%$ as Latinx, $5 \%$ are multiracial, $24 \%$ are Asian, $7 \%$ are Filipino, 3\% are Black, $2 \%$ are Pacific Islander, and $2 \%$ are Unknown/Other (CCCCO Datamart, 2018). Within CBA, Project Change is a program designed to provide wraparound educational services and resources to incarcerated and previously incarcerated youth. One the goals of the program is to unite the college and community together to help these underserviced students make the transition to and through community college. Although the program was designed specifically for PIY, the program has become a safe-haven for many students who attended the local continuation school as well. Students in the program range from 16-25, with the average student in the program being 19 . The program offers opportunities for incarcerated youth to gain exposure to college through a workshop series and college courses they offer at juvenile hall. As a collaborative effort, Project Change partners include college staff and faculty, San Mateo County Office of Education, Court Appointed Student Advocates (CASA) workers, probation, and local non-profits.

At the beginning of this study Project Change was in its third year of programming, having grown from simple mentoring of a handful of students to fullprogramming at CBA for 34 on-site students and classes within the local juvenile hall servicing 20-30 students every semester for 5 semesters consecutively. At the time of the pilot study, the demographics of the LCTR 105 course were reflective of larger demographics of the juvenile hall, with $70 \%$ identifying as Latino, $10 \%$ identifying as 
Pacific Islander, $10 \%$ identifying as African American, and 5\% identifying as White and remaining $5 \%$ as multiracial or unknown. When discussing the demographics of the course, I am explicitly not including the official data of the school within juvenile for two reasons; 1) as with any school, the demographics and required citation are specific to that location, and I would like my site/participants to remain anonymous, and 2) many of the students participating in the course are not reflected in school demographic data. The school within juvenile hall only tracks youth placed in the juvenile hall that attend the school within its gates. Many students who participated in the course were from the local boys' camp (a different physical location in which students who are sentenced to longer stays are placed) and/or had already received their GED or passed their HiSet.

The largest class offered to incarcerated students within the juvenile hall is LCTR 105, a student success course designed to get students prepared for college. Although the student learning outcomes (SLOs) for the course centered around the ability to set goals and exhibit help-seeking skills, as primary instructor of the course I ensured that the larger focus of the course would be helping students feel validated within higher education, and to view themselves as college students. Since I began teaching within the program, other online courses have been offered to currently incarcerated students in smaller numbers. In partnership with a local university, students within the juvenile hall participate in a writing program, although the course is no- 
credit, student have a chance to improve their writing while being exposed to college material. Additionally, every semester 4-5 students are given the ability to take an online sociology or psychology course. The number of students eligible for enrollment in these college courses in intentionally small, as the courses are online, and permission to use the internet has to be coordinated on a case-by-case basis with probation.

\section{Participant Selection}

With the goal of investigating how PIY describe their academic experiences, I chose to use a purposive sample of five students. This method is intended to allow students to go more in-depth about their experiences as PIY at CBA. My intent was to select participants that were representative of the students in the local juvenile hall, however, the demographics of students participating in Project Change on campus do not match those who participate while incarcerated. Black males are missing. Of those students who participate within juvenile hall, African American students do not transition and/or continue with Project Change. My being intentional in including students from different backgrounds, my intent was to create an accurate discussion on the experiences of PIY within Project Change.

All students interviewed were over the age of 18 and had completed at least 30 transferable units. The identification of units was chosen was in line with how CBA classifies full-time students within a year. With at least 30 units students would have been at CBA for a least a year and have enough time at CBA to be able to make 
meaning of their experience. Students who were not Project Change members and/or did not complete at least 30 units were excluded from the study. As a Project Change mentor, I often attend Project Change community meetings and during the last meeting of Spring semester 2018 I asked if anyone would be interested in participating in my study. During that meeting I explained the purpose of my study, the time-commitment requested, the risks, benefits, the voluntary nature of the request, as well as my intention to keep all of their information confidential. The students chosen volunteered during that meeting and were also the leaders within student organizations on campus. All participants completed consent forms and have been provided copies of this study's findings and conclusions.

\section{Participants.}

\section{Heather.}

Heather was born in the Kingdom of Tonga and brought to the Bay Area by her parents when she was a toddler. Out of all the participants in this study Heather has attended CBA the longest. Despite the fact that Heather has been raised in the Bay Area, in Richmond, the City, and on the Peninsula, she is considered undocumented. In fact, she is the only undocumented person in her family. Because of Heather's incarceration history she in ineligible for AB 540 and cannot legally work. Despite the emotional toll being undocumented brings, Heather is considered the problem solver in her family, a bit rambunctious and silly, but the problem solver nevertheless. Being the 
only person in her family with a degree (Heather currently has 2 associate degrees) and no ability to work, Heather often plays the role of caregiver. She regularly watches her nephew and is asked by her siblings to help them complete government forms, and she has enrolled her little sister at CBA in a dual-enrollment program. Heather volunteers on campus with a Pacific Islander Learning community as outreach coordinator and is a "volunteer" intern in the Learning Center. Essentially, Heather told me that my "student assistants are garbage" and that she would help out since she needed to wait around until her little sister was done with her school day at the local high school. I tried previously to hire Heather, but her status as undocumented prevented her from being able to take the position. Heather has shared with me her desire to help educate people on their culture and histories, and has the desire to eventually move onto graduate school in ethnic studies. Despite her desire to move on in her studies, Heather has been accepted to universities twice in southern California, and twice she has found reasons why she couldn't attend. Most recently Heather confided that she finally realized she can't leave her family because they rely on her so she will apply to transfer to the local state school so she can continue to live at home. Although Heather has all of the courses required to transfer, she still chooses to take fitness and Spanish classes at CBA as a way to stay active in her community. 


\section{Carlos.}

Carlos grew up with a single mother who was addicted to drugs. When he was in elementary school he was sent to live with his grandparents on the Peninsula and is an only child. Carlos is currently in his third year at CBA with the goal of transferring to UC Berkeley next fall. Carlos is the current president of the Project Change club, frequently volunteers with local nonprofits deigned to help incarcerated youth, and attends statewide conferences on justice impacted students. Carlos is usually described as well-spoken with an almost regal demeanor. Carlos's gregarious personality is obvious to most, he always greets everyone with warm-smiles, is helpful, and is wellliked by faculty and staff. Carlos is even one of 10 student ambassadors on campus, who go into high schools and recruit students to attend CBA. Part of this function is giving tours to groups who visit CBA, and he is consistently rated the best tour guide. Carlos is a straight " $\mathrm{A}$ " student majoring in sociology and tries to help everyone around him. Most recently Carlos has volunteered to be a program ambassador for Project Change, holding office hours and helping students navigate colleges processes, such as class registration and navigating campus resources. Last year Carlos applied to transfer to Stanford, although he was visibly disappointed when they did not accept him, he has decided it is an opportunity to continue "helping young people" and put more time into his community before he transfers. 
Sonya.

Sonya is currently a new transfer student at a local university majoring in Business. At the time of the study she was finishing her last semester at CBA. Sonya's parents immigrated to the United States from Mexico in the 1980s. As a single-mother, Sonya has worked very hard to not only ensure she spends quality time with her daughters but maintains straight A's in all of her business and accounting classes. With the birth of her second daughter, Sonya decided that she could no longer work and attempt to go to school. The daycare on campus informed Sonya that with her income from working she was just above the threshold of free childcare, thus helping Sonya choose to focus on her studies. Despite Sonya's grueling schedule she worked as a student ambassador on campus as well as a math and accounting tutor in the Learning Center, she has been able to not only dedicate time to volunteer but also maintain a high GPA. Sonya often jokes that when people see her they assume she is "a chola", mainly because she has good eyebrows. Sonya is very passionate about school reform for justice impacted students and was an ambassador for UC Berkeley's Underground Scholars Program, a program focusing on formerly incarcerated students successfully using education as a vehicle for success. Although Sonya began her journey at CBA unwilling to share her incarceration story, she now easily shares her journey through incarceration with any young person as a way to encourage them that they too can be successful in school. 
Esme.

Esme is a quiet woman who, at the time of the study, was entering her fourth year at CBA majoring in administration of justice. Esme works full-time at the local airport and cannot take full-time classes. Although her desire is to support incarcerated youth by becoming a probation officer, her short-term goal is to find the time to be able to complete her associate's degree and transfer. As the oldest sibling, Esme feels responsible for supporting her mother and younger brother. They all live together is office buildings that are secretly rented out as housing units. Esme's mother emigrated to the United States from Mexico after Esme was born. Until recently her mother had supported their small family by working as a cleaning woman for a hotel. When her mother was hurt on the job the hotel decided to let her go, because of her legal status, Esme's mother feels she cannot complain. Esme has increased the hours she works since her mother's injury, but there was a month-long period this last summer in which she was afraid to go to work, for fear of being deported herself. Although Esme is eligible to work as a DACA recipient, with the delay in processing times of DACA renewal forms there was a month-long period in which her paperwork was expired working at the airport with police officers all around, Esme thought it was safer to not go in until her paperwork was up-to-date. Working full-time has limited the classes Esme can take per semester, delaying her transfer to a 4-year college or university. 


\section{Rafael.}

Rafael is a self-described anarchist. As a Chicano male with a shaved head, nose ring, and shirts that usually say "Fuck Trump," Rafael is not afraid to share his political views. As an ethnic studies major, Rafael is engaged in many activist movements in the community, ranging from support for undocumented peoples to activism to dismantle the carceral system. At the time of the study Rafael was 21 and beginning his third year at CBA. Although Rafael is beginning his third year at CBA, some of those semesters Rafael was unable to take courses. At the beginning of his second year of college Rafael was homeless. He found long-term temporary housing in shelters in the South Bay, about a 1-hour train ride from CBA. Although Rafael attempted to enroll in school during this period, he had to withdraw. Without permanent housing, Rafael felt he needed to find full-time employment and could not focus on school. This fall Rafael has again returned to CBA and has found permanent housing with a family member closer to CBA. Rafael is a founding member of the Project Change Club, a student worker in the Multicultural Center on campus, and a student commissioner in the country's juvenile justice prevention commission that works to improve the state of the juvenile hall.

\section{Data Collection}

For this phenomenological case-study, interview data consisted of open-ended, face-to-face, 30-minute interview with participants at a time designated by them. A 
three-30-minute interview protocol was used (see Appendix A) to guide conversation. Interviews were all audio-recorded and transcribed. Once interviews were transcribed, I allowed all participants the opportunity to review the transcripts and check for accuracy. The open-ended questions were designed to emphasize the voice of the students, allowing them to freely share their lived experiences without restraints from me as the interviewer (Creswell, 2008). All interviews were conducted one-on-one and were scheduled one week apart. Interviews were not scheduled back-to-back to as a way to insure privacy and confidentiality and a way to avoid risk of participants crossing paths as they began or completed an interview. I took great care to ensure that students' confidentiality was respected and that my research did not harm my students. In order to protect the confidentiality of my students, pseudonyms were used for participants names and locations (such as the name of the educational institutions, cities, and/or communities). Participants understood the voluntary nature of the interviews and were able to withdraw from the study and withdraw their data from the study at any time.

In addition to conducting multiple interviews to collect data, I incorporated other meaningful data from a pilot study conducted as a class project within my doctoral program. For the pilot study I conducted informal interviews with the Project Change coordinator (Katie), an educator within juvenile hall, and a CASA (court appointed student advocate) supervisor. I also took ethnographic field notes from numerous Project Change meetings, classroom interactions, and because I have interaction with 
Project Change students daily within my work-role, I regularly journaled about our interactions. Additionally, a key data set came from Project Change students attending the College of the Bay Area. I recorded and transcribed 2-hour long panel interviews with four Project Change students and had a follow-up phenomenological interview with one of the students on the panel. In the interview, I asked the student about her educational experiences during incarceration and at the College of the Bay Area. Through this project I sought to explore the educational experiences of PIY, with the goal of exploring factors that contribute to academic success. Through this process I gained experience not only as a researcher, but it allowed me to refine my techniques as an interviewer.

\section{Data Analysis}

For data analysis I employed a ground theory approach beginning with line-byline process coding (Charmaz, 2014). All interviews were transcribed and after coding line-by-line I engaged in process descriptive, in vivo, and process coding methods simultaneously. Coding my data, I began to identify patterns within my codes and grouped these patterns into larger categories. While coding the data, I wrote analytic data memos to document my thought processes, and I presented emerging themes to my critical colleagues. I used my data memos to help guide my ongoing data collection, and conducted multiple cycles of coding, using both descriptive and in vivo codes. I developed the codes inductively and then grouped codes together thematically. 


\section{Internal and External Validity}

The goal of phenomenological interviews is to allow participants the ability to share their experiences without being overpowered by questions and the researcher, as such, their voice, their words, and their stories are important. In an effort to increase internal validity of the research, all interviews were audio recorded and transcribed. To increase the validity of the interview data all participants were invited to participate in member-checking which Seidman (2013) describes as important to the credibility of research and critical for validity. The process of member-checking involved providing all participants the opportunity to review their transcribed interviews and make edits as they saw fit. The process of member checking ensures that the portrayal of participants is accurate and ensures that all research is presented in a respectful manner and Seidman (2013) emphasizes the importance of sharing with participants all material that involves them. Through the intentional use of triangulation of qualitative data, member checking, the use of critical colleagues including the dissertation chair, and the pilot study the validity of this research was increased.

The findings from this research are not generalizable to the entire population of PIY of color, as the sample size includes only 5 participants. Despite the fact that my findings might not be generalizable to all PIY of color within higher education, the stories and experiences of the participants can positively impact instructors, program directors, institutions, and policy makers within the community college system. 


\section{Chapter Four: Results}

So, I didn't graduate high school, so I had never been in a graduation before. I didn't understand it. I have never been in one. I have never had the candy lei experience so... when CBA emailed me, they email people in Spring, and they were like, oh hey, congratulations, you're uh...what's the WebSmart thing? - Well it says you are $99.9 \%$ done with your degree or whatever. I didn't know kind of how to feel. Because I think in high school, and my educational experience before here was so horrible. Nobody really thought that like, I was a good student and not much would become of me. So, when I got that email I didn't feel upset anymore because like people always have not thought much of me, cuz it's like shit... I did it. I got two AA's. That's more than most of my family who don't even have one. I feel...it's crazy. I think I cried every day of the last half of Spring semester, because it's like...not crying because I'm upset, but crying because like ...shit...I really endured college...I finished something. I did something. I accomplished something.

- Heather (Interview Summer 2018)

\section{Overview}

I began researching previously incarcerated youth to answer two questions. The first: What are the educational experiences of five previously incarcerated youth attending the College of the Bay Area? The second: What are the barriers and facilitators for program completion within community college? I used CRT to help frame my understanding on the racialized experiences for PIY and as frame for understanding. The use of a series of in-depth, phenomenological interviews provided me insight into the experiences of the five students in this study. Interview One consisted of a focused educational history and students shared their educational experiences up until they entered college. Interview Two, students discussed their educational experiences while in college and framed the details of facilitators and 
barriers to educational completion. In Interview Three, students reflected on the meaning of their educational experiences in community college and their entire schooling experience. In addition to the data gathered from student interviews I also had data from a pilot study that examined the effectiveness of Project Change from a qualitative method course I completed Spring semester 2017. I collected primary data for the pilot study through field notes and coursework from classes I taught in juvenile hall. Other data included transcriptions from student interview panels, and faculty/staff interviews.

Findings are organized along a chronological educational path that emerged from an analysis of students' experiences within schooling and fall into three broad themes for discussion. The first theme School-Prison Nexus is centered on participants' $\mathrm{K}-12$ experiences and how their traumatic educational experiences influenced how they view themselves and their surroundings once they enter community college. The four sub-themes are: segregation, abandonment, recycled education, and criminalization. The second theme is Baggage Carried from the School-Prison Nexus to Higher Education. This theme helps describe students' experiences related to the stigma of being previously incarcerated, and the emotional consequences of the school-prison nexus on students once they are within community college. The sub-themes include: feelings of judgement, self-doubt, and consequences of a disjointed educational experience. The final theme is Academic Reengagement. This theme describes the processes that helped 
students connect with their schooling experience in a positive manner. Four sub-themes are: re-identification of self, homemaking, authentic care, and healing through sharingemerged from the data.

I organized themes by focusing on student voice and prioritizing student experience. I began each section defining the theme, and then introducing the theme in detail with student narrative. Students' quotes were used to further illustrate and develop each strand.

Table 1

Summary of Findings

\begin{tabular}{|c|c|c|}
\hline School-Prison Nexus & $\begin{array}{c}\text { Residue of the School- } \\
\text { Prison Nexus to HE }\end{array}$ & Reengagement \\
\hline $\begin{array}{c}\text { Segregation: Why put us } \\
\text { in solitary? }\end{array}$ & feelings of judgement & reidentification of self \\
\hline $\begin{array}{c}\text { Abandonment: They gave } \\
\text { up on me }\end{array}$ & self-doubt & Homemaking \\
\hline $\begin{array}{c}\text { Recycled education/lack } \\
\text { of education }\end{array}$ & $\begin{array}{c}\text { Consequences of a } \\
\text { disjointed educational } \\
\text { experience }\end{array}$ & Authentic Care \\
\hline Criminalization & & Healing through sharing \\
\hline
\end{tabular}

\section{School-Prison Nexus}

The school-prison nexus is a metaphor used to describe an intentional process of racialization and criminalization that captures the historic origins of racism, the 
systemic use of schooling as a process of push students of color into incarceration, and attempts to describe the "multifaceted nature of the intersections of education and incarceration" (Meiners, 2007, p. 32). There is a common understanding within the school-prison nexus; that children who end up in the criminal (un)justice system do not travel on a non-stop trajectory from early childhood education to prison, but instead they are more than often hurled in a non-linear process between several institutions including foster-care, juvenile hall, and court-school (Meiners, 2007;Heitzeg, 2016; McGrew, 2016, Annamma, 2018).

Participants in this study have all been forced to negotiate the school-prison nexus and have chosen to pursue community college. Although these participants have been able to pursue college, my study has found that traumas experienced by participants while in the school-prison nexus remain, and in some cases persist in community college. While the following section is used to help describe students' lived experiences while they were in the school-prison nexus, the residual trauma that remains is discussed in the theme titled Baggage Carried from the School-Prison Nexus to Higher Education.

\section{Segregation: "Why put us in solitary confinement?"}

This theme is directly linked to feelings of isolation and trauma, either caused by physical displacement, or feelings of being shut out of a group (an outsider). All students discussed how they felt quarantined during their P-12 schooling and feared this 
feeling would continue as they entered college. I chose to keep the in vivo coding because it described the feeling represented in the data with more accuracy. The theme is more than loneliness, it comes across as feeling like an outcast and unwanted within educational spaces, like juvenile hall and classrooms. Nearly all the participants expressed feeling isolated, and that is was typically caused by educators or probation officers physically separating them from other students.

The following excerpt is from a free-write that I assigned to students after a math lesson that was designed to show students how to examine how race and socioeconomic status correlate with incarceration rates. Students were presented poverty rates and incarceration rates for all fifty states. Students needed to place states in ascending order based on poverty rates and incarceration rates. After the lesson, I asked students to take five minutes and write a few sentences about what they learned from the math lesson. While most of the responses I received were more limited in scope to the assignment, Elias chose to respond to the data and connected the math lesson with his educational experience in what I interpret as a resistance piece. Elias commented on the poor treatment he received while he was in juvenile hall and how that created a distrust of the juvenile justice system. One of the strengths of his piece is that the he chose to express his powerful emotions without being promoted to connect the lesson with his own experiences. Students were asked to identify any correlation 
between poverty rates and incarceration rates and identify the correlation between these two categories. Elias wrote:

Every night, all throughout the U.S. more than 54,000 kids are sleeping behind bars, that's the population of Charleston, South Carolina. Institutions believe that they are "rehibilitating" these kids, but in reality, they are making their behavior worse. $70 \%$ of these kids also have mental health issues, and without addressing this problem first and foremost, how can you fix their mindstate, decision making, and future? The "system" thinks that we care about their feelings and what they have to say, if you don't care about our feelings, and what we have to say, why should we even try to interpret yours words and use it in the future? Additionally, if $70 \%$ of us have mental health issues, why would you put us in solitary confinement? (Elias, Written reflection, March 15, 2017) Elias' comment speaks to how juvenile hall is an oppressive environment and creates disengaged students. These exclusionary disciplinary practices further perpetuate any existing antagonistic feelings toward schooling (Cammarota, 2001), and makes school seem unwelcoming and unsupportive.

Rafael discussed how he was physically quarantined from other students in his schooling because of his perceived criminality. Other participants discussed that they too had felt that schools had pathologized their actions and treated criminality as a contagion. Students felt that schools deliberately kept them segregated from other 
students, and as a result, these quarantined students received subpar education. Once Rafael was expelled from his middle school in eighth grade, he was sent to a court school called Pathway. Pathway is the local court school in which all the participants have also attended as they ricocheted back and forth from juvenile hall. Rafael discussed how instead of placing him in a traditional classroom he was sent to a single room with students from various grades. Rafael was an eighth grader in a class with seniors at the time. Unlike the typical middle school and high school experience in which students transition to different classes throughout the day for different subject areas, Rafael and his peers remained in the same class all day. Rafael noted;

And then when I was in eighth grade and like I was going to school with like all the seniors that are like you know top notch badass. So then it kind of further pushed that agenda on this where they were just simply trying to contain this and do the same thing not to contaminate other folks I felt. (Rafael, excerpt from interview, Summer 2018)

Rafael's comments about being quarantined in a space that functioned to prevent the contamination of other students illustrates a larger mechanism of the school-prison nexus, in which students are excluded from participating in caring educational settings and are instead managed. Rafael was managed in the sense that he was contained in a classroom setting. Instead of being able to participate in a quality education, Rafael felt the school "pushed that agenda" of criminality on him. I interpreted Rafael's comment 
"top notch badass" seniors as the school's deliberate act of categorizing him as a serious criminal. To Rafael, the institutions deliberate acts of isolating the "top notch badasses" together only pushed these students further away from school altogether. Rafael believed his P-12 schooling ended with this particular classroom placement, as he shared how he was in "juvenile hall, at the camp, or on the run" (Rafael, student interview, Summer 2018).

Pathologizing the behaviors of students and placing them in quarantine to be managed can be interpreted as explicit acts dehumanization. Feelings of isolation and being managed were highlighted by other participants, as Sonya equated her experiences in the court school classrooms to jail.

It just felt like it lacked actual education. It didn't feel like we were there to learn, it just felt like we were there to be babysat, to be watched. I don't know. Like they didn't want us out on the streets with others, like they didn't want us. So they were like let's just put them in here (Sonya, except from interview, Summer 2018)

Sonya's description of her experience at Pathway aligns with Rafael's feelings of segregation. Both Sonya and Rafael believed that because they were perceived as criminals they were no longer worthy of an education, just supervision. Although the classes that Rafael and Sonya describe are staffed by credentialed teachers, both participants viewed the instructors of these classes as nothing more than bodies hired to 
supervise and manage students. During an earlier interview, Sonya expressed she was arrested, and was bounced between juvenile hall and Pathways, she also expressed that she never had "a teacher, a normal teacher, again" (interview, Summer 2018).

The young people in this study were clear and demonstrated their understanding about how the act of isolation and quarantine pushed them to disengage with school. For many of the participants, they believe they were pushed onto the fringe of society where they were further criminalized. Participants also described their beliefs that isolating students does not work. Elias writes,

Rather than punishing children for their shortcomings a bigger and more helpful step would be to teach them. Teach a child that just because you have done something wrong you are not a criminal. Everyone makes mistakes but the biggest mistake that society has made was the decision to build institutions such as juvenile correction facilities. It does not work and isolating a child and telling them to think about their mistakes they have made DOES NOT help and overall is arrogant. (Elias, Written reflection, March 15 2017)

In this excerpt, Elias believes the act of isolating students does nothing to actually help the student. I first met Elias while he was incarcerated in juvenile hall. Elias was a student in my inaugural "Keys to Success" course. Though Elias earned his HiSet diploma earlier while he was incarcerated, he was also excluded from the educational department while serving most of his time in juvenile hall. because he was locked up in 
juvenile hall off and on for three years. Once students have completed their high school education or the equivalent (HiSet or GED) they are excluded from participating in the school department while incarcerated. Since my course was for college credit, Elias was able to attend, so in addition to earning credit for completing the course the first time, he also audited the course two additional times, mainly to be able to get out of his unit where he was kept locked away until the others were done with school for the day. Elias was held in juvenile detention until he was 19. and then released. Elias did not register for community college upon his release Spring 2017 because he associated school with being confined, isolated and quarantined. It took Elias another 18 months before he would find me in the Learning Center at CBA. Elias entered the Learning Center with conviction and said, "Tabitha, I want to come back to school. I want to take classes at CSM" (personal communication, August 31, 2018).

\section{Abandonment: They gave up on me.}

Another sub-theme that students identified as a barrier to education was the feeling of being given up on, being abandoned. I am referring to the sub-theme They gave up on me in the following way: a feeling that no one cares about your well-being; feeling worthless or abandoned. Multiple students shared the idea that people whose job it was to care for their well-being within the School-Prison nexus decided that they were not worth caring for. These feelings of abandonment were also noticed in students' written reflections, and captured in my field notes, as Bianca stated, "Mrs. Smith 
(juvenile hall teacher) don't care if I pass, she thinks I'm dumb.... she don't even call on me anymore...she don't fuckin care (this phrase was almost inaudible, as she said it under her breathe as she looked away)" (Field Notes, 2/15/17). While Sonya's story is not typical of my sample, as her story is more emotionally charged than others, her story is also more complete. My focus when I talked with Sonya last year for my qualitative methods course was centered on discussing the benefits of Project Change. I was surprised when she focused more on the barriers to success she faced, and regularly expressed the feeling that her probation officer gave up on her. I found other students who expressed feeling abandoned did so through anger, or they attempted to make light of the issue and change the conversation topic. Sonya was the only participating student who went into great detail about her story. I believe Sony's story is truly representative of the other students' experiences, and emotions. Sonya wrote:

My wakeup call was my daughter. I got out of juvenile hall at fifteen and it took me a few years to really get my act together, to find myself-I mean, I was an angry kid. I was in the gang life and I felt alone. My probation officer gave up on me (audibly crying)- she just gave up on me. That's how I finally got off probation, not because I was good or anything, but because she just gave up on me. I had a scholarship to a private high school and I blew it. Your friends who are your friends now won't be your friends later I was stuck in that gang life-I regret that now (crying). I had a job and was making good money, but I didn't 
even do anything with it, ya know. They even offered me to have my own store, to be manager, but I wanted more. (excerpt from student interview 4/7/17)

Sonya's comment portrays a student who feels abandoned by a system that many believe has been designed to help her. The juvenile (un)justice system is designed as a rehabilitation process, yet instead of helping youth reconnect, it continues to push students out. Like Sonya, Bianca felt unvalued within this system that disregarded her. In the same way that authentic care creates students who feel supported and encourages them to strive further in education, blatant neglect can have the opposite effect.

The interviews participants provided described various instances where in their P-12 schooling they felt invalidated by educators. Treatment by educators which consistently causes students to feel uncared for, worthless, and abandoned constitutes invalidation. Rendon (2009) goes on to define invalidation as a "form of oppression, a way that people in power exert dominate over others" (pg. 94). Educators who exert their power over students contribute to students feeling uncared for. Feeling invalidated and abandoned can have profound consequences on how students view education. Esme recounts an interaction with her vice principal at her high school shortly before she was expelled.

And then after that she told me 'I don't care about the students that are doing bad at my school'. She said 'I just want to get rid of them, I want them out. I don't want to deal with that.' And she 's like, that's what I'm going to do to you. 
Like if you don't change, like, I'm going to kick you out. And a couple of months later that's what ended up happening. (excerpt from interview, Summer 2018) Esme stated in an earlier interview that her vice-principal saw Esme's acting out as causing trouble, and not as a way of seeking the attention of others. Esme didn't know what to do when she found out her mother was abusing drugs. Esme was in her sophomore year of high school at the time. She was afraid to mention it to anyone at school and hoped that the vice-principal would support her. Instead of receiving the support she needed, Esme was accused of being gang-affiliated and blamed for leading a group of girls to ditch their classes. Esme was invalidated in her educational journey by these dehumanizing experiences. She was then further excluded once she was incarcerated because she began to feel unworthy of receiving an adequate education.

Recounting her educational experience while incarcerated, Esme shared: It wasn't like real education. It's like they think of you like you're less, you know, like you don't deserve anything in life, you know, you're in jail. They act like that will be your life from now on. You're going to go to prison and be nothing in life. I feel like that's how they view it. That's why they don't care what type of education they give you because they don't think you'll ever need it. Like they know you aren't going into higher education. That's how I view it, you know, because why else would you do that? Not care about children, not educate them, make them read the same book. I mean the whole point of the 
juvenile justice system is to rehabilitate. So how are you rehabilitating anyone by watching Nemo for science class? You know, if you felt cared for, if you felt that you were being prepared, like school-wise, then maybe you could envision yourself not coming back. But they are only preparing us to come back. (Esme, excerpt from interview, Summer 2018)

This excerpt helps describe Esme's dehumanizing experiences that led her to ultimately disengaging from school. Fine and Ruglis (2009) discuss that within the School-Prison Nexus young students of color are consistently being told that they are undeserving of a quality education. In Esme's estimation, substituting watching a Pixar film for science class constitutes telling her that she is not worthy of a quality education. For Esme, disengaging from school was a gradual process that came as a result of actions within educational institutions which illustrated to her that they deemed her worthless of care. Refusing to educate youth within juvenile facilities reiterates to them that their future is not in the outside world, but in prison. This majoritarian narrative is so pervasive within these facilities, that the added stressor of inadequate education make it almost impossible for students like Esme to "envision yourself not coming back." Through a CRT lens, the School-Prison Nexus illustrates how the juvenile (un)justice system, is used as a tool to maintain an oppressive state on a captive population. Instead of preparing her for success in life, Esme maintains that her schooling post-incarceration, prepared her a life of incarceration. 
In the following excerpt, Heather describes how her interactions with her high school college and career counselor made her feel hopeless and almost made her give up on her dreams of higher education.

(crying into her sleeve she whispers) I'm sorry... high school was hard. (30 seconds of silence). Honestly, she sucked as a college and career person because I don't remember being helpful to anybody. (talking through her tears). Like I always go to college and career center, and I like... the 2 years I went to Hillside I think I only talked to her once, and it was to ask her (crying louder) why I couldn't do the SAT prep class and she told me I need a social and without a social I couldn't do it. And that was it... And then she told me she doesn't know how matriculation works for undocumented students, well she called me illegal, for illegal people, and that I would have to wait and find out on my own. Sooo... I stopped going after that.... There's no point in me or anyone going back to someone who just like tells you no. And doesn't even tell you why it's a no, she told me it's a no, so I was like fuck it. (Heather, excerpt from interview, Summer 2018)

Heather described how she tried to seek help from the school college and career counselor and was instead met with feelings of being unworthy of help. Heather's pain from her high school experience was evident in our initial interview. Heather cried heavily during the interview. I have worked closely with Heather for 4 years and had 
never seen her cry. Heather's physical demeanor changed from cheerful to seeming emotionally overwhelmed when she began to share her experiences working with her teachers and counselors during her years in high school. Heather appeared frozen for some moments during the interview. I watched her body contort and pull away from the voice recorder as she talked. Her feet remained anchored to the ground pointing at me, but her torso and face turned away from me as she spoke about the incidents. It looked as though one part of her wanted to participate in the interview while another part of her was telling her not to talk about her educational journey. It was apparent that Heather's psychological scars remained.

\section{Recycled education.}

All participants described their educational experience post-incarceration as a form of recycled information after they were incarcerated. I am referring to the subtheme recycled education in the following way: a feeling that curriculum students are exposed to is no longer advancing, that curriculum, course material, and instruction are low-level and reoccurring. Participants noted these sub-par educational experiences as they were moved between juvenile hall, camp, court school and back to juvenile hall. With that, participants were exposed to the same low-level curriculum at each of these institutions. Sonya describes her educational experience at Pathway as almost nonexistent. She states: 
And I don't feel like it was anything new because I felt like the material was always being recycled. So it was always being the same material being taught and it wasn't any new material to me, it was material that I had learned already, that I already knew about like in middle school or whatnot. So that's why I say that I have no high school education. After that I pretty much dropped out. I went to the district. I had to go sit down in the district and they pretty much told me to tell them what my reasoning was and I just told them why I didn't' want to go to school and whatever and they signed off on me. And I was an official high school dropout. And they didn't really try and keep me after that and try to get me to finish high school or anything. I don't think they like pushed me to like independent studies or anything like that. (Sonya, excerpt from interview, Summer 2018)

Sonya's description of her recycled education highlights the lack of academic rigor many PIY experience in their schooling. As Sonya's schooling experience moved away from teaching and learning and onto the containment of bodies, her desire to continue with education slowly dissipated. With material constantly being "recycled" and her feeling as though she was not learning anything new, she saw no use in continuing to attend school. Sonya's description provides insight about the types of mundane educational experiences that push students to leave school, and oftentimes to not return. 
Participants frequently talked about how the worksheets that they began in juvenile hall were replicated in court schools and continuations. Heather reflected on her schooling experiences while she was at juvenile hall. She stated, "they make you do class for like three hours a day, but really all you're doing is coloring pictures. That's what I recall the most." Esme echoes Heather's sentiment as she described her own educational experience while she was incarcerated:

So it's like by the time I was inside the juvenile hall, I was already reading a book in English class at Pathway. Then I went to the juvenile hall and they were reading the same book but they were like chapters behind where I had been and already read. Like it was starting the same book all over again in the same class and it's like these students have been there longer you know, or like that go back and forth and they're just like this is the same book we always read, it never changes. Like it's like we are always stuck on this same book. It's one of the most books they use throughout the semester. It was better than science class though. At some point, the science teacher just brought in a fish tank and then was like, 'oh, I was going to play Nemo. 'So like, we were sitting there and watching Nemo for science class instead of like learning anything. For history we just colored maps of the world, we sat there and color like the different continents like we were in kindergarten you know instead of learning actual history and it's all like it's not really like education. They taught us a 
basic ass education. I think their reason was that they thought we weren't going to do the work. Like they were generalizing everybody and just grouping all the criminals as lazy. It's like they never thought about the people who wanted an education and needed a little more challenge. (Esme, excerpt from interview, Summer 2018)

This excerpt details Esme's experience and aligns with the literature on the idea that the kinds of facilities described in the current study are under-preparing students (Youth Law Center, 2016; Leone \& Weinberg, 2012). Moreover, these are the same students that exit juvenile hall with less ability to score on exams than they entered with. Rafael states:

And then one thing I noticed at least when I was in education and in a locked setting, it was like I'd been there so damn much that the curriculum just started repeating where I was learning the same thing I just learned my last day I was there. So that was just something where it's like I'd never learn nothing new, you know. So that kind of pushed me away from education as well. Like what am I doing here, you know. (Excerpt from interview, Summer 2018).

This excerpt helps to emphasize how the practices that are employed within these facilities do not prepare students for life beyond bars. Students are not being prepared for continuing their education in these facilities, they are utilizing education as a way of socializing well-behaved captives. Students are rewarded for following rules by being 
allowed free time to watch videos, and color maps as participants described. Unfortunately, these youth are systematically denied the opportunity to receive an adequate education. As witnessed in the current study, many students who are involved in the criminal (un)justice system are subjected to recycled curriculum, and eventually disengage from school altogether. PIY who continue on to higher education can find themselves spending a significant amount of time trying to catch up on certain habits other students learned during their P-12 schooling.

\section{Criminalization/dehumanization.}

Participants shared experiences about times when were treated differently than their peers for similar actions. Participants felt that they were being accused for things like committing crimes, or for being the ring leader of wrong doings. They often felt they were misappropriately identified as troublemakers. While participants in the current study describe how they were perceived as criminals, those criminal identities were first created within public schools and then solidified within juvenile hall. Sonya shared how after her first period of incarceration that her high school Principal began associating her with all wrong doing on campus. Sonya recounts:

So I remember, I don't remember if I went on the campus, or I don't remember what, but I pretty much wasn't allowed on the campus anymore. He told me as long as you have gang affiliations you are not allowed here, all this stuff. Like I know he would say things. I think the police one-time were looking for 
somebody, He directed them to me for whatever reason I dunno. So I knew all the way people used to look at me. They were, it wasn't the same. They were looking at me differently. (excerpt from interview, Summer 2018).

Sonya's recollection emphasized that all of your actions and all missteps on campus are blamed on you once you are labeled a criminal within an educational institution.

Despite the fact that the police were looking for someone specific, the principal directed them to speak with Sonya. The actions of the principal are very telling, they emphasize his belief that all "criminals" are known associates. Sonya's principal no longer views her as a student, but as a criminal, as gang affiliated. A key factor that contributed to Sonya dropping out of was her feeling that no matter how hard she tried to stay out of trouble, she was blamed for criminal actions.

Similar to Sonya's experiences, Carlos describes his experiences with teachers at a court school once he was released from juvenile hall.

Throughout my 12 years in my previous education I never did my homework never wrote the essays barely showed up to class, would just take the test and try and hope... HOPE that I pass, because you know because I didn't care, I didn't care at all. And a lot of it has to do with like as soon as I came into the classroom I'm sent to the office because I was late or or because like someone said something to me and I would say something back and then now I'm a behavioral problem. And now every time I do something, I do something small, 
I'm criminalized for it and I'm sent out of classroom. A lot of it has to do with oh my teachers know I have a probation office, so they are going to say something, so I mean, why even come. (excerpt from interview, Summer 2018)

For youth like Carlos, efforts to reintegrate themselves into schooling post incarceration are juxtaposed with spaces that target these students as criminals and outcasts (Rios, 2017). Carlos stopped trying to complete assignments within his court school, he saw any effort as futile. He believed no matter what he did he was going to be viewed as a "behavioral problem", as a criminal. Latino males This process of criminalizing students teaches students that they are not welcome within education.

Carlos describes his experiences as criminalizing. He also expressed how educators would regularly ask him to leave the classroom for typical student behavior such as being tardy or responding to someone making a comment directed at him. Probation adds an additional layer of stress on Carlos. He recalled "... just being late to school, like I was late a few times and they threatened to lock me up for that." These ongoing factors contribute to feeling as though you're not wanted, which leads to excluding yourself, or as Carlos stated, "why even come?" These students do not receive the care and understanding that other students receive in "normal" school settings. Carlos continued to describe another event in which he was threatened with incarceration for violating a dress code he was unaware of. Below is our exchange: 
Carlos: Yeah. So not so much towards the end of my stay at Pathways. But especially when I was when I first got there. Definitely when I first got there I had just got out of juvenile hall and I was on EMP which is like the ankle monitor thing, And I didn't know the rules. So I came there and I was wearing like wearing red shoes and like a shirt that had like red on it, and a hat little bit of red on it too.

Tabitha: (laughing hysterically) - just a gang member.

Carlos: Yeah just a gang member (laughing), But it was like a Mario shirt, It was like a video game shirt, you know, it was the nerdiest shirt that I owned, and like red vans, and like a red wings hat or something like that...

Tabitha: you can't be a gangbanger with a hockey hat.

Carlos: yeah, gang bangers don't watch hockey (laughing hysterically), I don't even watch hockey, I just like the hat you know what I mean. And like when the GS's came up it and was like why are you wearing all this red da da da da... like I was like like I didn't know like I'm not a gang member, like I don't have gang orders, it's not even like that you know. And he like called my P.O. and like my EMP officer, and my EMP officer came down and I threatened to give me 90 days for wearing red. And it wasn't even like a thing that I had on my it a restriction for me. You know what I mean but it was just cuz it was a restriction 
for the school and like I didn't know it was like my first or second day there. (excerpt from interview, Summer 2018)

Carlos described being threatened with 90 days of time in juvenile hall because he is wearing a gang color. Youth like Carlos (the subaltern, poor, inner-city youth of color) are criminalized and assumed to be gang members. Common gang colors, like blue and red are prohibited at many schools. Although color restrictions are not strictly enforced for all students, students labeled as troublemakers, gang-affiliated, or previously incarcerated are scrutinized for their clothing selection. Once labeled as PIY, even students who are not gang members are treated as such. Carlos, although looking like a self-described "nerd" by wearing a videogame short and hockey hat, is not excluded from being harassed for possible gang-affiliation. Esme shared that she was identified as gang affiliated because of her "a blue bra strap and blue nail polish." Esme insists that she never even associated with peers that were in gangs, yet she was labeled as gang-affiliated. Being labeled gang-affiliated allows school personnel to monitor students more closely, enforce more stringent policies, and control their actions. For Esme, being identified as gang affiliated meant that she had to have a behavior contract with her public high school. Violating the behavior contract, by ditching, wearing blue, fighting, or excessive tardiness would be justification for immediate expulsion.

All participants regularly spoke with me about how they believed teachers and having to deal with probation in their P-12 experiences denied them adequate education. 
They were regularly identified as criminals. One day during class, I asked students to complete a storyboard of their educational journeys. Many students' storyboards illustrated their belief that they were treated poorly by their teachers because of their criminal history or their race, and sometimes as a combination of both.

Below is an image from Terrell's storyboard assignment. I chose to include Terrell's image to help share his story. Terrell was a student in my first and third cohort of the LCTR 105 course within juvenile. Although I am the primary instructor of the course, every semester CASA volunteers assist as TAs in the course. Growing up in the barrio (East L.A) I learned very quickly that it was rude, taboo even, to ask people why they were locked up (incarcerated). As an educator teaching in juvenile hall, it was pretty common practice that staff, and typically students as well, didn't ask why anyone was locked up, it just was. The majority of CASA volunteers did not have my preexisting knowledge of not asking the reason behind incarceration, and during a class with Terrell the classroom froze as Susan (an older White woman who was a CASA volunteer) asked Terrell what a nice boy like him was doing locked up. All eyes glared at Susan, Terrell looked away, I quickly stepped in and had the class move from small group work to watching a short TED talk. After class Susan asked what she had done to cause the awkward moment in class. I explained, and later that semester Terrell chose to share bits and pieces of his educational journey with me. Despite completing assignments, and excelling academically, Terrell was labeled a gangbanger and gang- 
affiliated. He insisted on wearing sagging pants, shirts that were the "wrong color", and shared that he found no reason to show respect to educators who he felt blatantly disrespected him. Teachers found his straightforward communication style intimidating, and he believed his tall stature and dark skin made it worse. He commented that many of his teachers had been white women, and even though he never felt he was threatening them, the school district saw it differently. Terrell was unable to complete his story board, they day after this assignment he was transferred to the adult system. Yet this one scene is powerful. Terrell's image parallels the thread in the literature that discusses how hypermarginalized students of color are criminalized and pushed out of education (Aud et al., 2011; Fabelo et al., 2011; Irwin, Davidson, \& Hall-Sanchez, 2013; Welch \& Payne, 2010). Terrell depicts a teacher telling a student that he is not welcome anymore. For all participants, they described, not usually in the detail Terrell did, times in their schooling in which they were pushed out and made to feel unwelcomed because of their perceived criminality. 


\section{8toryboard Template}

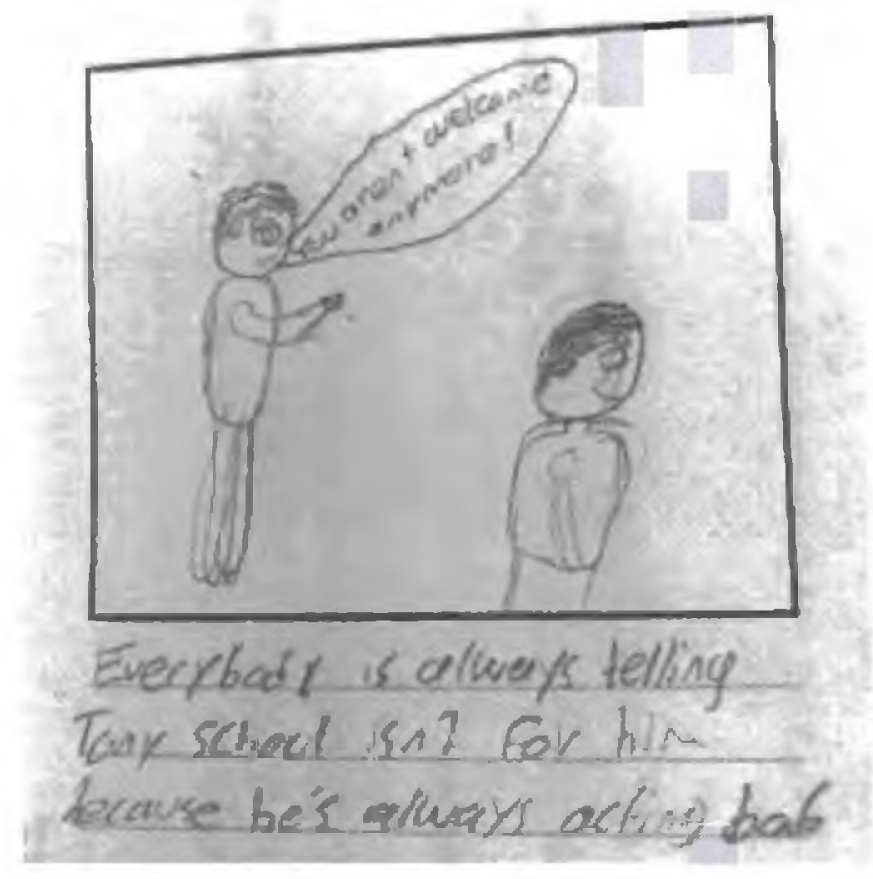

Figure 1. Terrell's Storyboard from LCTR 105 (Spring 2017)

\section{Residue of the School-Prison Nexus to Higher Education}

The residue from the experiences described above do not vanish once students decide to enroll in higher education. Residue, for this study, entail the residual effects of socialization and criminalization practices that form the School-Prison Nexus. Trauma from experiences within the School-Prison Nexus and the association of these experiences with places that are designed for learning, can cause PIY to doubt that higher education is a place for them. Students who decide to persist despite the SchoolPrison nexus carry with them doubt of their abilities, feeling they are constantly being 
judged or criminalized for their actions, as they were in P-12, and carry the burden of a hidden stigma with them into classrooms. These students, if not supported by programming designed to help them, often disengage from higher education altogether.

Feelings of judgement.

In my interactions with students, I noticed how often they used the phrase, judgement. Students spoke of feeling judged by teachers and society because they had been incarcerated. Students also spoke of the trepidation they experienced for being judged. They were often discouraged from attempting higher education because of these unwelcoming feelings associated with being judged. These students have internalized fears that they will be judged in the same matter that they were by their teachers during their P-12 schooling.

Project Change students expressed how they feared faculty would assume the worst of them because of their previous experiences. Sonya expressed these feelings of judgement succinctly when she said, "Everybody always thinks that either we're all gangsters, we're all drug dealers, we're all rapists, stuff like that. So it's like they think the worst" (personal communication, 6/4/2018). Carlos expressed feeling anxiety about the stigma associated with being previously incarcerated. Carlos's feelings were evident, even when the microaggression occurred from educators who were well meaning. Carlos: 
My first sociology professor, best professor I ever had. But when I told him that I had these experiences with the juvenile justice system he said he would have never known and it's because there are all these biases towards like what it means to be formerly incarcerated and those biases are great. You know people don't expect people to be in college because like only like $17 \%$ of young people that go into the system graduate high school. So they definitely don't expect you to even attend college, let alone excel and be articulate and intelligent. (except from interview, Summer 2018)

In this excerpt Carlos described his professor being surprised that Carlos was never incarcerated. It could be argued that the teacher's comment was meant as a compliment. However, the comment actually highlights stereotypes that surround the views of previously incarcerated youth, particularly PIY of color. Carlos is an articulate young man who comes to school in slacks and button-ups. Carlos does not fit into the typical stereotype of students returning to college after incarceration. Carlos identified this particular professor as his favorite professor. Carlos also waited until the end of the semester to reveal to the professor that he has been incarcerated. Carlos hoped his decision to delay telling the professor about his incarceration would mitigate any consequences associated with the incarceration stigma.

Similar to Carlos, Esme shared that she never reveals her incarceration status at the beginning of the semester, she waits until the professor gets to see the real her, her 
work-ethic before she shares information that may influence the professor to think less of her. Esme is particularly wary of disclosing her incarceration experience in classes with other PIY. She's particularly wary because she fears the professor will group her with the other PIY in the class, and not judge her by her own merits. Esme:

But some of the kids I've had in my classes, they are only like not as mature and they still act out and I see teachers judging them. I feel like they'll judge the program and connect their negative attitudes to them being incarcerated and it makes us look bad and I feel disappointed. (excerpt from interview, Summer 2018).

Esme is afraid that PIY who do not fit the description of a "good student" will reflect badly on her. She has shared openly with me that she worries. She worries particularly that new students joining Project Change may be attending college as a way to satisfy their probation officers, and that the faculty at CBA will judge all PIY the same. As a result, she fears that faculty may be reluctant to work with her if she is grouped with other PIY.

Like both Carlos and Esme, Rafael shares his own experience of feeling judged, and how his incarceration experience excludes him from classroom assignments that focus on a high school experience.

I would like have old baggy clothes you know and stuff like that. I didn't feel comfortable here at all. I had my sense of community with project change, 
definitely. But like once I was out in the classroom it was like. There were the teachers and their pedagogy did not reflect my own experience. Their reality it was very different from mine. So like even then with assignments like, Oh how was your high school experience. I didn't have a high school experience. You know how can I comment on that or even feel comfortable like in that space. Explaining that to someone I don't know. So I think that might be another barrier that's been set up in communities too. (excerpt from interview, Summer 2018)

This excerpt demonstrated one of the residual effects of the School-Prison Nexus is feeling that college experiences do not recognize your experience. A closer look at Rafael's experience suggests like Rafael, students who have no real high school and inclass experiences suggests students can easily be ostracized. Like all the participants in the current study, Rafael's schooling has revolved around bouncing between institutions.

In the following excerpt Sonya shares her feelings about being judged. Sonya's feelings about being judged are not related to her ability to complete community college classes, but her ability to transfer to a 4-year university. I chose this excerpt because it demonstrates that feelings of judgement because of incarceration status have farreaching consequences and do not easily dissipate. 
Before EOPS, like I felt like counselors thought I would fail. I don't know if it was my incarceration history, high school background, or skin color. I just felt like they, I mean at least in my experience and from what I've heard from others, they put us towards CSUs and never UCs, they just know that UCs are not in our future. Even when I protested they would be like, sure...ok.. but let's complete the CSU requirements first because it's more realistic. Even at juvenile justice conferences they mention it all the time. (excerpt from interview, Summer 2018).

This excerpt illustrates Sonya's wonderment about which marginalizing identity is causing counselors to doubt her ability to transfer to a UC. We can suggest from this excerpt that the disbelief by the counselors Sonya's academic abilities discourage her from seeking their help. Until Sonya learns of EOPS and their own counselors she does not make any further counseling appointments. Other students noted how they have been discouraged from majors that were "too difficult to complete."

Carlos talks about trauma when discussing his Flex Day activity for faculty. CBA holds regular professional development days referred to as Flex Days. These Flex Days are held at the beginning of each Fall and Spring semester and once in the middle of every Fall and Spring semester. Flex days are composed of 1-2 hour breakout sessions that are typically faculty lead. As faculty co-Chair of the Equity Committee, I am usually asked by the Professional Development coordinator to present a Flex Day 
session. This past summer both myself, and the Project Change Coordinator (Katie) were asked to present on best teaching practices for PIY. Although Katie and I were equally interested in presenting on the topic, neither of us felt we had the available time to dedicate to the task at that point. Shortly after the Professional Development coordinator approached Katie and myself, I had a conversation with Carlos and he shared his desire to facilitate a student led Flex Day activity discussing the role of Trauma and PIY. Understanding that CBA has never had a student-led Flex day, I advocated for Carlos and was informed that as-long as I supervised his work, he could facilitate a Flex Day activity. Carlos explains below his motivation for the Flex Day activity.

My goal for the next presentation for faculty is help them, because you know that people get stuck in their own biases. They really believe what they believe. And especially in regards to juvenile justice youth and their stereotypes, you know, they think we are all thugs, who got face tattoos, you know, we're going to rob your wallet or something. That we are bad students, that we're uneducated and that we're unable to function in higher education. And there is also a perception of what we look like what we talk like, what we present ourselves like, there's all these preconceived notions about what it means. And there's also this that, that maybe not everyone shares, that these kids should not be cared about any more than the average kids. These are kids who fucked up. 
These are kids who made the decision to get in trouble.

Carlos expresses his belief that faculty judge and criminalize PIY. The common stereotype of PIY being untrustworthy, that they are "going to rob your wallet or something" reinforce deficit view of students who have experienced juvenile incarceration. Undergirding these deficit notions regarding PIY is the belief that these students "made the decision to get in trouble." Carlos' implicit belief is that the view of PIY as criminals negates faculty's professional duty to teach them. This categorizing of PIY as criminals blames youth for their social woes and ignores structural impediments.

Carlos' desire to educate the faculty at CBA inspired his Flex Day Activity. Carlos chose to share with faculty a story of a young boy and his experiences growing up both external events and affective. As he told the story, faculty were asked to mark and ACES Risk Fact sheet, circling all the risk factors for trauma that the boy had experienced in his young life. At the end of the story Carlos revealed that he was the little boy in the story and went on to speak on how many youth who have spent time incarcerated have experienced trauma as children, at home, at school, and in society. After he was done speaking Project Change students presented their own stories as a panel and faculty were able to ask questions. Carlos's goal was that faculty would leave the presentation understanding that PIY are not innate criminals to be feared, but young people who need support and not to feel ostracized by their experiences. 


\section{Self-doubt.}

Participants in this study experienced years of hyper-surveillance, racialization, and criminalization. Participants were further traumatized by their schooling experiences, which often resulted in feeling excluded, abandoned, and isolated. Students in the current study have illustrated how their teachers, school counselors, and even probation officers have contributed to this process of marginalization. As a result, some students have disengaged with school completely, while others have chosen to push down their feelings of doubt and pursue their education. It is not uncommon for students to feel helpless in these moments, and as a result, they begin to develop selfdoubt. Self-doubt, for this study, is defined as feeling incapable of completing an educational goal, of being a college student. This self-doubt stems from being socialized into believing that criminalization and inferiority are innate and permanent. This form of socialization is incomplete, as demonstrated by these students attending community college. Yet, the seed of social marginalization and inability has been planted, watered and supported through their P-12 education and fear that this seed will come to bloom, that others are right about their inability to succeed academically, can be paralyzing.

Rafael explains the nonchalant manner in which educators and probation staff joke about the inevitability of incarcerated youth returning to a life behind bars.

So I think like the self-doubt is a very big experience even like if you've been locked up you're always told like oh you're just going to come right back even if 
it's jokingly the staff tell you that even like the other people who are getting out. But then it just kind of plays in your mind when you do go back and it's this constant cycle of incarceration often thinking that it is upon our own main decision but not understanding the bigger apparatus of life. (excerpt from interview, Summer 2018).

This excerpt described Rafael's process of his own struggles with self-doubt. I know this particular experience is true for many incarcerated youth, and really unfortunate. As an educator with teaching experience in juvenile halls, I regularly heard other educators lament about the incarcerated youth, "he will be back" and "how long do you think he will be out this time?"' Rafael's excerpt illustrates how youth of color are socialized to believe that they are fit for nothing more than a life of perpetual subordination (Allen \& White-Smith, 2014). Rafael's experience also highlights the majoritarian discourse that has historically characterized incarcerated youth of color as damaged or as innate criminals. Rafael's remark, "but then it just kind of plays in your mind" suggests Rafael was experiencing self-doubt.

To Rafael's point, the internal dialogue of incarcerated youth eventually begins to mirror society's discourse of the incarcerated. They begin to develop messages of hopelessness and the idea that they are undeserving of a quality education. In the excerpt below, Esme describes her experience with self-doubt:

I think students they're afraid that they will not fit in, that a lot of people will 
judge them. But really, I think the main reason is they feel like they're not capable of doing this work, or that we're not smart enough to do this work. Because once you enter the system your educational level goes completely down, like you lose your ability. You don't...They don't teach you anything to be successful in college to the point that you don't' even get assigned homework. And you know it's impossible to pass a class without doing homework here at college. And so I feel like I was afraid I wouldn't be successful, that I would have the same experience I had in high school...Growing up I had this best friend and we would do everything together and we were very alike and at some point we both found ourselves saying we weren't going to go to college. I would tell my friends and that's when my best friend would agree with me and be like 'yeah, we're not going to college.' Like, we were just stuck mentally in this category where troubled youth go, and it was weird. Like growing up I wanted to be a doctor, then to change into I don't even want to go to college. Like where was my head. It was just like we felt that we were already nothing, that we were nothing and that there was no way we could be successful. (Esme, excerpt from interview, Summer 2018).

This excerpt illustrates the complex associations between the criminal (un)justice system, peer dynamics, and self-doubt. While Esme offered multiple reasons as to why self-doubt occurs for students, she also was able to identify why she experiences self- 
doubt. Esme's comment, “once you enter the system, your educational level goes down, and you lose your ability" echoes Rafael's perspective that there are structural influences that contribute to feelings of self-doubt. Esme shares her painful memories of feeling that troubled-youth should not attend college, instead they are destined for prison. PIY are socialized to believe that their personal failure has caused them to be incarcerated, and this failure will also cause them to enter prison (Winn, 2010; Rios, 2017). Through the process of internalizing criminality, youth can come to believe themselves unworthy of a college education. Heather shares:

You know, I enrolled initially at Hill College cuz it was close to the house and I was living with my mom at the time and she has kind of always been the person whose like, oh you should go to college. Ummm and she kept bugging me and like harassing me to go to college, especially cuz at that point like some of the people I graduated high school with were graduating with their AAs that year. But I didn't want to go, I didn't think I was good enough, but I was like fuck it, I will just enroll so you will just leave me the hell alone. (excerpt from interview, Summer 2018).

As with Esme, Heather doubted if she was "good enough" for community college. Winn (2010) defines the reification of ahistorical stereotypes of criminality as incarceration discourse. Heather demonstrated incarceration discourse as she has internalized the belief that she was not worthy of an education. Earlier in the interview 
Heather shared that consistent interactions with educators that scrutinized her bad attitude, held low expectations of her, and criminalized her had helped her construct an identity that was on the margins of society, and not "good enough" for higher education. Heather shared that she did not even want to attend college, she only began taking classes as a way to appease her mother. This place of internalized self-doubt is the place where "troubled youth go mentally," an acceptance of their place within the carceral state as natural.

A profound contributing factor to the self-doubt identified by participants is the fact that their schooling has normalized a controlled environment, in which the students are taught that the gaze of authority is perpetually watching all of their actions. For PIY enrolled in community college, the fear of their actions being misconstrued to that of criminal behavior can be so pervasive that students simply stay stagnant. For Heather, as an undocumented Tongan woman, fear of being classified as dumb and criminal caused her to be afraid of asking tutors in a math resource for support. Heather confides: Talking to my professors and that was a big ass barrier for me. Just because my $K-12$ experience right. Like, talking to adults was hard. And then being in juvie and talking to authority...I didn't like talking to cops. I don't like talking to people in positions of power...like people that are like in charge of what I do so that was really hard for me to get to talk to professors. Like now I could talk to them, it's cool. But my first year and half I couldn't. I'd go to the Math 
Resource Center and I couldn't ask even the tutors for help. I would have to ask someone next to me like 'hey, you know how to do this?.' It wasn't until I took Dr. Gaines and he like made it comfortable enough to where I was like oh, can I talk to you after class. But before that I never talked to any of my professor. I just went to class and went home, just like you do in jail. You don't ask questions, you do time and go home. So...(she fades out into silence). Heather's experience is not unique. For PIY their schooling has demonstrated that there are severe consequences for not behaving in an acceptable manner. For Heather, being sent out of class for playing around, when she was attempting to ask the teacher for help on classwork, ingrained in her that asking for help was not something she had the right to do. In her transition to community college, the fear of adults punishing her did not initially dissipate, as she states that she continued to treat college like jail. Within jail, Heather states, “you don't ask questions, you do time and go home." Education while incarcerated with its focus on punishment over learning caused Heather to associate educational staff as "cops," as people able to punish. Penalizing students for not meeting White middle-class social norms has long lasting effects.

\section{Consequences of a disjointed educational experience.}

The criminalization of youth within their K-12 schooling experiences, the processes of excluding them from the opportunity to learn, has dire consequences into adulthood. Targeted groups of students are undereducated, and this undereducation is 
amplified once incarcerated. PIY enrolled in community college can find themselves severely underprepared for college level work because of their institutional experiences.

Juvenile hall and court schools do little to prepare students for life after high school. All participants stated that within juvenile hall, they "never gave us homework." Esme named the nature of education within juvenile hall as preparing students "for prison." Her justification was simple, what other reason would school have not to prepare young people for higher education or the workforce. The systematic disinvestment of education within juvenile halls and courts has left many PIY unexposed to practices and experiences that community colleges expect students to enter with. Carlos describes how his first semester at CBA left him feeling acutely aware of the shortcomings of his incarceration education.

My first semester in college I maybe slept maybe three or four hours a night because I didn't know anything. I didn't know how to do MLA. I didn't know to write essays, I didn't know how to structure them, I didn't know how to manage my time to do reading. I didn't know how to manage my time to do homework. Because I've never done any of it. (Carlos, conversation, September 13, 2017) Carlos' description of his first semester in college is different from his non-incarcerated peers feeling underprepared for college. Within juvenile hall and court school setting, education is viewed as a reward for good behavior, not a right. Misconduct within incarcerated spaces results in staying in your cell (your room) and being excluded from 
school. Since school is one of the only times youth are allowed out of their room, not being allowed to attend school is a severe consequence. Even within classroom settings there is an emphasis on regulation over learning, but submission to the rules means rewards. Instead of focusing on learning content, students who behave are provided nominal educational activities that are more fun than scholastic, like playing "Coolmath.com" on computers. School in these settings grades your behavior not necessarily your assignments, as Priscilla discussed how as long as she turned in complete work packets, that "no one even reads to see if your answers are right. I completed a semester long packet in a week and earned my credits for the course" (Priscilla, personal communication, January 26, 2018). Carlos' comments that he had to learn how to do seemingly simple tasks, like completing homework, are not exaggerations, but the real circumstances that can often reinforce to PIY that college is not a place for them.

The discourse surrounding incarcerated and previously incarcerated youth emphasizes that these students are not worth educational investment. Holding students accountable for assignments, for their actions, for learning, implies that the educator views the student as capable and worthy of an education. Rafael discusses how the pressure of being accountable for schoolwork was a new experience to him.

College is very different from high school middle school. For me I think my teachers passed me just passed me so they wouldn't have to have me retake their 
classes you know. Opposed to here saying no they'll keep you accountable you know. I think it was this accountability that I've never had to deal with. The unknown it's very hard because like I think we've grown to a custom of being institutionalized and being and even if you're institutionalized here it's very different from being institutionalized in a locked facility because you're used to that structure. You're used to that structure of being woken up every morning for breakfast. Being sent to your room to get ready for school. Being ready to come back from the school department to go. (Excerpt from interview, Summer 2018) Viewing incarcerated/previously incarcerated youth as deficient, educators typically disregard this group and view prison as their next logical transition. Schooling for Rafael before CBA had not focused on accountability of assignments but navigating acceptable normative behavior. Activities like completing your "hygiene routine ontime" and ensuring you were ready for breakfast were part of the expected behaviors that had to be traversed as part of the school day (Rafael, personal communication, May 17, 2018). Transitioning to CBA meant that Rafael was held accountable for his work for the first time since elementary school, it also meant that the professors believed Rafael was capable of completing the work and pushed him to complete assignments.

\section{Academic Re-engagement}

Hyper-marginalized youth that are hurled through the School-Prison Nexus often disengage from a system that has not served them well. For PIY who transition 
into community college, there is often an unstated hope that community college does not include the practices of hyper-surveillance, punitive disciplinary practices, and invalidation that encompassed their P-12 educational experiences. This theme of Academic Reengagement explores the processes which have helped PIY change their relationship with educational spaces, and for many, to change their beliefs about their own ability within academia. Students described how they gradually came to see themselves as college students and feel welcome within CBA. Subthemes for Academic Re-Engagement are: Re-identification of identify, sense of belonging, authentic care, and sharing as healing.

In recounting their educational experiences, many Project Change students talked about how the program helped them to move past the majoritized view of PIY as deficient and uneducated. Many of these students indicated that they were the first in their families to attend college, and that they never viewed themselves as college students. Carlos believed that "college was never something thought I would do." After being incarcerated, many students, like Elias, believed that society saw them as nothing but criminals, destined to remain uneducated. Rafael echoes this sentiment as he states, "I thought I didn’t look like a college student." With Project Change, students feel empowered and are able to view themselves as college students. While students do not use the term reinvention of identification, they do describe how they moved from 
feeling like an outsider at college to feeling like a college student. Rafael discusses his experience on a field trip to UC Berkeley:

Yesterday we went on a trip to UC Berkeley and what struck me was you know, I thought that I didn't look like a college student, didn't look like a Berkeley student, but I learned they want us there. (Rafael, personal communication, March 9, 2017).

Rafael describes how his experience within the School-Prison Nexus has informed his view of college students, of which he believed he was excluded. His statement, "I didn't look like a college student" is indicative of the long-term effects of a racialized social structure. When prompted to describe what he thought college students resembled, Rafael's response was a simple shrug, followed by, "Not me. Not with baggy pants, very kind of street, street oriented." For many youth, phrases like "street", "hood" and "ghetto" are phrases used to identify students of color who do not meet White middle class social norms. Although Rafael was attending CBA he simultaneously held onto this belief that college students were not "street." During his field trip to Berkeley with Project Change he finally began to identify as a college student.

Students with incarceration experiences often enter college with internalized beliefs that can hinder their success within higher education (Giraldo, Huerta, and Solórzano, 2017). Previously incarcerated youth enter higher education feeling like 
imposters, that they are not college students, this feeling can be amplified by fear of being identified as previously incarcerated and the stigma that accompanies the term. Rafael describes how he was able to gradually change his identity to that of a college student.

Project Change opened doors for me. It allowed me to embrace a new identity. I think throughout history we can kind of look at words being used or thrown at people and like kind of there being a sense of ummm embarrassment around those words, you're kind of discouraged, dehumanized. But once you are able to embrace being formerly incarcerated, once you are exposed to and able to network to people with like the same communities you are that are lawyers and educators. You know like, even with their titles, to know that we take all those titles away there's still a person there, like somebody like you that went through the carceral system. Like, I think if you would ask like the 15-year-old incarcerated me where I would spend my 20th birthday I would have probably said prison. So now I think it was like one of those things where it allowed me to see a different future for myself than one that I was already destined for. And then I think Project Change has just...it's just, yeah, it's been able to shape some of my identify, you know. (excerpt from interview, Summer 2018).

This excerpt demonstrates how Rafael initially associated being previously incarcerated with dehumanization and embarrassment, but it was in his ability to embrace the term 
that he was able to shift his identity from one of deficiency to one of college student. Participating in programming designed to help PIY transition to CBA, Rafael was exposed to professionals who also had spent time incarcerated. Identifying successful adults with incarceration backgrounds, Rafael's identify as a criminal began to shift. This shift is exemplified by Rafael stating that his younger self would have imagined his 20th birthday in prison, not in college. An integral part of Rafael's success within CBA was his ability to begin to adopt an identity of a student, an identity that the School-Prison Nexus had taken from him.

Heather describes how she began to change her own internal dialogue from that of failure to that of a college student.

CBA gave me the confidence to think I could succeed in college. Like I have always been compared to my older brother, he graduated high school and was like always soooo nice. I went to jail, I lived in his shadow. You know, before you asked to come and speak to your class at juvenile hall I hadn't thought about my high school experience, like your invite caught me off guard. I don't know. Like all that stuff happened in high school and juvie and I really tried to shut it out. Getting locked up and stuff. Like before feeling supported at CBA, I thought I was just a fuck-up. Like people would come to speak to us in juvie and tell you don't do this, don't do that, but it's like you can say whatever the fuck you want, you're not in jail, ain't never been in jail, like you don't have to go 
back to your cell after this and wear fucking county underwear and county socks (screaming). (excerpt from interview, Summer 2018)

Heather begins this excerpt stating that she developed the confidence to believe she could succeed in college. Yet, the pain she associates with her experiences within the School-Prison Nexus bubbles to the surface of her excerpt. I had seen Heather do this before, describe painful events with anger instead tears, it was easier to be angry. By the end of this except Heather was screaming, in my small office without window it felt like the phrase "county socks" bounced like a pinball for a long time. After screaming "county socks" Heather sunk into herself to regather, to calm down. Although I asked if she wanted to end the interview, she insisted she could continue, but we sat in silence for almost minute before we proceeded. Heather's description of how her time juvenile hall and the juvenile (un)justice system illustrates how these experiences help to create an identity of criminality for these youth. Ceiling youth, stripping them of their own clothing, their own underwear, reinforcing their own doubt of their academic ability is a long process that cannot simply change because these youth are powerful enough to begin classes at a community college. Intentional practices that help youth begin to shift their identity are necessary; it cannot be left to happenstance.

Through interviews and informal conversation with current Project Change students at CSM, this idea of viewing themselves as college students emerged in the data and it quickly became evident that this topic was crucial to understanding how 
Project Change empowered students. While speaking to a group of Bay area educators about creating their own programs to service PIY, Katie said:

Our students have a disjointed educational experience, you have to know that it affects their education. They come with negative views on school and addressing the educational aspect of college is not enough. (laughing) Naïvely when I started this program it was only focused on academics. I quickly realized that was not enough. You have to address these educational and social-emotional aspects. What is the first class our students should take to be college students? Out student success course offered in juvenile hall by Tabitha is about growth mindset, creating a new identity with focus on math and English since these are gatekeeper courses. We offer workshops, including financial aid and multidisciplinary programs. Our goal is to demystify college. Our model focuses on access, equity and achievement. For us, it has to start at juvenile hall for students to be college students. It is important for those who have achieved their diploma, GED, or HiSET to then look toward their future. Too often these students have been forced just to sit in the hall once done with high school, regardless of how long that is. It you reach them early enough you can let them know that college is not a foreign concept only reserved for others. Tell them, you are a college student. To tell students that being a college student is not just a concept, but possible. We are with you, we will continue to support you along 
this journey. It makes a big difference. (Presentation to Incarcerated Youth in the Bay Area, 4/20/2017)

Interestingly, while students emphasized this topic, the theme was almost nonexistent in the interviews with faculty and staff associated with the program, with one major exception. Katie, the programs coordinator and founder, highlighted this reinvention of identification as imperative to students' success in college. Katie's comment highlights the importance of changing the way students see themselves. Having observed Katie speak about Project Change to different organizations throughout the semester, her message is always consistent. Student's being able to reenvision themselves as college students is at the core of her focus.

\section{Homemaking.}

Throughout this research process, the theme of homemaking was consistent among all Project Change students enrolled at CSM. While the phrase "homemaking" was never mentioned by participants, their discussions of relationships on campus coupled with their belief that college faculty or staff believe in their ability to succeed, resonate with Kuttner's (2016) discussion of homemaking. Project Change creates a small community that serves a safe place, as Vicki explains, "the program was there for me when my dad kicked me out of the house, my mentor was there and she listened to me and... I mean she's an adult and give me real advice" (personal panel interview 2/23/17). Still other students identified how Project Change became "a new school 
family" (Ana, panel interview 2/23/17). Feeling like school is a home away from home requires more than just support, it requires students to feel like they belong, are wanted. As Rafael put it:

Like Sonya said- the friend part, telling them you know I can't go out tonight or I have to be back to have to wake up early tomorrow for class. I do a lot for my friends to make them happy instead of making myself happy. It made me mess up a lot in school you know it was so easy to start off the semester good and then fall off because I wasn't focused. And you know Katie is amazing, she knows everyone on campus, she'll hook you up. Actually, everyone at CSM loves what they're doing and they're willing to help. Like if you say you need money for college, its done, they'll just give you money. You here with Project Change right now that means your college is paid for. The way I look at it there's two institutions prison and college, choose one where at least you can make yourself some money and not the other way around. You know talk with your professors, meet like-minded people, we even started a Project Change club last semester and Katie got me a job. We went on a trip to UC Berkeley and what struck me was you know I thought I didn't look like a Berkeley student but we went to this Underground Scholars Program there and they want us there. Previous incarcerated youth or family of previously incarcerated youth this program helps you it's kind a like Project Change. Because you know when your family 
has been incarcerated you're locked up to emotionally behind bars with them.

Your friends who don't support you aren't really your friends. (excerpt from

Panel Interview 3/19/17)

What strikes me about this excerpt is Rafael's discussion of how the program and campus work together to support students. Rafael states that he was surprised that UC Berkeley wanted "us there", "us" referring to incarcerated students. What is more critical is that to me, this piece shows how he feels a sense of belonging on CSM campus and is surprised that this feeling can potentially expand to UC Berkeley. Kuttner (2016) discusses a sense of belonging as sense of accountability, a feeling of having someone's "back" (pg. 544). Within Rafael's discussion, Katie (Coordinator of Project Change) is discussed as dependable, and willing to share her social capital by introducing students to everyone on campus.

The process of making a home within public spaces has a long tradition of being instrumental in supporting liberation movements within marginalized communities (hooks, 1990). In this vein, Project Change and CBA have developed into a homeplace aspirationally, as a safe place in which students are supported in their journey for education and equity. Heather shares:

You know all the other schools I've been to I don't know anyone... like here I know faculty here and there. All of my other schools, like I started at City and have taken a handful of classes at Foothill, and aside from my professors I don't 
know anybody. (long pause). But I feel like it's also the environment of CBA.

Like I see hella people that I can identify with. Right. Like I see hella Polys, I see people and like...hmmm...like even people I went to jail with, they go here. When I went to Foothill, I felt hella out of place. And in my classes I was kind of behind everyone, I felt out of place. (excerpt from interview, Summer 2018) Heather's description as CBA as a place where she knows people is important. In this sense to know someone is more than the ability to recall someone's name, but for Heather, to know people is to identify and feel confirmed by people. Not only does Heather identify and feel confirmed by faculty, she also receives confirming signals from students who look like her and who have been incarcerated being welcomed into the space. Several students discussed how it were comforted by the fact that people they were incarcerated with also attended CBA. The presence of other students who shared their incarceration experiences made them feel at home.

Viewing CBA as a home can often cause strain when the safety and comfort of the home feels violated. Although students identified peers and faculty that made CBA feeling inviting and affirming, when these relationships are strained students noted tension. Heather confided recently that she had been avoiding coming to school for the past two weeks. When asked what prompted her to just not attend class for two weeks, she stated that she felt disrespected by Dr. Smith, her ethnic studies professor. 
Yo, I just have been avoiding coming. Like I drive to school every day and sit in my car because I don't want to deal with this. We were in class working on a group project that he assigned us, and I guess he thought we were goofing off, but he just called us out in front of the entire class. Yelling at us to sit right. I responded and said the way we are sitting shouldn't matter, cuz unlike the other groups, we were getting hella shit done. He mumbled under his breath that we were acting colonized. Like what the fuck. And I'm hella hurt and disrespected. Like he is the reason I wanted to be an ethnic studies major, he empowered me to continue my education and then for him to treat me this way. (Personal communication, 11/13/2018).

For Heather, having Dr. Smith call out her group and embarrass her was a betrayal. Her respect and familial love for him cause the slight to be amplified, causing her to avoid school altogether. During this conversation I told Heather that no matter how she felt, she couldn't just avoid class, as she needs it to transfer. Her response was, "I know, I'm going. You don't have to always like your family" (personal communication $11 / 13 / 2018)$.

Through Katie's leadership, Project Change staff and faculty continue to try and consistently build respectful mentor/mentee relationships with Project Change students. Understanding the importance of relational work, Katie brought in an outside trainer to facilitate a "How to Be a Mentor for PIY" for staff and faculty interested in supporting 
Project Change. I observed how Katie values her relationships with Project Change students, formally through checking in with students, inviting them to conferences, helping them schedule classes, but also how Project Change students have come to depend on her.

Yet, Katie is often difficult to find, as she frequently travels off the college campus to meet students in juvenile hall, and meet with community partners off campus. Katie's office is housed in the Village, a space designed for learning community students to relax, watch television, or work in the computer lab. Although Project Change students often enter the Village looking for Katie, they are noticeably absent from the village when Katie is not there. Students are often disappointed when they are unable to find Katie, and are often unwilling to ask others in the Village for help. Sonya reinforces this by stating:

That's what I see-people always asking for Katie, sometimes just to talk to someone. But she's not always there... Like EOPS, you see them, they are always in their office. They're there. The Village is cool, but it is not our own space. I think we need a Project Change counselor and staff specifically for us, someone that is there, someone always there just to have that personal connection. I mean, it's personal, right? But we need to know someone is always there, whether its stuff or student working on education stuff, personal stuff, we need someone there. (excerpt from student interview 4/7/17) 
Although not explicit, Sonya discusses a hidden tension within CSM, a fact that Project Change students may not feel truly welcomed in the Village. Often overflowing with members of the UMOJA, Puente, and Mana learning communities, the absence of Project Change students seems in sharp contrast to the welcoming nature of campus that students describe.

\section{Authentic Care.}

A salient finding from student interviews was the need for students to be authentically cared for. Students described their experiences within the School-Prison Nexus as uncaring, segregating, and exclusionary. Additionally, students described their experience within the juvenile (un)justice system as pushing them to accept the label and identity of a criminal. At CBA, their experiences were valued, students were encouraged to pursue their goals, and reciprocal relationships were created. Students discussed at length the faculty and staff they identified as caring, the faculty and staff that pushed them to go farther than they initially thought they were able.

Sonya describes feelings of frustration during her first semester at community college as she was placed into Basic-Skills English courses. She laments, II"I almost quit, like why would they place me in this low ass English, I can read and write." Although Sonya feels that she is not placed in a class that adequately reflects her ability, she decides to attend the class.

So I kind of felt discouraged because I felt like why did I place so low in English. 
Like, I know how to fucking read. But I guess the Professor I had was ...I dunno, I liked them. He like looked like he was one of those caring people that he wasn't just there to teach. He really enjoyed what he did. So that was cool, cuz I could have easily been like fuck this shit, I'm not doing this, because I was already working full time. But feeling like he cared about me made me comfortable. (Sonya, excerpt from interview, Summer 2018)

Sonya's comments demonstrate how important care was to her. In an earlier interview Sonya shared that she felt abandoned by P-12 institutions that has "given up on" her (Interview, Summer 2018). Here Sonya describes here how without feeling that her professor cared that she could have given up, "cuz I could have easily been like fuck this shit...I'm already working full time." Feeling that her professor actually cared, and was passionate about teaching was impactful, it motivated Sonya to continue with her schooling.

Students discussed how they felt acknowledged by professors who heard their story of incarceration and continued to care and hold high expectations for their academic work. For many students, expressing their painful experiences within the School-Prison Nexus exemplified being vulnerable and trying to begin to create a bond with faculty and staff. Esme recounted how professors pushed her to excel after she shared her incarceration history.

And, I just feel like nobody judges you here, like they just know. They hear your 
like story, and the professors, at least from my experience, most of them have been great at making you think outside the box. Really pushing you to like just think about stuff and like question society, and like open my eyes to racial barriers that are like real, that I had to go through. I just feel really pushed here you know. (Esme, excerpt from interview, Summer 2018)

The ability to "push students" and hold them to high expectation for academic success is an integral part of authentic care. Esme's emphasis that she was "pushed" at CBA is in stark contrast to her previous discussion on her $\mathrm{P}-12$ schooling experience in which she felt the curriculum had been subpar. It is important to note that to Esme, caring can only happen once students can share their whole selves with faculty, which means sharing her incarceration experiences. Esme needed to know that she would not be judged for her experiences. Esme also associates care with being exposed to critical literacies that allow her to question society and understand processes of racialization. It is the process of genuine care, of truly nutritive relationships, that keeps students attending CBA despite events and struggles that might otherwise push them away. Esme recounted:

You know I recently moved in with my mom. She stays already the way in the city, and like I am right near City. But like, I want to finish my degree at CBA. But to me like I've already built relationships with so much staff here, and ummmm, to a point where I feel comfortable and like supported. I know where to 
go to for help. And I know anytime I get stuck I always come to you, or Katie, or Estela. I'm always going to have that support. Even when Estela is yelling at me to stop procrastinating (laughing). (Esme, excerpt from interview, Summer 2018)

Esme shares that despite the fact that she has moved closer to another community college, she still travels over 40 minutes to attend CBA because she feels that she has created valuable relationships with staff at CBA. The recognition that Katie, Estela, and myself will support and help her is important; it highlights the humanization of students. Esme feels seen and believes that anytime she feels "stuck" she knows there are people who will listen and help her. As a staff member, Esme comes to Katie, Estela, and myself for more than questions about school. The relationships formed with Esme values her as a person, not just a student. In the same interview, Esme shared that she confided in Estela when she was having problems with her Dad, and felt that their relationship was "real" because she had even given Estela insights into how to discipline her teenage daughters. Their relationship was reciprocal, as Esme gave Estela advice on what to do with her teenage daughters.

For students, care is exemplified when faculty and staff that cared for them beyond their job, outside of the classroom. Students discussed how they began to see faculty and staff as family, with Ana stating that she considered Prof. Sina "like an older aunt," someone she could confide in. Heather shares: 
I love my experience here, it's been hard but...it's not one that like I'd go back and change. The support here is awesome. I think one of the big things that no one ever talks about like succeeding in community college or like in any college is like the support you get from faculty and staff. Like they talk about academics and stuff, but I be talking to a lot of you guys about how I feel emotionally. And like, I think that's the other unspoken part of community colleges. Nobody ever talk about like that sometimes faculty do care about your well-being, on top of academics, they want to support you emotionally right.

Heather's ability to share how she feels emotionally with faculty/staff is indicative of authentic caring. Valenzuela (1999) emphasizes that caring only topically, or aesthetically, places the concept of learning over creating true relationships with students. Such caring only appears as caring within a classroom setting, but ignores the student and all of their experiences that happen outside of the classroom. Heather values that faculty and staff care about her emotional well-being and events that take place outside of a school setting.

\section{Healing Through Sharing.}

One unforeseen theme that occurred was the concept of healing through sharing one's story. This process of sharing one's story of the School-Prison Nexus and finding a sort of release from sharing is found in Hill's (2009) work on wounded healing and hip-hop. For students within Project Change, sharing the story of their wound is a 
vulnerable act that demonstrates courage and the understanding that from sharing their story with others that not only do they get relief, but others around them can benefit.

Project Change students are regularly encouraged to share their experiences within the School-Prison nexus at conferences, faculty professional development, with students in juvenile hall, and within club meetings. The programs coordinator believes that only through sharing one's narrative can they gain control of the story. During an interview, Sonya shared the first time she was invited to a Project Change meeting by her brother Rafael.

Rafael didn't really tell me where we were going, just said some meeting that I would enjoy. You were there. It was the first time I had ever shared, you know, like my experience growing up and all that stuff. And it opened up this whole stuff. Project Change, working with youth in juvenile hall and stuff. So it definitely brought something that I never thought I was going to get involved in. Like I never thought that door would open again it was you know, going to create good for others. But it really opened me up again and well helped me grow because I always thought it was bad. I never realized how it brought good out of me and how it helped others. It was kind of like I had a closed wound that I never let heal properly. Like I was just covering it and covering it (audibly crying). So I am glad that happened. I got more comfortable and started to be more open, not just with my story, but with my feeling and thoughts in class. I 
created connections with people that I would have never been friends with.

(Sonya, excerpt from interview, Summer 2018).

Sonya's excerpt embodies the power of sharing one's story. Sonya describes her painful School-Prison Nexus story as a wound that remained raw, unhealed. Instead of sharing the story and allowing it to heal, she became ashamed of it, always thinking that her experience was bad. She hid her truth, "just covering it and covering it." Although sharing the story hurt, as revealing trauma often does, Sonya shares that she is glad she chose to share her story. Through this experience, she was able to be more vulnerable and share more of her true self.

Esme also stated that being able to share her story with others allowed the shame she associated with that experience to dissipate.

I feel like being able to share my story has really allowed me to embrace it way more. And, I'm able to speak freely and feel no type of shame for anything that I went through. I still get butterflies, but I feel stronger. I brought my little brother to a conference I spoke at, and he asked, 'how can I talk like you?'. I feel like I am a part of a world that I wasn't apart of until now. Like, it helped me grow and feel proud of myself. (Esme, excerpt from interview, Summer 2018).

Sharing her story has allowed Esme to take ownership of her truth, to "embrace it way more." Being able to share a traumatic story with the goal of helping others is powerful. Although Esme still gets nervous, she stated that she feels stronger each time. Her 
ability to share her story is an inspiration to those around her, especially her younger brother.

Students shared that being able to tell their story, either in written or oral form, made them feel more understood. Carlos told me that in his first English class he wrote about his experience mentoring a youth, who like him, has been bounced around between institutions and had been given up on. In his essay, Carlos shared that he "was angry like that too before" and it took a lot of work for him to not allow his past to determine his future. After submitting the essay, Carlo finally felt like he had been "adequately able to tell my story to this professor." Sharing this narrative, Carlos felt a closer bond with the English professor. Heather, confided in me that after sharing her story for the first time within the interview process that she was inspired to "help young people and prevent the pipeline."

For PIY, being able to disclose their narratives in a safe space build around concepts of homemaking and authentic care allows students to resist the majoritarian story of them as criminals, an instead allows them to see themselves as college students. 


\section{Chapter Five: Discussion and Implications}

Those who don't know us think we're twisted. They think we'll murder 'em and leave 'em dead in ditches. They think we'll slice their face and leave em stuck w/ stitches. They are all blind with their eyes misted. (Roach, Written reflection, March 15,

Community college serves as the main point of access for PIY seeking increased

job skills or a degree. While macro-structural factors, like segregation and racial inequalities, play a critical role in what kind of students are incarcerated, individuals and institutions contribute to the systemic incarceration and criminalization of youth of color (Annamma, 2018). It is my belief that community colleges can begin correcting years of harm done by the School-Prison Nexus. This study sought to use Project Change, a program dedicated to helping PIY meet their educational goals, to deepen our understanding of the experiences of PIY within community college. The two primary questions guiding this research were:

- What are the educational experiences of five previously incarcerated youth attending the College of the Bay Area?

- What are the main barriers to and facilitators for program completion within community college?

I used Critical Race Theory (CRT) as the primary lens to interpret student experiences. This is particularly useful because CRT posits that criminalization of students of color is part of a larger web of structures designed to maintain white privilege. I utilized a case-study design and a phenomenological approach to explore the 
experiences of five students at CBA who identified as PIY. The voices and stories of these students were highlighted in this study as a way to legitimize the experiences of PIY within community college (Harper \& Davis, 2012; Solórzano \& Yosso, 2009). The data collected for this study came from interviews, field notes, and student classwork. The interview protocol was standardized, open-ended and based on Seidman's (2013) protocol. The questions were highly influenced by the review of literature, and the previously conducted pilot study that was described in Chapter Three. Findings were categorized into three major themes: School-Prison Nexus, Residue of the SchoolPrison Nexus to Higher Education, and Academic Reengagement.

Following, you will find the discussion, summary of the findings, implications, and recommendations for future research.

\section{Interpretations of Findings (Discussion and Summary)}

Through my phenomenological case study of Project Change at CBA I was able to document the experiences of PIY both within the School-Prison Nexus, and their experiences within CBA. The stories and pieces of their lives that students shared with me, through interviews, written assignments, and in my classes allowed me to answer my research defining the main barriers to and facilitators for program completion within community college. Before community colleges can begin to adequately build programming to support PIY the experiences of PIY need to be understood. 


\section{School-Prison Nexus}

The school-prison nexus describes the complex process of racialization and criminalization that account for the over-representation of youth of color within our juvenile (un) justice system. Pipeline metaphors have been used to highlight a seemingly frictionless transition from school to incarceration but fail to adequately capture the complex process that includes the roles of other institutions within the incarceration process. Racialization and criminalization of youth of color is not limited to school and incarceration setting. The metaphor of the school-prison nexus exposes the interplay between a number of other institutions (e.g., welfare services, immigration, child protective services, foster care, public schools, police) in understanding the "web of punitive threads" which serve to criminalize and control youth of color (Annamma, 2018; Heitzeg, 2016; McGrew, 2016; Meiners, 2007). This study discusses several schooling practices that that disproportionately impact students of color within the School-Prison Nexus, these components include practices that remove students from learning environments, hopelessness, substandard education, and criminalization.

Participants described their experiences within their P-12 schooling as a process of reinforcing criminality. Their descriptions aligns with existing research on the School-Prison Nexus (Annamma, 2018; Fernandez, Kirshner \& Lewis, 2016; Rabaka, 2010; Rios, 2017). For example, Morris and Perry's (2016) study concluded that Black and Latino students were more likely than their White peers to be suspended for similar 
actions. Similarly, students in the current study discussed how they felt they were punished for innocuous actions simply because of their race. While Rios (2017) was able to depict how schools criminalize Latino boys, students in this study expanded upon feeling criminalized, and described how they felt that the ways they were criminalized was a contagion. Wun's (2016) focus on zero-tolerance policies illustrates Black youth are "structurally positioned as guilty subjects who warrant punishment" (pg. 744). Participants in this study aligned with Wun's conclusion, that no matter their action, they were deemed guilty. The overarching theme of the School-Prison Nexus is the criminalization of youth. Students in the current study explained how they were isolated, marginalized, and excluded once they were labeled as criminals within school settings.

\section{Segregation: Why put us in solitary?}

All participants noted that they felt excluded from the learning processes that other students participated in. Participants described segregation as being isolated, often being subjected to isolation with a group of youth who were also labeled as criminals. I interpreted students' descriptions of isolation and segregation as in school exclusionary practices. Excluding students of color from the learning process is one of the key components of the School-Prison Nexus (Annamma, 2018; Aud et al., 2011; Fabelo et al., 2011; Krezmien, Leone \& Wilson, 2014; Rabaka, 2010; Welch \& Payne, 2010). Instead of being allowed to join a traditional classroom, participants described how they 
were placed into a special day class in which they remained for the entire day. Participants described experiences akin to being in quarantine from an illness, except it was their actions that were being pathologized. Participants also described how their schooling experiences were focused on how adults needed to maintain order, instead of allowing students the opportunity to learn.

There is an ongoing criminalization of PIY within educational settings. While under the guise of maintaining safety, in school and juvenile hall, students were forced to practice incarceration rituals within their segregated spaces (Annamma, 2018; Annamma, 2014; Backer, 2017; Foucault, 1977). Describing Black and Brown students as violent and different allows for institutions to segregate these students and socialize them into criminals (Rios, 2017; Rios and Galicia, 2013; Ferguson, 2000). Students described walking in hallways with their hands at their sides, and not being allowed to make eye contact with the other students. Even within classroom spaces students were not given the support by teachers that is expected in a traditional classroom setting. Students were confined in one classroom, with one teacher, and given packets or independent work online to complete. The more these students are forced to participate in incarceration rituals forces them to disengage with schooling because they come to equate schooling with incarceration.

\section{Abandonment: They gave up on me.}

At the beginning of this study, I knew understanding students' P-12 schooling 
experiences was vital to supporting PIY within community college. While the literature on the School-Prison Nexus highlights themes of criminalization and poor schooling experiences, I was surprised that all participants mentioned feelings of abandonment. Students described feeling being given up on and ignored by probation officers, and staff and faculty within institutions who they thought were supposed to care about their well-being. Students described how being abandoned by faculty and staff reinforced feelings of inadequacy. Students also shared how lowered teacher expectations, disbelief in their ability to transition to from high school to college would result in feelings of hopelessness. Having their experiences and needs ignored by educators caused students to feel invalidated within their schooling experiences and doubt their own ability to succeed.

These findings build on existing literature that demonstrates the harm of discrimination and invalidation within schooling. Rendon (2009) defines invalidation as a form of exerting power over others, to oppress. Educators who choose to actively view students as criminals and unworthy of support or education are invalidating students. Students frequently referred to the term abandonment when school-related staff expressed their doubt in students' ability, and projected futures of criminality upon students. The experiences of participants with abandonment and invalidation are not isolated, Fine and Ruglis (2009) state that school-prison nexus is constantly reinforcing the idea that students are undeserving of an education. Student who feel abandoned by 
educational personnel are more likely to disengage with school and not return.

\section{Recycled Education.}

The sub-theme of recycled education was a through line in all of interviews students shared about their educational experiences within P-12. Participants described their schooling experiences as recycled education because they felt that the curriculum was no longer advancing, and that they were subjected to a recurring watered-down schooling experience. Participants discussed the use of worksheet packets that were substituted for actual teaching and learning experiences. Overwhelmingly students emphasized how their schooling experiences seemed aimed at solidifying their place within the carceral state. Students seemed hyper-aware that they were being presented substandard learning experiences because they were classified as criminals, and therefore unworthy of quality education.

Students' experiences with recycled education further illustrates the targeted racial criminalization of the school-prison nexus (Rabaka, 2010). Rather than using education as a liberatory experience, the process of recycled education is a form of social control. Youth are taught that all behavior outside of idealized white-middle class norms is deviant. Majoritarian discourse describes innate deficiencies to justify incarcerated youth's downward academic trajectory yet ignore racially targeted underpreparation. Multiple students described how the adults that were supposed to teach them would frequently give them coloring maps and watch Pixar films instead of 
engaging students in more substantial learning activities. Swain and Noblit (2011) argue that education, and the withholding of adequate education, is a punishment and a form of maintaining marginalization of people of color. Based on my interviews with students, the consequence of recycled education is that students realize that their schooling has no real value. As a result of substandard educational experiences, these students tend to disengage from school altogether.

\section{Criminalization.}

Criminalization of Black and Brown students serves as an ideological tool to control and subordinate. Students discussed how they were watched more closely during their schooling experiences and penalized for actions that were deemed appropriate for their non-incarcerated peers. Teachers, school administrators and probation staff assumed participants were gang members and criminals. These feelings of criminality were constantly reified by educational staff that punished and threatened students more severely than their peers. Carlos described being threatened with 3 months of incarceration within a juvenile facility if he wore his red video game shirt to school again, as red associated with being a gang-color.

A key function of the school-prison nexus is the oppression and criminalization of youth of color, Within this process students of color, especially Latino and Black males, are hyper-labeled as troublemakers or criminals (Annamma, 2018; Meiners, 2007; Rios, 2017; Rios and Galicia, 2013). Once labeled as deviant students are 
expected to misbehave, as their actions are interpreted as disrespectful and/or intimidating (Davis, 2003; Monroe, 2005). Labeled as a troublemaker, students described how the act of being tardy for class was interpreted as intentional defiance punishable by incarceration. The persistent use of criminalization as a form of control pushes students away from education.

\section{Residue of the School-Prison Nexus to Higher Education}

Participants described how their experiences within the School-Prison Nexus continued to negatively affect their engagement and desire to pursue community college. While the school-prison nexus reinforces identity based on criminality, this process is not ineluctable, as students' desire for higher education is in itself a struggle against this process of criminalization (Swain \& Noblit, 2011). The residual effect of the school-prison nexus, the residue, continues to impact students within higher education, just as the effects of a virus can linger. Participants within this study, enrolled in community college, struggled in their ability at times to ignore the trauma they experienced within the school-prison nexus. The overarching theme of the Residue explains how PIY, without proper support within community college, easily disengage. Students in the current study explained how they feared being criminalized for their actions, doubted their own academic ability, and often suffered because of their substandard educational experiences within the school-prison nexus. 


\section{Feelings of judgement.}

Participants throughout the study shared their feelings that they were going to be judged as criminals, in a similar manner as they were labeled within the school-prison nexus. Students expressed fear that they would be treated as criminals and excluded from the learning process if faculty and students knew about their experiences within the juvenile (un) justice system. The school-prison nexus has reinforced to many PIY that being labeled a criminal is connected with exclusionary educational experiences (Giraldo \& Huerta, \& Solórzano, 2017), and these students view their incarceration experience as a stigma. The trepidation associated with being judged initially caused many students to try to conceal their previous incarceration experience from their professors. It was not until professors personally knew a student's work ethic did students reveal their incarceration experience.

Unlike individuals who have spent time within adult correctional facilities, PIY carry with them the concealable stigma of their incarceration experience. Although concealable, participants shared how labels of criminality negatively affected their relationships with faculty and peers. Stereotypes about individuals with incarceration experiences frequently encouraged microaggressions on campus, emphasizing that negative associations of PIY to being hardened criminals is persistent (Giraldo, Huerta, \& Solórzano, 2017). Feelings of judgement expressed by participants align with current literature on formerly incarcerated adults as they transition into higher education 
(Copenhaver, Edwards-Willey, and Byers, 2007; Maruna, 2011; Strayhorn, Johnson, \& Barrett, 2013). Similar to participants in Strayhorn, Johnson, and Barrett's (2013) study, my participants spoke of their intentional decision to resist falling into stereotypes by ensuring faculty saw them as mature and focused, and not as deviant, or "gangstas."

\section{Self-doubt.}

The most expressed consequence of the school-prison nexus was students doubt in their own ability. If "punishment is the deprivation of education" (Swain \& Noblit, 2011), then educational facilities while incarcerated can take on dehumanizing practices, practices that attempt to convince students of their criminality and inferiority. The consequence of students feeling excluded, marginalized, and hopeless is doubt in their ability to succeed. For this study, self-doubt is specifically referring to students' doubt that they will achieve their educational goal. Participants shared that doubt in their own ability has caused them to give-up on education. For some this period of giving up was short, for others it caused them to disengage for long-periods of time.

These findings build on literature that contend that the juvenile (un) justice system intentionally creates conditions that mimic prison and pushes students away from education (Fuentes, 2012; Nolan, 2011, Wun, 2016). According to students' accounts, it was commonplace for educators and staff within juvenile hall to make demeaning comments about students and the inevitability of their trajectory to prison. Although students prefaced these stories with phrases like, "staff joked," it was apparent 
to me by students' tones that these remarks had lasting consequences. Being bombarded with messages of deficiency can cause students to internalize the majoritarian discourse and believe they are not capable of educational attainment.

\section{Consequences of a disjointed educational experience.}

Within the School-Prison Nexus, while maintaining domination of labor and racial hierarchy may be the primary goal (Bonilla-Silva, 2001), a collateral consequence is a sub-par educational experience for PIY. The subjection of PIY to decreased opportunity to learn, recycled curriculum, and social control designed to criminalize can have severe effects on PIY and their ability to adjust to college curriculum and expectations.

Participants all discussed how their P-12 schooling experiences had left them unexposed to practices and expectations required of them in community college. With their P-12 schooling focusing on confinement instead of education, participants in this study expressed that tasks like completing homework felt foreign to them. This aligns with a large body of literature that asserts that the American educational system intentionally prepares certain groups of students better for prison than competition in the free-market (Brewer \& Heitzeg, 2008; Fasching-Varner, et al., 2014; Noguera, 2003). For students that choose to continue their education post-incarceration, they are at a disadvantage. As a result of undereducation, PIY face additional hurdles when choosing to attend community college, without proper support many PIY may choose to 
leave college and not return.

\section{Academic Reengagement}

Despite the experiences of hyper-surveillance, hyper-labeling, hyperpunishment, and suffering PIY experienced within the School-Prison Nexus (Annamma, 2018; Dumas, 2014; Rios, 2017), this study is innately about triumph and resilience. The students interviewed for this study decided to persist and pursue a higher education despite being actively pushed out of the learning process within their P-12 experiences. Yet, the experiences of PIY within higher education, and specifically community college, remain understudied despite their criticality in understanding how to support this group of students. The theme of Academic Reengagement explores the ways PIY have overcame barriers to their reintegration into education. Students discussed how through re-identification of their identity, developing a sense of belonging, authentic care, and sharing as healing they were able to ultimately transition and persevere within community college.

\section{Reinvention of Identification.}

Throughout the interview process, participants discussed their initial feelings and beliefs about themselves upon entering CBA. In addition to being socialized within the school-prison nexus to believe in the majoritized view of PIY as deviant, participants were all first-generation college students. Initially, participants shared that they did not view themselves as college students despite being enrolled in classes. 
Students credited Project Change with helping them feel empowered enough to be able to reinvent themselves, to view themselves as college students.

Despite being enrolled in classes, participants struggled with identifying themselves as college students. For example, Rafael felt that with his cholo appearance, he was not a college student. It is not surprising that PIY would struggle with creating their college-going identity, as Tintiangco-Cubales et al. (2016) explain that majoritarian views are internalized by students. Project Change exposed Rafael to new ideas about the college student identity and allowed him to embrace his new role as a college student. These findings connect two similar, sometimes overlapping, strands of literature; one focusing on creating a college-going identity (Howard, Flennaugh, \& Terry, 2012) and one strand focusing on rejecting the stigmatization of incarceration (Case \& Hunter, 2012; Ibarra \& Barbulescu, 2010; Gaskew, 2014). The PIY in this study developed their racialized belief through years of subjection to the School-Prison nexus and needed support to be able to resist the internalization of deficit beliefs. Through exposure to the historical and racial origins of the School-Prison Nexus students were able to recreate their own narrative. Students expressed that their incarceration experience, once a source of embarrassment and humiliation, shifted to a source of empowerment.

\section{Homemaking.}

All participants discussed how they viewed Project Change, and CBA, as their 
home. Students keyed in on how Project Change and CBA helped them feel like they belonged in college. The sub-theme of homemaking references Kuttner's (2016) discussion of students of color and their engagement within asset-based spaces. For this study, homemaking is defined as having a sense of belonging and believing that educational personnel believe in students' ability to succeed. Participants shared stories of their interactions with faculty and staff of how they felt safe and supported while sharing their struggles.

These findings support the literature of sense of belonging within higher education. Links between academic achievement, retention, and sense of belonging have been well-documented (Hausmann, Schofield, \& Woods, 2007; Hurtado \& Carter, 1997). Participants in the study shared that they viewed CBA personnel as family, and actively sought their advice on personal matters as well as school related support. This process of seeing and treating students as whole, allows students to feel that their personhood is welcomed within educational spaces (Terenzini et al., 1994; Locks et al., 2008). Creating a culture that intentionally supports and welcomes students can begin to help PIY counter their previous experiences of discouragement within the school-prison nexus.

\section{Authentic Care.}

Throughout the interview process participants juxtaposed their experiences within the School-Prison nexus to their experiences at CBA. While students described 
their educational experiences within the school-prison nexus as uncaring and exclusionary, their experiences within CBA were described as the opposite. For this study, the sub-theme authentic care is defined as the creation of reciprocal relationships between school personnel and PIY which seek to empower PIY to succeed with their goals.

Findings from this study expand the current literature on authentic care into higher education. While there are a number of studies demonstrating the value of authentic care within P-12 educational settings (Noddings, 2005; Walker, 1993; Valenzuela, 1999; Beauboeuf-Lafontant, 2002; Rolan-Dow, 2005; Duncan-Andrade, 2009; Hidalgo and Duncan-Andrade, 2009), there is not a current emphasis on the value of authentic care within higher education literature. Yet, participants within this study emphasized that it was the care that faculty and staff provided that encouraged them to continue to come to school and feel empowered to seek support. These findings echo Watson, Sealey-Ruiz, and Jackson's (2016) findings on the benefit of authentic care within mentoring relationships between system-impacted youth and their mentors. Valuing students' humanity and creating relationships that seek to empower PIY, is a necessary component to ensuring PIY succeed within community college.

\section{Healing Through Sharing.}

Participants shared that throughout their schooling experiences within the school-prison nexus that they were inundated with stories that reified incarceration 
discourse (Winn, 2010a). As PIY began to see themselves as college students, they actively worked to gain control of their own narrative and found healing in sharing their story. Students expressed how they by sharing their stories of their incarceration experiences that they were finally able to allow their wounds to heal.

This sub-theme of healing through sharing aligns with literature on wounded healing and healing through testimonio (Hill, 2009; Huber 2009). Students identified that being able to share their stories of incarceration with others helped them feel understood and allowed them to challenge the mainstream narrative surrounding criminality and incarceration. Hill (2009) describes a similar process, in which students engaged in storytelling practices that allowed for them to understand the "commonality of their experiences." (pg. 265). Participants noted that sharing their incarceration narrative, and having it embraced by others with similar experiences allowed them to embrace their story.

\section{Implications and Recommendations}

While I think it is important to highlight the voices of PIY, the ultimate goal of this research was to find ways for community colleges to better service and support PIY. My findings suggest a number of ways in which community colleges can begin to support PIY. 


\section{Recommendations for classrooms}

\section{Authentic Care.}

This study confirms that meaningful relationships are at the nexus of success for PIY. Findings suggest that students experience within the school-prison nexus often leave students with a trail of negative experiences with school faculty and staff. Exclusionary disciplinary practices, and a sub-par educational experience while incarcerated often propagate an adversarial relationship between PIY and college educators (Huber et al., 2015; Rios, 2017). Findings highlighted in Chapter 4 emphasize how lack of care can become a barrier to PIY succeeding within community college, often leaving students feeling abandoned by educational faculty and staff, placing them at-risk for disengaging from school.

One way to intentionally engage PIY in the college environment is the intentional practice of authentic care. A way to reverse the school-prison nexus is to disrupt this system which, though hyper-punishment and impoverished educational experiences, creates a group of students who see education as out of reach. At the College of the Bay Area, Project Change is designed to help students succeed. Students create relationships with peers and build trust. The literature highlights that authentic care has a profound impact on students' ability to stay in college longer and earn better grades (Rivera-McCutchen, 2012; Watson, Sealey-Ruiz, and Jackson, 2016; 
Valenzuela, 1999). Community colleges can be the catalyst for change in the lives of PIY, ensuring that they are able to thrive as adults.

\section{Professional Development.}

Professional development for faculty and staff is imperative to create a campus environment that forefronts authentic care within the classroom and student services. Authentic care emphasizes the ability for students to bring their whole-self into spaces, including their incarceration experiences. Challenging deficit views of PIY is vital for authentic care to become a reality. Understanding the complexities of the school-prison nexus is integral for school personnel to begin to chisel away at the calcified racialized beliefs they may hold, implicitly or explicitly, about PIY.

It is my recommendation that professional development for the purpose of creating a college culture that values authentic care is not a one-time standalone training, but instead a community practice. The ability to interrogate long-held beliefs and begin to change praxis requires a safe-place for educators (administrators, faculty, and staff) to think critically about their pedagogies. Working with peers to begin to change approaches, activities, ways of thinking, is an iterative process that requires knowledge of theory as well as time to implement.

Additionally, I would like to make my position clear, I am of the firm belief that all educational personnel (classified staff, faculty, and administrators) have (or should have) an intentional educational philosophy and pedagogy that they regularly enact and 
examine. A community of practice that allows all educational staff to become better educators and knowledgeable about authentic care creates a college culture that truly is able to center students. Often within community college spaces pedagogical trainings are limited to faculty participation. This is a mistake. Students' first contact is often with classified staff in admissions and records, financial aid, placement testing, or counseling. Findings from this study testify to the reality that poor interactions initially with staff can easily dissuade students from higher education. Creating spaces on campus, not just within classrooms, which value students' whole selves, is one way to begin to create a truly inclusive college culture.

\section{Recommendations for programming}

A need for intentional programming and support for PIY on community college campuses is evident as students who participated in this study very clearly discussed the need for personnel and space that were their own. Participants shared that support provided through Project Change helped them transition to CBA, despite the fact that many had not initially viewed themselves as college students. Based on student testimony and observations, I recommend programming that supports the following categories; 1) college exposure/readiness within local juvenile hall, 2) postsecondary bridging, and 3) First-Year Support.

For incarcerated youth, community college programming would provide inperson college credit courses and matriculation support while incarcerated. Many 
incarcerated youth are denied educational experiences while incarcerated, if they have completed a high school diploma or equivalent. Findings from this study suggest that even those students allowed to go to school while incarcerated may disengage from school once they are released due to their negative experiences with recycled education. One way Project Change has actively sought to support students' education is to offer a "Keys to Success" course as students' introductory college course. The course explores the historical origins of the school-prison nexus, encourages students to (re)create their own college identities through educational maps and activities, and allows them to explore career options. Exposing incarcerated youth to college courses while incarcerated allows for students to begin to see themselves as college students.

Once students are ready to enroll in community college, wrap-around services within the community college can ease the transition for PIY. Providing knowledgeable financial aid and academic counseling support will be key in helping students succeed within community college. For example, some PIY may be able to claim "ward of the state" on their financial aid paperwork depending on their incarceration status in high school. Support-services for PIY on campus need to focus on supporting students academically and scaffolding to ensure students are successful in their early postsecondary coursework. Support mechanisms can include mentoring, supplementary instruction, and tutoring. Additionally, programming/the college should provide monetary other support for coursework, including support for books, transportation, and 
other college materials.

While first year success if important for all students, for PIY the stakes are higher. Intentional programmatic support within their first-year of community college can mitigate challenges that might disrupt them from their educational trajectories. A knowledgeable and caring program can help students feel at home within the college and strengthen their sense of belonging as well as their college identity.

\section{Recommendation for Policy and Initiatives}

The findings of this study suggest that PIY, with their histories of trauma, undereducation, and criminalization, are a special population that need to be given greater support within higher education. Currently within California, there are two groups of students with similar histories of trauma, limited academic preparation, and marginalization: foster youth and formerly incarcerated adults.

Foster youth and PIY often share similar experiences of institutionalization, exclusionary punishment, and trauma (Herz \& Ryan, 2008). Yet within the majoritarian discourse, foster youth are described as innocent children in need of support services even through transition age. PIY, as a group, are seen as criminals, and the juvenile (un)justice system, instead of protecting or supporting these youth, instead view their role as protecting the community from deviants. Viewed as criminals, PIY are viewed as breaking a social contract and undeserving of support. It is my premise that these two groups are similar is their experiences (Herz, Lee, Lutz, Stewart, Tuell, \& Wiig, 2012; 
Herz \& Ryan, 2008). Allowing PIY to benefit from initiatives and support programs designed for foster youth is one way community colleges can begin to equitable support to students.

Within California Community Colleges, the NextUp program is one way foster youth are being intentionally supported. NextUp is housed under the existing community college program, Extended Opportunity Programs and Services (EOPS), and provides financial assistance with textbooks, cost of school supplies, parking passes, and other non-tuition costs associated with community college. Additionally, NextUp provides support and access to academic support programs, counseling, childcare, and college tours for participants. Although NextUp is currently only available at 45 out $114 \mathrm{CCC}$, this holistic approach to student support aligns with the programmatic needs of PIY (NextUp, 2018).

Findings from this study suggest that PIY and formerly incarcerated adults share similar experiences of criminalization, stigma, and trauma, yet programs focusing on helping justice-impacted adults typically ignore PIY. The liminality of PIY is often ignored, as PIY are neither innocent enough for support under the foster care system, nor criminal enough for support as re-entry students. With a focus on reduced recidivism, and the cost of adult incarceration, California has made a large push to help reentry students succeed (Gov. Brown allocated \$5million to CCC to serve this population (Martinez, 2018). CCCCO this past year has seen a resurgence of support 
dedicated to helping currently and formerly incarcerated adults (CIFIA) obtain a high education.

While adequately serving CIFIA is a definite need, these programs for CIFIA, since they are tied to funding, dichotomize a population that has more similarities than differences. Conferences coordinated by the $\mathrm{CCCO}$ in partnership with other community organizations have focused on strategies to support in CIFIA within prisons and as they transition into traditional community college classrooms. Webinars and communities of practice have been offered focusing on Trauma Informed Pedagogy specifically designed to reduce barriers for CIFIA. Additionally, the CCCCO has put out an RFP to fund CCC which seek to establish on-campus programming for CIFIA. All of the current momentum to support CIFIA is an impressive step towards educational equity on $\mathrm{CCC}$ campuses, but with the language of the support aiming to reduce expensive prison costs; it ignores the need to support previously incarcerated students (Adult and youth) simply because of their history of marginalization. Expanding support to include all students affected by incarceration and detainment allow community colleges to provide equitable support to students.

\section{Abolishment of the Carceral State.}

The previous recommendations within this study focus on helping PIY succeed within community college, yet these recommendations are simply treatment for the symptoms of a virus, and not the virus itself. Treating the negative effect of the school- 
prison nexus is necessary, as PIY leave incarceration traumatized and in need of support. But, treating the ill effect of the school-prison nexus is not going stop the school-prison nexus, to do that the United States must abolish the carceral state and the policies of criminalization that view students of color as criminals instead of students. The carceral state is a form of neocolonialism continuing to use race as a way to control labor. The school-prison nexus metaphor exemplifies how disciplinary regulations, subpar educational experiences, and deficit beliefs coalesce to normalize criminality and incarceration for youth of color (Meibers, 2007). The pathologizing of youth of color as thugs, cholos, trouble-makers, and at-risk, solidify in the mainstream narrative that these students should be incarcerated (Chávez-García, 2015). Abolition of prisons and the carceral state will not stop crime, but it will stop the criminalization of youth of color and the poor.

\section{Recommendations for Further Study}

This study has focused on bringing the experiences of PIY to the forefront for the purpose of understanding the barriers and facilitators to program completion. A limitation of this study was the small size of students interviewed $(\mathrm{N}=5)$. Although other sources of data, including classwork assignments, expanded the pool of student voices, a larger study interviewing more students from different community colleges would be beneficial. A study examining the support PIY receive within community colleges nationwide is also recommended and could add to the finding of this study. 
While it was important for me to highlight the voices of PIY as my source of data within this study, further research can add to this work by evaluating CC programming for PIY and comparing retention and completion rates to support PIY versus those of unsupported PIY. This information will better inform program coordinators, faculty, classified staff, leaders on campus, and policymakers as to the most effective components of programming for PIY.

\section{Conclusion}

During the final class session of LCTR 105 in Spring, we were all sharing our "vision board" PowerPoint presentation when Malik stopped mid-sentence and looked at me. He said, "Ms. Tabitha, you not this cool on the outs." While there was no inflection at the end of his phrase, I interpreted this as a question. My response was my usual half-laugh followed by, "I didn't know I was cool in here." At this point the whole class seemed focused on our conversation. "No, I mean, like you won't fuck wit us on the outs. Like hella staff see me when I'm out and act scared or brand new," Malik looked away as he finished his sentence. For PIY, like Malik, there is an urgency to support them as they transition into community college. This research has sought to privilege the reader with a small snippet of the students I am glad to work with in a daily basis. Uplifting the experiences and knowledge these students have can help community colleges identify how to help these students succeed. 


\section{References}

Abrams, L. S. (2012). Envisioning Life "On the Outs" Exit Narratives of Incarcerated Male Youth. International Journal of Offender Therapy and Comparative Criminology, 56(6), 877-896.

Abrams, L. S., \& Franke, T. M. (2013). Postsecondary educational engagement among formerly-incarcerated transition-age young men. Journal of Offender Rehabilitation, 52(4), 233-253.

Advancement Project. (2013). Handcuffs on success: The extreme school discipline crisis in Mississippi public schools. https://adrancementoroiect,org/resources/handcuffs-on-success/

Anderman, L. H., \& Freeman, T. M. (2004). Students' sense of belonging in school. Advances in motivation and achievement, 13, 27-63.

Anders, A. D., \& Noblit, G. W. (2011). Understanding effective higher education programs in prisons: Considerations from the incarcerated individuals program in North Carolina. Journal of Correctional Education, 77-93.

Annamma, S. A. (2017). The Pedagogy of Pathologization: Dis/abled Girls of Color in the School-prison Nexus. Routledge.

Aud, S., KewalRamani, A., \& Frohlich, L. (2011). America's Youth: Transitions to Adulthood. NCES 2012-026. National Center for Education Statistics.

Balfanz, R., Spiridakis, K., Neild, R. C., \& Legters, N. (2003). High-poverty secondary 
schools and the juvenile justice system: How neither helps the other and how that could change. New Directions for Youth Development, (99), 71-89.

Basic skills completion: The key to student success in California community colleges. Effective practices for faculty, staff and administrators. Calıfornia Community Colleges Chancellor's Office

Baston, M., \& Miller, B. (2017). On the Other Side. Race, Education, and Reintegrating Formerly Incarcerated Citizens: Counterstories and Counterspaces, 61.

Bauer, K. (2014). Black male community college students and faculty-student engagement: Differences in faculty validation and time status. Journal of Progressive Policy \& Practice, 2(2), 157-164.

Bell, C. (1992). Ritual theory, ritual practice. Oxford University Press.

Bernal, D. D. (2002). Critical race theory, Latino critical theory, and critical racedgendered epistemologies: Recognizing students of color as holders and creators of knowledge. Qualitative inquiry, 8(1), 105-126.

Bernburg, J. G., \& Krohn, M. D. (2003). Labeling, life chances, and adult crime: The direct and indirect effects of official intervention in adolescence on crime in early adulthood. Criminology, 4l(4), 1287-1318.

Blomberg, T. G., Bales, W. D., \& Piquero, A. R. (2012). Is educational achievement a turning point for incarcerated delinquents across race and sex?. Journal of youth and adolescence, 41(2), 202-216. 
Blumenstyk, G. (2015). American higher education in crisis? What everyone needs to know. New York, NY: Oxford University Press.

Bogdan, R., \& Biklen, S. (2007). Qualitative Research for Education (5th.).

Bryson, C., \& Hand, L. (2007). The role of engagement in inspiring teaching and learning. Innovations in Education and Teaching International, 44(4), 349-362.

Butin, D. W. (2010). The education dissertation: A guide for practitioner scholars. Thousand Oaks, CA: Corwin Press.

California Department of Corrections and Rehabilitation. Office of Research. (2010). 2010 Juvenile justice outcome evaluation report: Youth released from the Division of Juvenile Justice in fiscal year 2004-2005. Retrieved from http://www.cdcr.ca.gov/reports Reserach/docs/recidivism\%20Report.FY0405. \%20FINAL.DJJ.pdf

Cammarota, J. (2004). The gendered and racialized pathways of Latina and Latino youth: Different struggles, different resistances in the urban context. Anthropology \& Education Quarterly, 35(1), 53-74.

Case, A. D., \& Hunter, C. D. (2012). Counterspaces: A unit of analysis for understanding the role of settings in marginalized individuals' adaptive responses to oppression. American Journal of Community Psychology, 50(1-2), $257-270$. 
Castro, E. L., Brawn, M., Graves, D. E., Mayorga, O., Page, J., \& Slater, A. (2015). Higher education in an era of mass incarceration: Possibility under constraint. Journal of Critical Scholarship on Higher Education and Student Affairs, 1(1),

2.

Charmaz, K. (2014). Constructing grounded theory. Sage.

Chávez-García, M. (2015). Youth of Color and California's Carceral State: The Fred C. Nelles Youth Correctional Facility. The Journal of American History, 102(1), 47-60.

Copenhaver, A., Edwards-Willey, T. L., \& Byers, B. D. (2007). Journeys in social stigma: The lives of formerly incarcerated felons in higher education. Journal of Correctional Education, 268-283.

Crenshaw, K., Ocen, P., \& Nanda, J. (2015). Black girls matter: Pushed out, overpoliced, and underprotected. Center for Intersectionality and Social Policy Studies, Columbia University.

Creswell, J. W. (2008). Educational research. Planning, conducting, and evaluating quantitative and qualitative research.

Culhane, D. , Metraux , S. , \& Moreno, M. (2011). Young adult outcomes of youth exiting dependent or delinquent care in Los Angeles County. Retrieved from https:/hilton- 
production.s3.amazonaws.com/documents/97/attachments/Hilton Foundation R eport Final.pdf? 1440966405

Darling-Hammond, L. (2010). The flat world and education: How America's commitment to equity will determine our future. New York: Teachers College Press.

Delgado, R. (1989). Storytelling for oppositionists and others: A plea for narrative. Michigan Low Review, 87(8), 2411-2441.

Dixson, A. D., \& Rousseau, C. K. (Eds.). (2006). Critical race theory in education: All God's children got a song. Taylor \& Francis.

Drysdale, D., Modzeleski, W., \& Simons, A. (2010). Campus attacks: Targeted violence affecting institutions of higher education. Washington, DC: U.S. Department of Justice. Retrieved from http://www.secretservice.gov/ntac.shtml.

Dumas, M. J. (2014). 'Losing an arm': schooling as a site of black suffering. Race Ethnicity and Education, 17(1), 1-29.

Duncan-Andrade, J. (2009). Note to educators: Hope required when growing roses in concrete. Harvard Educational Review, 79(2), 181-194.

Fabelo, T., Thompson, M.D., Plotkin, M., Carmichael, D., Marchbanks, M.P., \& Booth, E.A. (2011). Breaking schools' rules: A statewide study of how school discipline relates to students' success and juvenile justice involvement. New York: Council of State Governments Justice Center. 
Ferguson, A. (2000). Bad boys. Ann Arbor, MI: University of Michigan Press.

Fernández, J. S., Kirshner, B., \& Lewis, D. G. (2016). Strategies for Systemic Change: Youth Community Organizing to Disrupt the School-to-Prison Nexus. Contemporary Youth Activism: Advancing Social Justice in the United States: Advancing Social Justice in the United States, 93.

Fine, M., \& Ruglis, J. (2009). Circuits and consequences of dispossession: The racialized realignment of the public sphere for US youth. Transforming anthropology, 17(1), 20-33.

Fine, M., Torre, M. E., Boudin, K., Bowen, I., Clark, J., Hylton, D., \& Martinez, M. (2001). Changing Minds: The Impact of College in a Maximum-Security Prison. Effects on Women in Prison, the Prison Environment, Reincarceration Rates and Post-Release Outcomes.

Fisher, B. W., \& Hennessy, E. A. (2016). School resource officers and exclusionary discipline in US high schools: A systematic review and meta-analysis. Adolescent Research Review, 1(3), 217-233.

Foley, R. M. (2001). Academic characteristics of incarcerated youth and correctional educational programs: A literature review. Journal of Emotional and Behavioral Disorders, 9(4), 248-259.

Franklin, A. J. (1999). Invisibility syndrome and racial identity development in psychotherapy and counseling African American men. The Counseling 
Psychologist, 27, 761-793. doi:10.1177/0011000099276002

Gaskew, T. (2014). Rethinking prison reentry: Transforming humiliation into humility. Lexington Books

Gay, G. (2010). Culturally responsive teaching: Theory, research, and practice. Teachers College Press.

Gilliam, W. S., Maupin, A. N., Reyes, C. R., Accavitti, M., \& Shic, F. (2016). Do early educators' implicit biases regarding sex and race relate to behavior expectations and recommendations of preschool expulsions and suspensions. Research Study Brief. Yale University, Yale Child Study Center, New Haven, CT.

Giraldo, L. G., Huerta, A. H., \& Solórzano, D. (2017). From Incarceration to Community College. Funds of Knowledge in Higher Education: Honoring Students' Cultural Experiences and Resources as Strengths.

Gordon, E.W., \& Wilkerson, D.A. (1966). Compensatory education for the disadvantaged, programs and practices-preschool through college. Chicago

Gregory, A., Skiba, R. J., \& Noguera, P. A. (2010). The achievement gap and the discipline gap: Two sides of the same coin?. Educational Researcher, 39(1), 5968.

Halkovic, A. (2014). Redefining Possible: Re-Visioning the Prison-to-College Pipeline. Equity \& Excellence in Education, 47(4), 494-512. 
Harper, S. R. (2009). Race-conscious student engagement practices and the equitable distribution of enriching educational experiences. Liberal Education, 95(4), 3845.

Harper, S. R., \& Davis III, C. H. (2012). They (Don't) Care about Education: A Counternarrative on Black Male Students' Responses to Inequitable Schooling. Educational Foundations, 26, 103-120.

Herz, D., Lee, P., Lutz, L., Stewart, M., Tuell, J., \& Wiig, J. (2012). Addressing the needs of multi-system youth: Strengthening the connection between child welfare and juvenile justice. Retrieved from Center for Jivenile

Herz, D., \& Ryan, J. P. (2008). Exploring the characteristics and outcomes of 241.1 youth crossing over from dependency to delinquency in Los Angeles County. Center for Families, Children \& the Courts Research Update, 1-13.

Hidalgo, N. D., \& Duncan-Andrade, J. M. R. (2009). When stepping to college is stepping to consciousness: Critical pedagogy, transformational resistance, and community building with urban Latin@ and African American youth. Handbook of Latinos and education: Theory, research and practice, 262-275.

Hjalmarsson, R. (2008). Criminal justice involvement and high school completion. Journal of Urban Economics, 63(2), 613-630.

Hooks, B. (1992). Yearning: Race, gender, and cultural politics. 
Howard, T. C. (2010). Why race and culture matter in schools: Closing the achievement gap in America's classrooms (Vol. 39). Teachers College Press.

Hurtado, S., \& Carter, D. F. (1997). Effects of college transition and perceptions of the campus racial climate on Latino college students' sense of belonging. Sociology of education, 324-345.

Ibarra, H., \& Barbulescu, R. (2010). Identity as narrative: Prevalence, effectiveness, and consequences of narrative identity work in macro work role transitions. Academy of management review, 35(1), 135-154.

Illowsky, B., Molloy, K., Deegan, P., Lopez, C., Neault, L., Wojcik, A., \& Richards, R. (2013).

Irwin, K., Davidson, J., \& Hall-Sanchez, A. (2013). The race to punish in American schools: Class and race predictors of punitive school-crime control. Critical Criminology, 21(1), 47-71.

Jacobson, L., \& Mokher, C. (2009). Pathways to Boosting the Earnings of Low-Income Students by Increasing Their Educational Attainment. Hudson Institute (NJ1).

Jain, D. (2009). Critical race theory and community colleges: Through the eyes of women student leaders of color. Community College Journal of Research and Practice, 34(1-2), 78-91.

Johnson, D. R., Soldner, M., Leonard, J. B., Alvarez, P., Inkelas, K. K., Rowan 
Kenyon, H. T., \& Longerbeam, S. D. (2007). Examining sense of belonging among first-year undergraduates from different racial/ethnic groups. Journal of College Student Development, 48(5), 525-542.

Kirk, D. S., \& Sampson, R. J. (2013). Juvenile arrest and collateral educational damage in the transition to adulthood. Sociology of education, 86(1), 36-62.

Komarraju, M., Musulkin, S., \& Bhattacharya, G. (2010). Role of student-faculty interactions in developing college students' academic self-concept, motivation, and achievement. Journal of College Student Development, 51(3), 332-342.

Kuh, G. D., Cruce, T. M., Shoup, R., Kinzie, J., \& Gonyea, R. M. (2008). Unmasking the effects of student engagement on first-year college grades and persistence. Journal of Higher Education, 79(5), 540-563.

Krezmien, M. P., Leone, P. E., \& Wilson, M. G. (2014). Marginalized students, school exclusion, and the school-to-prison pipeline. Juvenile Justice Sourcebook, 267288.

Kupchik, A. (2010). Homeroom security: School discipline in an age of fear. New York, NY: New York University Press.

Kupchik, A., \& Farina, K. A. (2016). Imitating authority: Students' perceptions of school punishment and security, and bullying victimization. Youth Violence and Juvenile Justice, 14(2), 147-163. doi:10.1177/1541204014557648. 
Ladson-Billings, G. (1995). But that's just good teaching! The case for culturally relevant pedagogy. Theory into practice, 34(3), 159-165.

Ladson-Billings, G., \& Tate, W. F. (1995). Toward a critical race theory of education. Teachers college record, 97(1), 47.

Leone, P. E., \& Weinberg, L. A. (2010). Addressing the unmet educational needs of children and youth in the juvenile justice and child welfare systems.

Washington, DC: Georgetown University, Center for Juvenile Justice Reform. Retrieved from httn:/ciir.georgetown.edu/pdfs/ed/edpaper.pdf.

Lightfoot, S. L. (1986). On goodness in schools: Themes of empowerment. Peabody Journal of Education, 63(3), 9-28.

Locks, A. M., Hurtado, S., Bowman, N. A., \& Oseguera, L. (2008). Extending notions of campus climate and diversity to students' transition to college. The Review of Higher Education, 31(3), 257-285.

Maldonado-Torres, N. (2007). On the Coloniality of Being: Contributions to the Development of a Concept. Cultural studies, 21(2-3), 240-270.

Martinez, K. (2018). California budget includes $\$ 5$ million for incarcerated and formerly incarcerated community college students. Opportunityinstitute.org. Maruna, S. (2011). Reentry as a rite of passage. Punishment \& Society, 13(1), 3-28. Maslow, A. H. (1954). Motivation and Personality Harper \& Row New York Google Scholar. 
McGrew, K. (2016). The Dangers of Pipeline Thinking: How the School-To-Prison Pipeline Metaphor Squeezes Out Complexity. Educational Theory, 66(3), 34I367.

Miller, B., Mondesir, J., Stater, T., \& Schwartz, J. (2014). Returning to school after incarceration: Policy, prisoners, and the classroom. New Directions for Adult and Continuing Education, 2014(144), 69-77.

Monahan, K. C., VanDerhei, S., Bechtold, J., \& Cauffman, E. (2014). From the school yard to the squad car: School discipline, truancy, and arrest. Journal of youth and adolescence, 43(7), 1110-1122.

Morris, E. W., \& Perry, B. L. (2016). The punishment gap: School suspension and racial disparities in achievement. Social Problems, 63(1), 68-86.

Nicholson-Crotty, S., Birchmeier, Z., \& Valentine, D. (2009). Exploring the impact of school discipline on racial disproportion in the juvenile justice system. Social Science Quarterly, 90(4), 1003-1018.

Newman, C. B., Wood, J. L., \& Harris III, F. (2015). Black men's perceptions of sense of belonging with faculty members in community colleges. Journal of Negro Education, 84(4), 564-577.

Nieto, S. (2005). Public education in the twentieth century and beyond: High hopes, broken promises, and an uncertain future. Harvard Educational Review, 75 (1), $43-62$. 
Noddings, N. (2015). The Challenge to Care in Schools, 2nd Editon. Teachers College Press.

Nurse, A. M. (2013). Juveniles and college: Inside out as a way forward. The Prison Journal, 93(2), 234-247.

Osgood, D. W., Foster, E. M., \& Courtney, M. E. (2010). Vulnerable populations and the transition to adulthood. The future of children, 20(1), 209-229.

Paris, D., \& Alim, H. S. (2014). What are we seeking to sustain through culturally sustaining pedagogy? A loving critique forward. Harvard Educational Review, 84(1), 85-100.

Pietersen, C. (2002). Research as a learning experience: A phenomenological explication. The qualitative report, 7(2), 1-14.

Pike, G. R., Kuh, G. D., \& McCormick, A. C. (2011). An investigation of the contingent relationships between learning community participation and student engagement. Research in Higher Education, 52(3), 300-322.

Quijano, A. (2000). Coloniality of power and Eurocentrism in Latin America. International Sociology, 15(2), 215-232.

Rabaka, R. (2010). Africana critical theory: Reconstructing the black radical tradition, from WEB Du Bois and CLR James to Frantz Fanon and Amilcar Cabral. Lexington Books. 
Rios, V. M., \& Vigil, J. D. (2017). Human targets: Schools, police, and the criminalization of Latino youth. University of Chicago Press.

Rios, V. M., \& Galicia, M. G. (2013). Smoking guns or smoke \& mirrors?: Schools and the policing of Latino boys. Journal of the Association of Mexican American Educators, 7(3), 54-66.

Rivera-McCutchen, R. L. (2012). Caring in a small urban high school: A complicated success. Urban Education, 47(3), 653-680.

Roberts, M. A. (2010). Toward a theory of culturally relevant critical teacher care: African American teachers' definitions and perceptions of care for African American students. Journal of Moral Education, 39(4), 449-467.

Roberts, S., Zhang, J., Truman, J., \& Snyder, T. D. (2012). Indicators of school crime and safety: 2011. National Center for Education Statistics, US Department of Education, and Bureau of Justice Statistics, Office of Justice Programs, US Department of Justice. Retrieved from http://nces. ed. gov/pubsearch/pubsinfo. asp.

Rocque, M., \& Paternoster, R. (2011). Understanding the antecedents of the" school-tojail" link: The relationship between race and school discipline. The Journal of Criminal Law and Criminology, 633-665.

Rosenthal, A., NaPier, E., Warth, P., \& Weissman, M. (2015). Boxed out: Criminal history screening and college application attrition. Retrieved from Center for 
Community Alternatives, Inc., website: http://www. communityalternatives. org/fb/boxed-out. html.

RP Group. (2013). Student support (re)defined: Using student voices to redefine support. Retrieved from www.rpgroup.org Saldaña, J. (2011). Fundamentals of qualitative research. OUP USA.

Seidman, I. (2013). Interviewing as qualitative research: A guide for researchers in education and the social sciences. Teachers college press.

Solorzano, D. G. (1997). Images and words that wound: Critical race theory, racial stereotyping, and teacher education. Teacher Education Quarterly, 5-19.

Sólorzano, D. G. (1998). Critical race theory, race and gender microaggressions, and the experience of Chicana and Chicano scholars. International journal of qualitative studies in education, 11(1), 121-136.

Solorzano, D., Ceja, M., \& Yosso, T. (2000). Critical race theory, racial microaggressions, and campus racial climate: The experiences of African American college students. Journal of Negro Education, 60-73.

Sólorzano, D. G., Villalpando, O., \& Oseguera, L. (2005). Educational inequities and Latina/o undergraduate students in the United States: A critical race analysis of their educational progress. Journal of Hispanic Higher Education, 4(3), 272294. 
Solórzano, D. G., \& Yosso, T. J. (2002). Critical race methodology: Counterstorytelling as an analytical framework for education research. Qualitative inquiry, 8(1), 23-44.

Stanford Criminal Justice Center. (2015). Degrees of freedom: Expanding college opportunities for currently and formerly incarcerated Callfornians. Retrieved from http://law.stanford.edu/wn-content/uploads/sites/default/files/childpage/443444/doc/slspublic/DegreesofFreedom2015 FINAL.Ddf

Strayhorn, T.L. (2008). Sentido de pertenencia: A hierarchical analysis predicting sense of belonging among Latino college students. Journal of Hispanic Higher Education, 7(4), 301-320.

Strayhorn, T. L. (2012). College students' sense of belonging: A key to educational success for all students. Routledge.

Strayhorn, T. L., Johnson, R. M., \& Barrett, B. A. (2013). Investigating the college adjustment and transition experiences of formerly incarcerated black male collegians at predominantly white institutions. Spectrum: A Journal on Black Men, 2(1), 73-98.

Terenzini, P. T., Rendon, L. I., Upcraft, M. L., Millar, S. B., Allison, K. W., Gregg, P. L., \& Jalomo, R. (1994). The transition to college: Diverse students, diverse stories. Research in higher education, 35(1), 57-73. 
Tintiangco-Cubales, A., Daus-Magbual, A., Desai, M., Sabac, A., \& Torres, M. V. (2016). Into our hoods: where critical performance pedagogy births resistance. International Journal of Qualitative Studies in Education, 29(10), 1308-1325.

Umbach, P. D., \& Wawrzynski, M. R. (2005). Faculty do matter: The role of college faculty in student learning and engagement. Research in Higher Education, $46(2), 153-184$.

Valenzuela, A. (1999). Subtractive schooling: Issues of caring in education of USMexican youth. State University of New York Press.

Van Thompson, C., \& Schwartz, P. J. (2017). A New Normal. Race, Education, and Reintegrating Formerly Incarcerated Citizens: Counterstories and Counterspaces, 95 .

Vasquez Urias, M. (2012). The impact of institutional characteristics on Latino male graduation rates in community colleges. Annuals of the Next Generation, 3(1), $1-12$.

Velasquez, P. (1999). The Relationship between Cultural Development, Sense of Belonging, and Persistence among Chicanos in Higher Education: An Exploratory Study. ASHE Annual Meeting Paper.

Watson, W., Sealey-Ruiz, Y., \& Jackson, I. (2016). Daring to care: The role of culturally relevant care in mentoring Black and Latino male high school students. Race Ethnicity and Education, 19(5), 980-1002. 
Webber, K. L., Krylow, R. B., \& Zhang, Q. (2013). Does involvement really matter? Indicators of college student success and satisfaction. Journal of College Student Development, 54(6), 591-611.

Welch, K., \& Payne, A. A. (2010). Racial threat and punitive school discipline. Social Problems, 57(1), 25-48.

Weissman, M., Rosenthal, A., Warth, P., Wolf, E., \& Messina-Yauchzy, M. (2010). The use of criminal history records in college admissions reconsidered. The Center for Community Alternatives.

Weiss, M. J., Mayer, A. K., Cullinan, D., Ratledge, A., Sommo, C., \& Diamond, J. (2015). A random assignment evaluation of learning communities at Kingsborough Community College - seven years later. Journal of Research on Educational Effectiveness, 8(2), 189.

Winn, M. T. (2010). 'Betwixt and between': literacy, liminality, and the celling of Black girls. Race Ethnicity and Education, 13(4), 425-447.

Winn, M. T. (2010). 'Our side of the story': moving incarcerated youth voices from margins to center. Race Ethnicity and Education, 13(3), 313-325.

Winn, M. T., \& Behizadeh, N. (2011). The right to be literate: Literacy, education, and the school-to-prison pipeline. Review of Research in Education, 35(1), 147-173.

Wolf, K. C., \& Kupchik, A. (2017). School suspensions and adverse experiences in adulthood. Justice Quarterly, 34(3), 407-430. 
Wood, J. L., \& Turner, C. S. (2010). Black males and the community college: Student perspectives on faculty and academic success. Community College Journal of Research and Practice, 35(1-2), 135-151.

Wun, C. (2016). Unaccounted foundations: Black girls, anti-Black racism, and punishment in schools. Critical Sociology, 42(4-5), 737-750.

Yang, K. W. (2009). Focus on policy: Discipline or punish? Some suggestions for school policy and teacher practice. Language Arts, 87(1), 49-61.

Yosso, T. J. (2006). Critical race counterstories along the Chicana/Chicano educational pipeline. Routledge.

Yosso, T., Smith. W., Ceja, M., \& Solórzano, D. (2009). Critical race theory, racial microaggressions, and campus racial climate for Latina/o undergraduates. Harvard Educational Review, 79(4), 659-691.

Youth Law Center. (2016). Educational injustice: Barriers to achievement and higher education for youth in California juvenile court schools. Retrieved from htto://www.vlc.org/wp/wp-content/uploads/EDUCATIONAL INJUSTICE.pdf

Zhao, C.-M., \& Kuh, G. D. (2004). Adding value: Learning communities and student engagement. Research in Higher Education, 45(2), 115-138.

Zobac, S., Spears, J., \& Barker, G. (2014). Identical profiles, different paths: Addressing self-selection bias in learning community cohorts. Learning Communities Research and Practice, 2(1), 3. 
Zumbrunn, S., McKim, C., Buhs, E., \& Hawley, L. R. (2014). Support, belonging, motivation, and engagement in the college classroom: a mixed method study. Instructional Science, 42(5), 661-684. 